SERVIÇO DE PÓS-GRADUAÇÃO DO ICMC-USP Data de Depósito: 08.07 .03

Assinatura: How Yaula pmpaw jufore

\title{
Uso de Data Warehousing e Data Mining na \\ busca de relações e conhecimento em um \\ ambiente de comércio eletrônico
}

Jorge Anthony Félix Herrera

Orientador: Prof. Dr. Edson dos Santos Moreira

Dissertação apresentada ao Instituto de Ciências Matemáticas e de Computação - ICMC-USP, como parte dos requisitos para obtenção do título de Mestre em Ciências de Computação e Matemática Computacional.

USP - São Carlos

Julho/2003 
A Comissão Julgadora:

Prof. Dr. Edson dos Santos Moreira

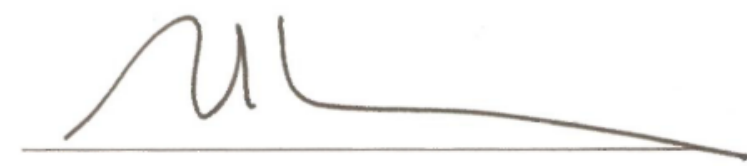

Profa. Dra. Solange Oliveira Rezende

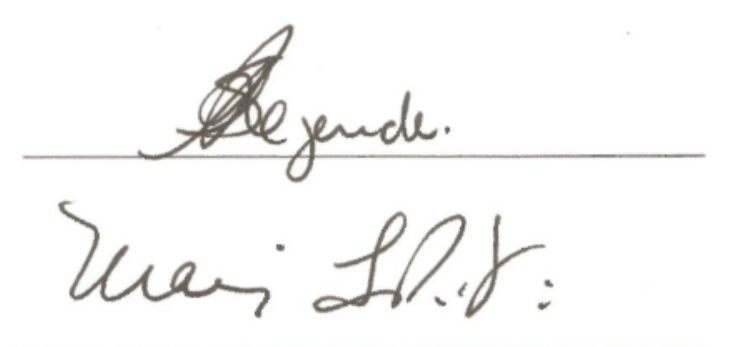

Profa. Dra. Marina Tereza Pires Vieira 


\section{Agradecimentos}

A conclusão do presente trabalho não teria sido possivel sem o apoio dos meus colegas e meus amigos, que me ajudaram tanto com temas terrenos como a formatação do documento, a implementação das ferramentas utilizadas assim como com as excelentes irséias que foram me propondo para este trabalho.

Aproveito também para agradecer a infinita paciência do meu orientador e meus professores, que souberam nos ajudar, responder e criticar nosso trabalho no dia a dia. 


\section{indice Geral}

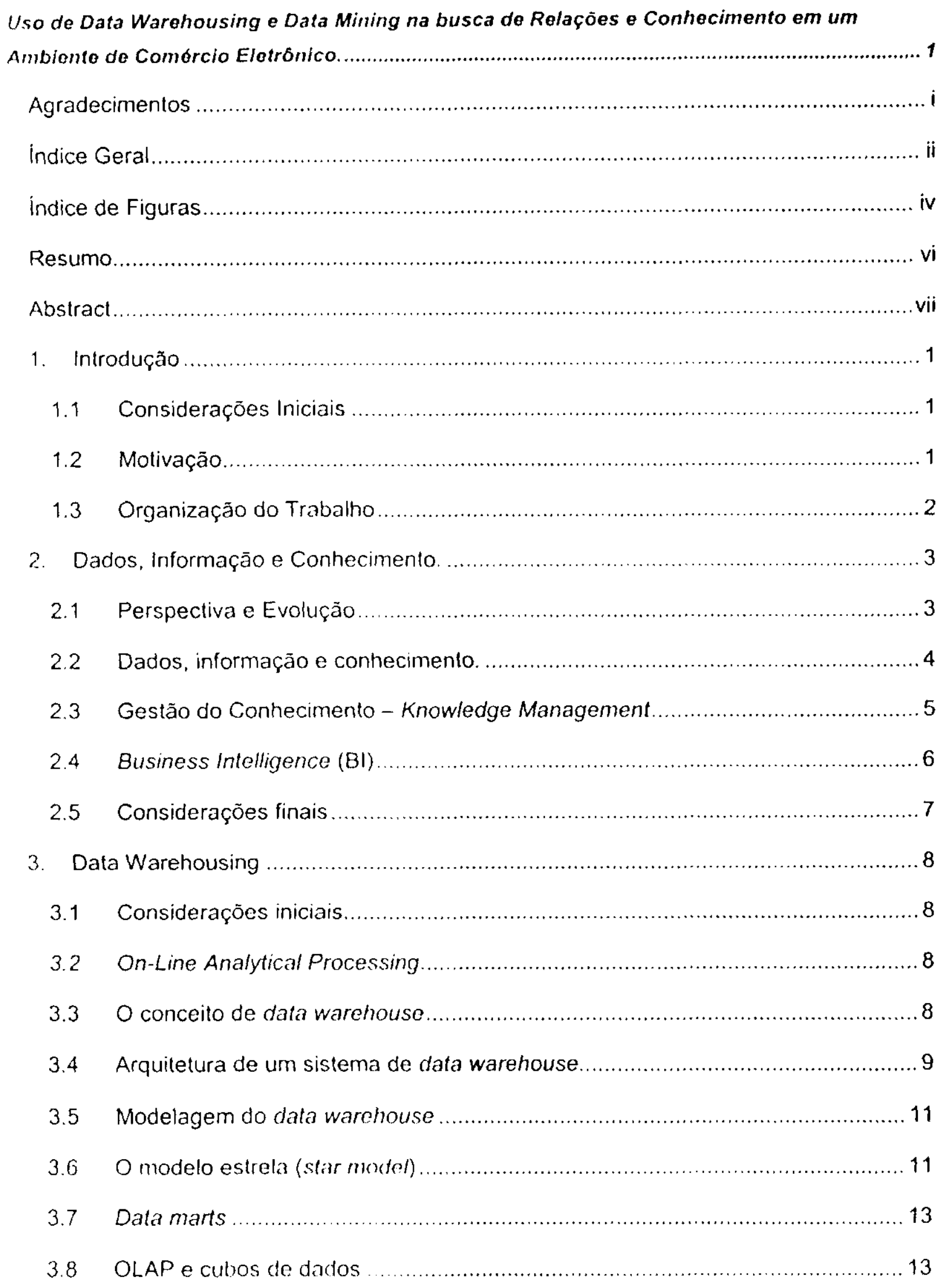




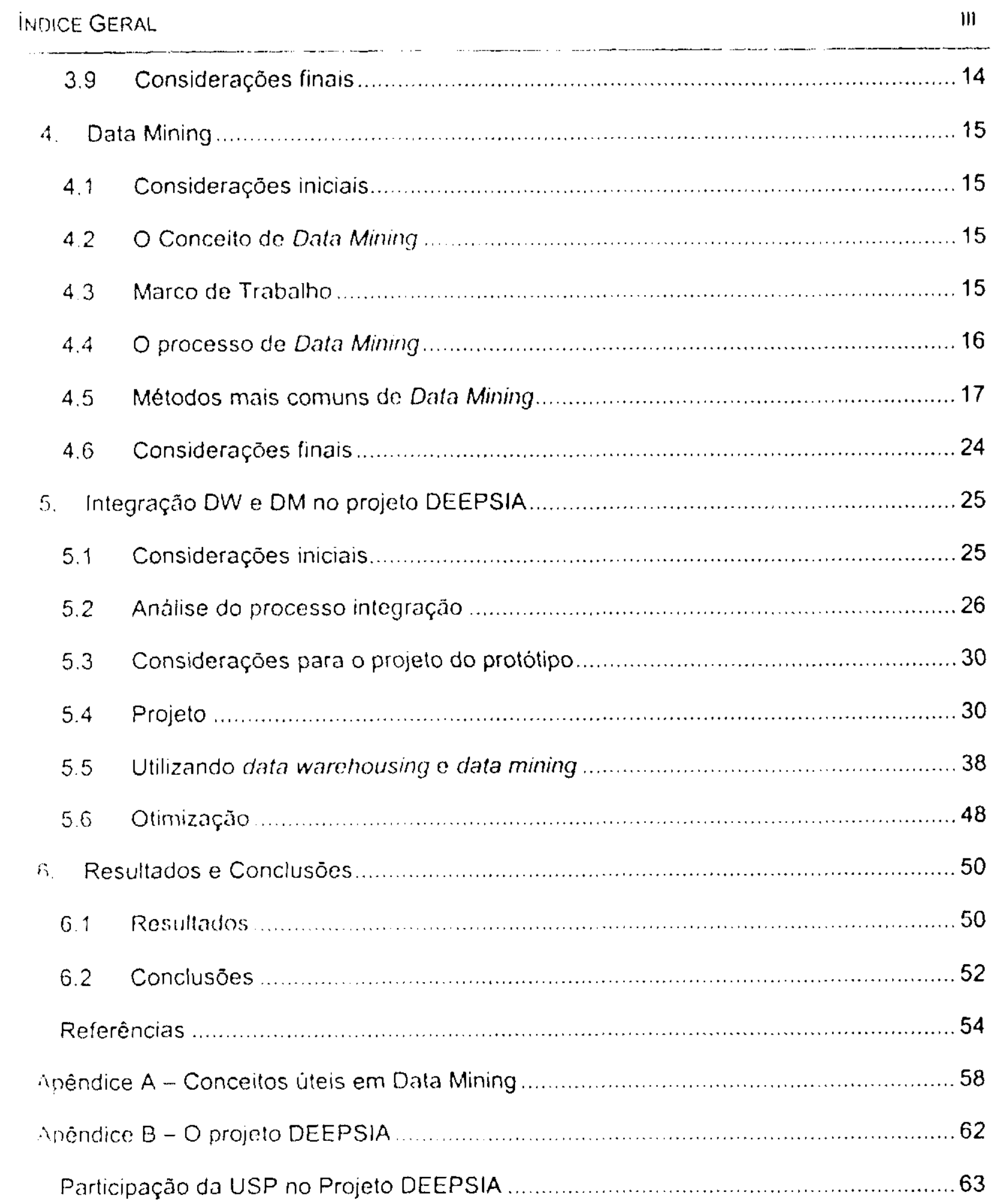




\section{indice de Figuras}

Figura 2-1 Evoluçăo dos dados, informação e conhecimento.

rigura 2-2 Visăo geral das relações entre Bl (Business Intelligence) e KM (Knowledge

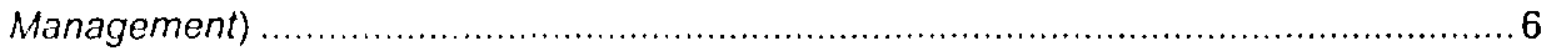

Figura 3-1 Papel dos sistemas de data warehousing na integração dos dados. ................... 9

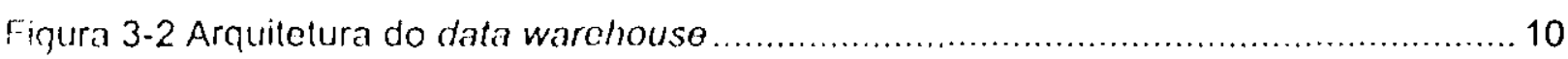

¡igura 3-3 Estrutura genérica de um esquema estrela................................................. 12

Figura 3-4 Exemplo de um esquena estrela para análise de visitas a um web site............ 13

Figura 3-5 Cubo de dados correspondente ao exemplo da Figura 3-4 ............................ 14

Figura 4-1 Arquitetura geral para integração de data warehouse e data mining ................... 16

Figura 4-2 Dados organizados em grupos de valores similares................................... 18

:iiłłura 4-3 Visão esquemática de una rede neural [HAY99] .......................................... 20

Figura 4-4 Visão esquemática de um nódulo de Rede Neural. ....................................... 21

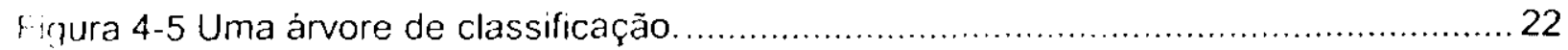

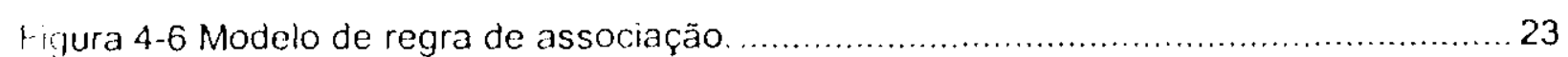

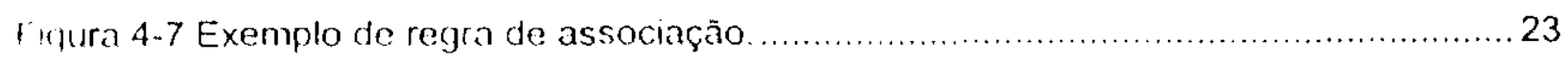

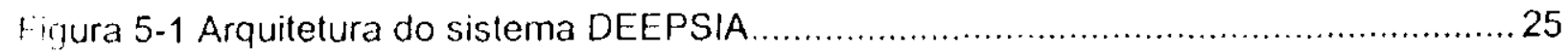

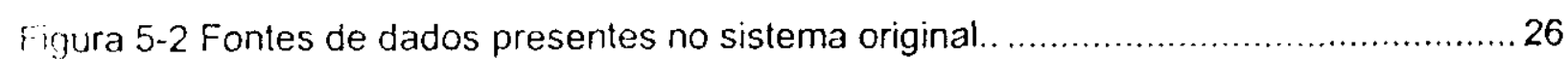

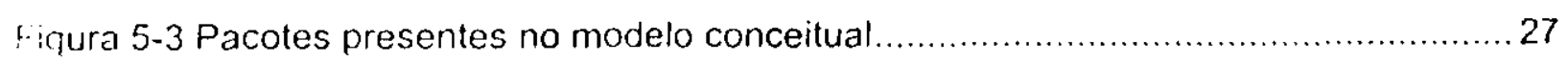

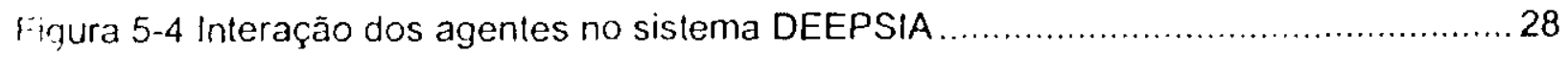

1. nura 5-5 Resumo das ferramentas utilizadas neste trabalho..........................................29

Figura 5-6 Arquitetura dos componentes de software do protótipo. ................................ 31

Fiçura 5-7 Parte do modelo relacional do banco de dados do protótipo.............................. 32

Fqura 5-8 Descrição das tabelas utilizadas no protótipo. .................................................. 33

*... iura 5-9 Nomenclatura dos atributos fisicos no banco de dados................................... 33

" : Iıra 5-10 Visāo da interface de usuário proposta no projeto DEEPSIA ..........................34

: ura 5-11 Arquitetura da camada de software para manipulação da ontologia............... 35 


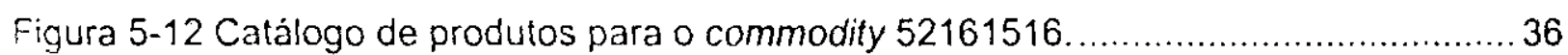

Figura 5-13 Arquitetura da camada de software para manipulação do catálogo. ...............37

Figura 5-14 Componentes para suporte de conexão e idioma no banco de dados, ............ 38

Figura 5-15 Listagem de eventos na interface ............................................... 39

Figura 5-10 Operação de filtragem dos eventos coletados na interface....................... 40

Figura 5-17 Dimensões utilizadas na análise de navegação.................................... 40

Figura 5-18 Esquema estrela do data mart para análise da navegação na interface. ........ 41

F igura 5-19 Disposição física da tabela fato NAVIGATION ...................................41

Figura 5-20 Distribuição de densidade da freqüência de acesso aos nós........................4 42

Fịura 5-21 Modelo para a distribuição de densidade de acessos. ................................4 42

Figura 5-22 Classe em Java para a execução da tarefa de mineração ..........................4 43

Figura 5-23 Regras de associaçáo extraidas da tabela fato NAVIGATION .....................44

Figura 5-24 Esquema de integração de data mining no protótipo .................................4 45

Figura 5-25 Esquema de transferência de dados do SQL Server para o Oracle...............46

Figura 5-26 Execução de uma tarefa no Oracle através de uma RPC. .........................446

ịgura 5-27 Recuperaçāo dos resultados de mineração para o SQL Server.....................4 47

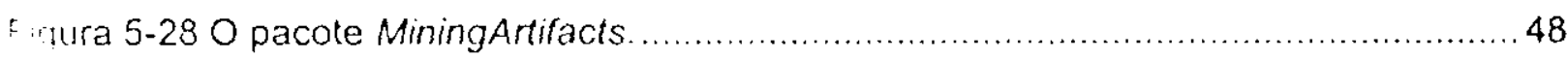

Fitura 5-29 Inserindo outro processo de mineração no esquema................................. 48

(. uura 5-30 Exemplo de grupos obtidos no processo de aglomeração...........................4 49

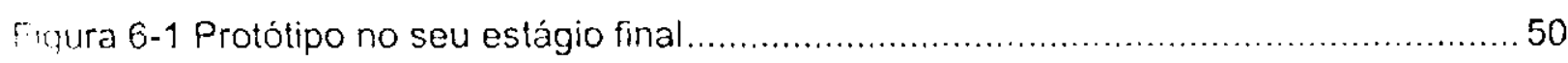

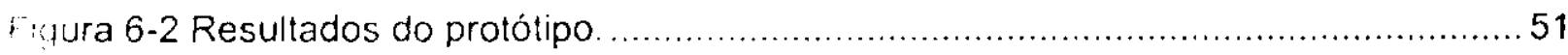

ficura 6-3 Médias comparativas dos resultados obtidos ........................................ 52 


\section{Resumo}

O presente trabalho explora a integração dos processos de data warehousing e data mining inn um sistema de comércio eletrônico multi-agente (especificamente o projeto DEEPSIA Uynamic on-fine IntErnet Purchasing System based on Intelligent Agents) através da implementação de um protótipo que interliga diferentes fontes de dados procedentes dos distintos subsistemas presentes no projeto.

Como resultado deste trabalho, é apresentado um protótipo para a análise da navegação dos usuários utilizando a exploração de regras de associação e análise de conglomerados (s:lustering) 


\section{Abstract}

Current work explores data warehousing and data mining process integration in an enmmerce multi agent system (more specifically in the DEEPSIA project - Dynamic on-linE IntErnet Purchasing System based on Intelligent Agents) through a prototype development that interlaces data sources from several subsystems.

As working resultant, a prototype for user navigation analysis is delivered using association niles exploration and cluster analysis. 


\section{Introdução}

\subsection{Considerações Iniciais}

A grande quantidade de dados disponiveis nos sistemas eletrônicos, incluido o âmbito da Internet laz necessária a disponibilidade de metodologias e, conseqüentemente, técnicas que possam ser aplicadas para a recuperação e transformação dos dados existentes em informação e relações úleis para a geração de conhecimento

Dentro deste âmbito destacam-se duas técnicas que, conjuntamente, permitem a exploraçāo e busca de relações não triviais existentes nos dados disponiveis. Estas duas técnicas sāo conhecidas como data warehousing e data mining.

Data warehousing è atualmente uma aplicaçāo importante dentro do ambiente de banco de dados. Sen e Jacob [SEN98] estimaram o mercado de data warehousing em 8 bilhões de dólares em 1998, incluindo software e hardware. Fontes mais recentes, tais como [LACOO] estima o mercado conjunto de data mining e data warehousing em 20 bilhões de dólares a partir de 2000, com um crescimento anual projetado na ordem de $47 \%$ até 2005 .

O presente trabalho de pesquisa está focado na aplicação das técnicas mencionadas de data warehousing e data mining para a exploração e melhora da navegação dentro da interface de usuário implementada no projeto DEEPSIA (Dynamic on-linE intErnet Purchasing System based on Intelligent Agents). O DEEPSIA é um sisterma voltado a ajudar ao consumidor na aquisição de bens de consumo disponiveis na Internet.

\subsection{Motivação e Justificativa}

Existem poucos trabalhos explorando a integração de data mining com sistemas de comércio eletrônico, em [SUHOO] faz se referência ás possiveis aplicaçōes mas nāo se exploram de forma detalhada os processos de integração. Segundo o mesmo autor, o ambiente comércio eletrônico é considerado como o dominio ideal (killer domain) para a aplicação de data mining.

O projelo em questão, do qual este trabalho forma parte, precisa melhorar a interface de usuário e nos propomos utitizar dala mining como parte da solução a este problema 


\subsection{Organização do Trabalho}

O presente trabalho está organizado da seguinte maneira:

- No C apítulo 2, os conceitos básicos relacionados a os d ados, informaçāo e conhecimento sāo apresentados;

- No Capitulo 3, abordamos o conceito de data warehouse, ressaltando sua importância na estruturação dos dados e incluindo aspectos tais como sua conceição, projeto e estruturação.

- No Capítulo 4, é examinada a técnica conhecida como data mining e suas múltiplas variantes para extração de informação de um conjunto de dados.

- No Capitulo 5, realizamos a descrição de um processo de construção e integração de data warehousing e data mining em um protótipo operacional,o qual inclui uma interface de usuário com um sisterna de busca de produtos na Internet.

- O Capitulo 6 serve de epilogo a este trabaiho, apresentando os resultados da pesquisa e as conclusões. 


\section{Dados, Informação e Conhecimento.}

\subsection{Perspectiva e Evolução}

A primeira geração de sistemas de manipulação eletrônica de dados no mediados dos anos 70 estava baseada no modelo hierárquico, simulando de certa maneira, a forma em que as empresas eram organizadas (rigidamente estruturadas em niveis). Essa primeira estruturação permitiu que sistemas complexos fossem implantados, ainda que sob um foco mais tecnológico do que orientado aos negócios, substituindo arquivos físicos por estruturas de árvores e ponteiros de dados.

Com o surgimento dos novos movimentos metodológicos liderados por [MAR89] na década de 80, que tentavam apartar o empirismo inerente à análise de sistemas, os dados atingiram uma enorme importância. Foi a época do surgimento da gestão de dados (Data Management), da modelagem de dados (Data Modelling), da engenharia da informaçāo (Software Engineering) e da análise de dados (Data Analysis), tudo se contrapondo fortemente ao estilo "orientado ao processo" vigente. Com o surgimento do modelo entidade relacionamento (Entity-Relationship model), criado por [CHE76], a rigidez das estruturas hierárquicas foi trocada pela flexibilidade das relações entre registros de dados. No entanto, o escopo permaneceu mais focado no âmbito tecnológico do que no âmbito de negócios.

A inicios da década de 90 , a Internet começa a impulsionar o conceito de Aldeia Global, criado por Mc Luhan' nos anos 60. Este conceito envolve uma espécie de comunidade virtual, globalmente conectada, com possibilidades de relacionamentos remotos de compra, venda, envio de mensagens, etc., e que hoje identificamos através dos sistemas de noticias, e-mail, mensagens instantâneas e lojas virtuais.

As empresas, entidades e consórcios do final dos anos 90 começaram a ser induzidas a melhorar a qualidade da informação fornecida aos seus funcionários com o intuito de serem mais competitivos em um mercado que se tornava cada dia mais seletivo. Este cenário permitiu aos clientes e consumidores em geral escolher os produtos e serviços com maior qualidade, variedade e menor preço.

Com a concorrência crescente no ambiente de negócios, a informaçāo começa a ser um componente cada vez mais importante dentro do esquema de comércio. Com o

'.. inceilo apresentado por vez primeira em [LUH62]. 
incremento na capacidade de processamento, os bancos de dados corporativos começaram a produzir variantes do modelo relacional. Uma dessas variantes são os data warehouses, os mesmos que foram criados com a finalidade de "fornecer aos responsáveis pela tomada de decisōes, a informação na forma mais precisa e manipulável possivel" [INM96]. Tais repositórios de dados possibilitam aos analistas extrair informaçōes que normalmente os sistemas transacionais não possuem, por médio da exploração, já seja analítica, visual ou utilizando técnicas de extração de associações e regras. Dentre estas últimas, destacam-se as técnicas de data mining. que objelivam melhorar o uso dos grandes bancos de dados através da identificação de padrões de correlação normalmente invisiveis através das análises convencionais.

\subsection{Dados, informação e conhecimento.}

Os conceitos de dados, informaçāo e conhecimento estão interligados, para este trabalho, serão usados os conceitos discutidos por Kock et al. [KOC96]:

A Figura 2-1 é uma representação gráfica do relacionamento entre dados, informação e conhecimento, em função da capacidade de entendimento e da independência de contexto que cada um destes conceitos implica.

Dados são fatos, números, texto ou qualquer midia que possa ser processada pelo computador. Hoje em dia, as organizações estão acumulando vastas e crescentes quantidades de dados em diferentes formatos e em diferentes tipos de repositórios. Estes dados incluem:

- Dados operacionais ou transacionais tais como vendas, custos, inventários, folhas de pagamento e contas correntes.

- Dados não operacionais como previsões de mercado, vendas ao nivel industrial, e dados macro-econômicos.

- Metadata, ou dados descrevendo a estrutura dos dados armazenados, tais como projelos lógicos de bancos de dados ou dicionários de dados.

- Midia contendo imagens, sons ou uma combinatória de ambos, que além de ser armazenada, pode ser catalogada eletronicamente.

A informação é constituida por padrōes, associaçōes ou relaçōes que todos aqueles dados acumulados podem proporcionar. Por exemplo, a análise de pontos de equilibrio no mercado pode fornecer informação acerca de quais produtos estão sendo vendidos e a freqüência de tais operaçōes. 
A informaçăo pode gerar conhecimento que ajude na análise de padrỏes históricos para conseguir uma previsão dos fatos futuros (pelo menos no contexto das variáveis que estão sendo envolvidas na análise). Por exemplo, a informação dos dados sumarizados nas vendas de um determinado ambiente comercial pode ser analisada com a finalidade de fornecer informações acerca da nalureza dos clientes. Com isto em mãos, o fabricante ou varejisla pode saber quais são os itens com maior probabilidade de venda.

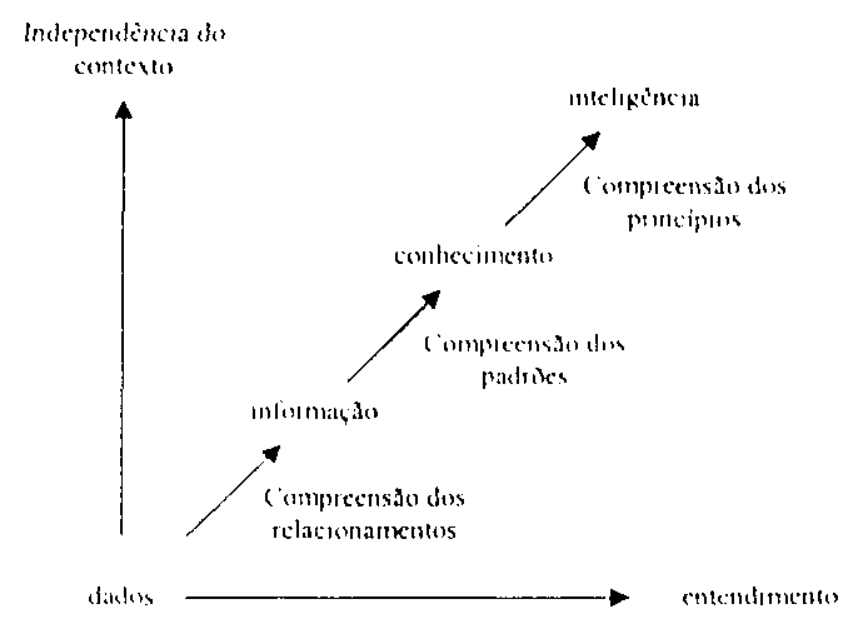

Figura 2-1 Evolução dos dados, informação e conhecimento.

Enquanto que a informação é descritiva, o conhecimento é utilizado fundamentalmente para fornecer uma base de previsão com um determinado grau de certeza, baseado em informaçāo acerca do passado e do presente [KOC97]. Neste contexto, a organização é fundamental para manter a coerência das informaçōes que estão armazenadas nos diferentes repositórios e a diferentes niveis. Esta organização é função dos sistemas para a Gestão do Conhecimento (Knowledge Management).

\subsection{Gestão do Conhecimento - Knowledge Management}

A Gestão do Conhecimento (Knowledge Management - KM), tem o objetivo de estabelecer uma aproximação integrada e colaborativa para capturar, criar, organizar e usar todos os ativos de informação de uma corporação.

Segundo o Foro da Gestão do Conhecimento (The Knowledge Management Forum) [KMF96], a Gestão do Conhecimento é "a coleção de processos que governam a criação, publicação e utilização do conhecimento". 
O KM é o primeiro passo na criação de uma estrutura lógica para realizar processos sobre as informações que uma determinada entidade possui e gerenciar tanto as entradas quanto os resultados das mesmas ${ }^{2}$.

O grande desafio das empresas hoje, não é apenas organizar seus Sistemas de KM (Knowledge Management Systems - KMS), mas estabelecer uma ponte entre ela e a Inteligência de Negócios ou Business Intelligence (BI) (vide Seção 2.4). Enquanto o BI transforma dados em informaçāo, produzindo as visões (views), relatórios, etc., a KM realiza as devidas combinaçōes, compilaçōes, subscriçōes e a distribuição, inserindo pontos de discussão, com o complexo objetivo de transformar informações em conhecimento.

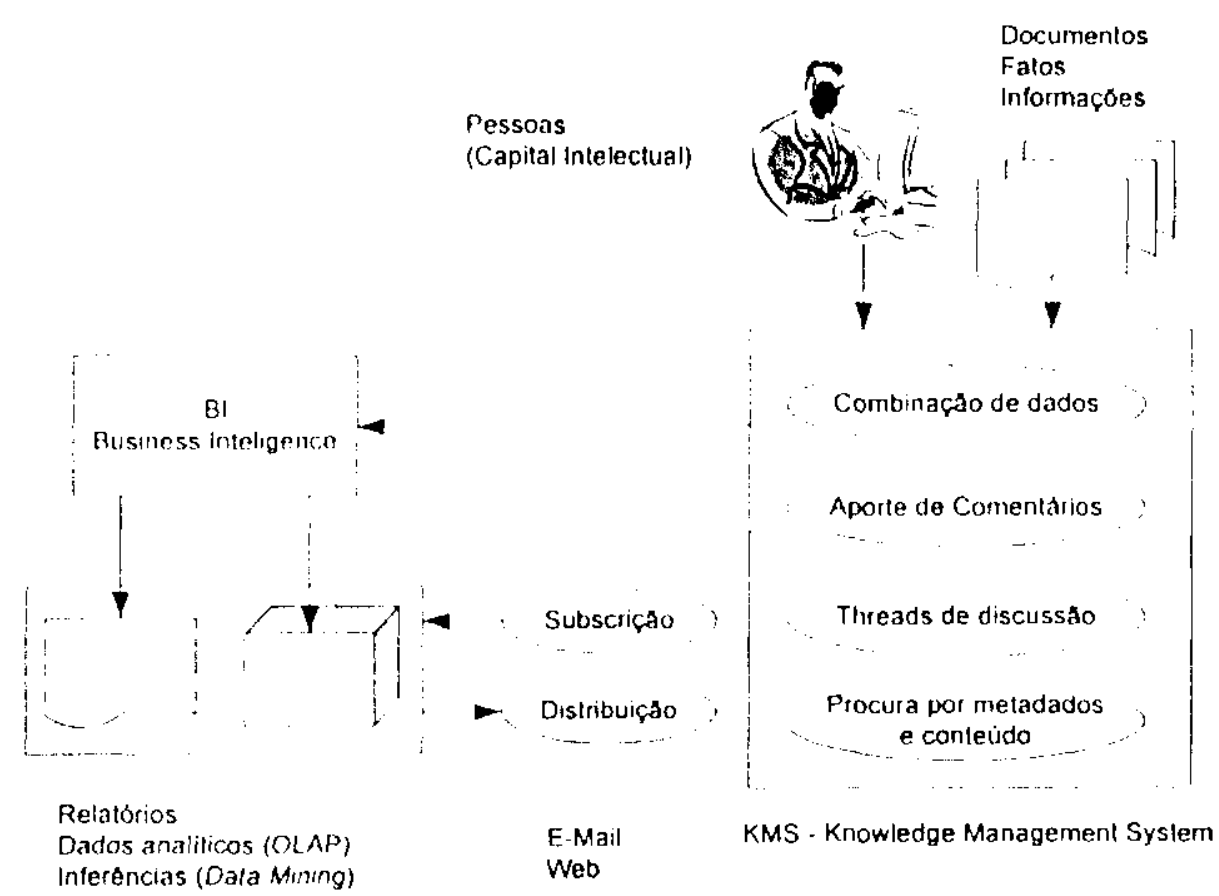

Figura 2-2 Visảo geral das relaçoes entre BI (Business Intelligence) e KM (Knowledge Management)

\subsection{Business Intelligence (BI)}

O conceito de Business Intelligence (BI), de forma mais ampla, pode ser entendido como a utilizaçāo de variadas fontes de informação para definir estratégias de competitividade nos negócios.

$\therefore$ estão do Conhecimento (KMS) não deve ser confundida com o conceito de Gestão da

- intução (Information Management). 
Existe uma grande problemática ao nivel empresarial e de mercado: uma grande quantidade de dados está disponivel, provocando muitas dificuldades na extração de informaçð̄es a partir deles. Essa crescente inundaçð̃o de informaçðes dificulta o processo de tomada de decisão na medida em que a média e alta gerencia se sentem impotentes no processo de sua busca e recuperação.

As informações vitais para tomadas de decisões estratégicas estão escondidas em milhares de tabelas e arquivos; ligadas por relacionamentos de correlações transacionais, em uma organização inadequada para o estabelecimento de decisões.

O objetivo maior das técnicas de BI neste contexto está exatamente na definição de regras e técnicas para a formalação adequada destes volumes de dados, com a finalidade de transformálos em depósitos estruturados de informações, independentemente da sua origem.

\subsection{Consideraçōes finais}

A obtenção do conhecimento é um processo que envolve o uso de múltiplas técnicas e métodos, que evoluiram à medida que os requerimentos de informação tornaramse uma prioridade dos ambientes de negócios. As Seçōes 2.1 e 2.2 fornecem um resumo deste processo evolutivo, cujo estágio final é a inteligência de negócios - BI, que tem o objetivo de incrementar a compelitividade nos negócios ou processos, algo que de certa forma è a meta de toda corporação ou entidade comercial.

Na seção seguinte, apresentaremos o conceito de Data Warehousing, uma das abordagens mais estendidas para a estruturação e consolidação de dados obtidos a partir de fontes heterogêneas. 


\section{Data Warehousing}

\subsection{Consideraçōes iniciais}

A abordagem tradicional de dados desenvolvida ao longo dos últimos vinte ou trinta anos, conhecida como modelagem de dados, foi um instrumento de extrema utilidade na formatação de estruturas capazes de serem implantadas e entendidas pelos gerenciadores de bancos de dados. O modelo entidade relacionamento desenvolvido por [CHE76] tem sido a abordagem mais utilizada para as operações de modelagem, armazenamento e processamento em bancos de dados. No entanto, maioria das implementações é inadequada para a complexa análise que requerida no mundo real [PED99].

- avanço da tecnologia para a captura de dados, poder de processamento. transmissão de dados e capacidades de a rmazenamento e stão permitindo que as organizações integrem seus bancos de dados em repositórios centralizados. denominados data warehouses.

\subsection{On-Line Analytical Processing}

Seguindo a linha apresentada no parágrafo 3.1, varias técnicas tem sido desenvolvidas para a análise de dados em grandes bancos de dados de forma eficiente e efetiva. Uma das técnicas mais populares, e que tem demonstrado ser uma das mais efetivas, rápidas e com maior suporte ferramental, è OLAP (On-Line Analytical Processing)

OLAP é uma tecnologia que utiliza uma visão "multidimensional" de dados agregados com $O$ intuito de fornecer um rápido acesso de informação estratégica para a realização de analises adicionais. Ela facilita consultas em grandes quantidades de dados de forma mais rápida que as tradicionais técnicas de bancos de dados relacionais [CHA97].

\subsection{O conceito de data warehouse}

No inicio da década de 90 . data warehousing foi proposto como uma solução de propósito geral ao problema de satisfazer as necessidades de gerenciamento da informação organizacional.

Inmon [INM96] define o conceito de data warehouse como uma "coleção de dados consistentes. integrados, dependentes do tempo, persistentes, e orientados à 
atividade; os quais estão baseados na informação disponivel e que permitem a tomada de decisões ou a realização de previsões".

Segundo o mesmo autor, o conceito de data warehousing representa uma visão ideal de um repositório centralizado de todos os dados organizacionais. A centralização dos dados é necessária para maximizar a eficiência de acesso e análise dos dados.

\subsection{Arquitetura de um sistema de data warehouse}

Um dos problemas mais importantes relacionados com a estruturação de um data warehouse é precisamente a obtenção de um repositório centralizado. Calvanese et al. [CAL99] analisa esta problemática no contexto da Integração dos Dados ${ }^{3}$, e conclui que quando os dados passam das fontes de ambientes orientados à aplicação para o data warehouse, as possiveis inconsistências e redundâncias devem ser resolvidas, para que o mesmo possa fornecer uma visão integrada e reconciliada dos dados da organização. A Figura 3-1 mostra o data warehouse como o pivô para a centralização e integração dos dados de um sistema ou organização.

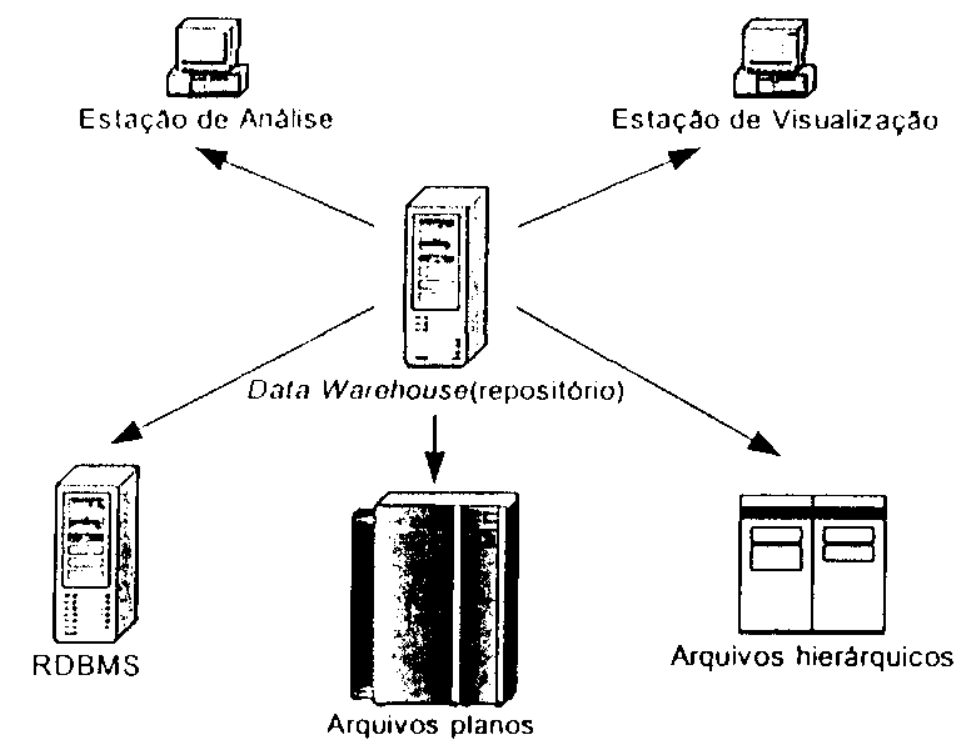

Figura 3-1 Papel dos sistemas de data warehousing na integração dos dados

Data warehousing está baseada na metáfora da cadeia de abastecimento (supply chain). Os dados são obtidos das diversas fontes e armazenados em um repositório (warchouse) central. Os dados são expostos aos usuários através de data marts. A

\footnotetext{
conceito de Integração dos Dados pode ser visualizado como "a problemática de aquisição dos
} "udos das múltiplas e diferentes fontes disponiveis para a aplicaçăo de nosso interes" [CAL99]. 
Figura 3-2 apresenta uma visão genérica da arquitetura de um data warehouse, dividida entre o back-end $d^{4}$ o front-end $d^{5}$ do sistema.

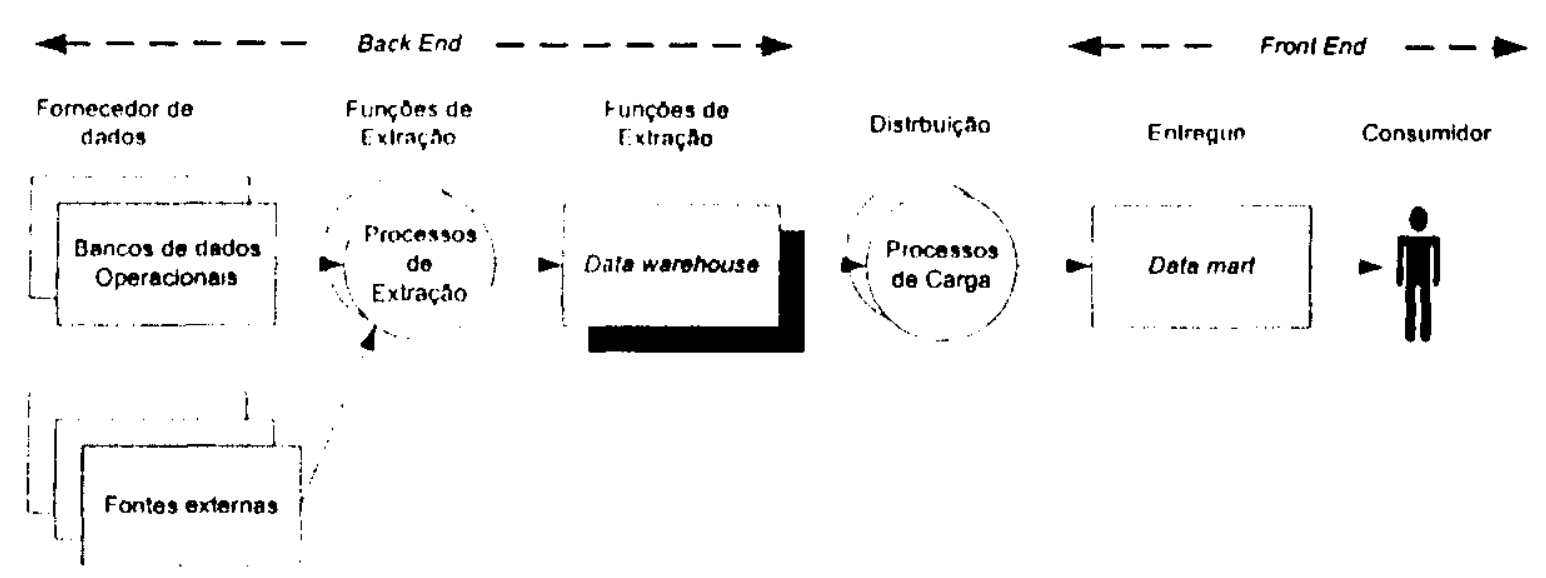

Figura 3-2 Arquitetura do data warehouse

Moody e Kortink [MOD00] apresentam uma abordagem para definir a arquitetura de um data warehouse baseada em referências e trabalhos prévios, e identificam os seguintes componentes dentro dela:

- Sistemas operacionais - os que possibilitam a coleta das transações do sistema global.

- Fontes externas - DBMS, planilhas de dados corporativos, sistemas legados, etc.

- Processos de extração - estes processos armazenam os dados no warehouso de uma forma estruturada. Estes dados são conciliados e consolidados em um formato consistente.

- Data warehouse central - que atua como uma fonte central para o suporte à tomada de decisōes dentro da corporação, sendo implementada geralmente utilizando os RDBMS (DBMS relacionais) tradicionais.

- Processos de Carga - estes processos distribuem a carga dos dados do data warehouse central para os data marts.

- Data marts - representam os pontos de saida ou de resultados do data warehouse e fornecem dados em formatos úteis para análise por parte dos usuários. Os data marts estāo geralmente orientados às necessidades

$\because$ :rk-end-programas que execulam larefas nåo diretamente controladas pelo usuário

$\therefore m t \cdot e n d-p a r t e$ do programa (computacional) que é responsável pela interface do usuário 
especificas de um grupo de usuários ou de uma tarefa de elaboração de decisões, podendo ser implementados utilizando RDMBS e/ou ferramentas de OLAP \{On-Line Analitical Processing).

- Usuários - elaboram consultas e análises utilizando os dados armazenados nos data marts através de ferramentas de consulta "amigáveis ${ }^{6 "}$.

Na seção 3.5, é discutida a forma em como o data warehouse é concebido e estruturado

\subsection{Modelagem do data warehouse}

Kimball propôs a lécnica de modelagem dimensional [KIM96] para o projeto de um data warehouse, sendo que ela é hoje em dia a técnica mais referenciada neste contexto e a que será utilizada no presente trabalho. Diferente do ambiente operacional-transacional ou OLTP (On-Line Transaction Processing), geralmente baseado em bancos de dados relacionais otimizados para o processamento de transações, a modelagem dimensional está baseada no uso de um banco de dados multidimensional (Multidimensional Database - MDDB). Tal banco de dados fornece um ambiente integrado para as consultas de suporte às decisōes. $O$ banco de dados multidimensional pode também ser definido como um data warehouse no qual, a informação está organizada segundo o modelo estrela.

Além do trabalho de Kimball, outros autores [ANA97, KRI97, THE98, LEH98, PED99, MOD00. HUSO0] tem realizado trabalhos formais acerca de como projetar um esquema de data warehouse a partir de um esquema conceitual [INM96, G OL98, SAP98, TRY99]. Os principais aportes neste sentido sāo o modelo estrela e o conceito de banco de dados multidimensional, que serão discutidos nos parágrafos seguintes ( 3.6 a 3.8 )

\subsection{O modelo estrela (star moden)}

A modelagem dimensional não está baseada em teoria nenhuma, mas foi bemsucedida na prática e tem sido adotada como a abordagem predominante para a conceição dos data warehouses.

O modelo estrela é o bloco fundamental utiłizado na modelagem dimensional. Um esquema estrela consiste de uma tabela central denominada "tabela fato" e um

:ermo "amigável" no contexto do software refere-se à facilidade de uso e interaçāo com uma : 
número de tabelas chamadas de "tabelas dimensão" projetando-se radiaimente a partir da tabela fato. Como mostrado na Figura 3-3, a tabela fato constitui o centro da estrela enquanto que as tabelas dimensão formam as pontas. O esquema estrela pode ter uma quantidade qualquer de dimensões

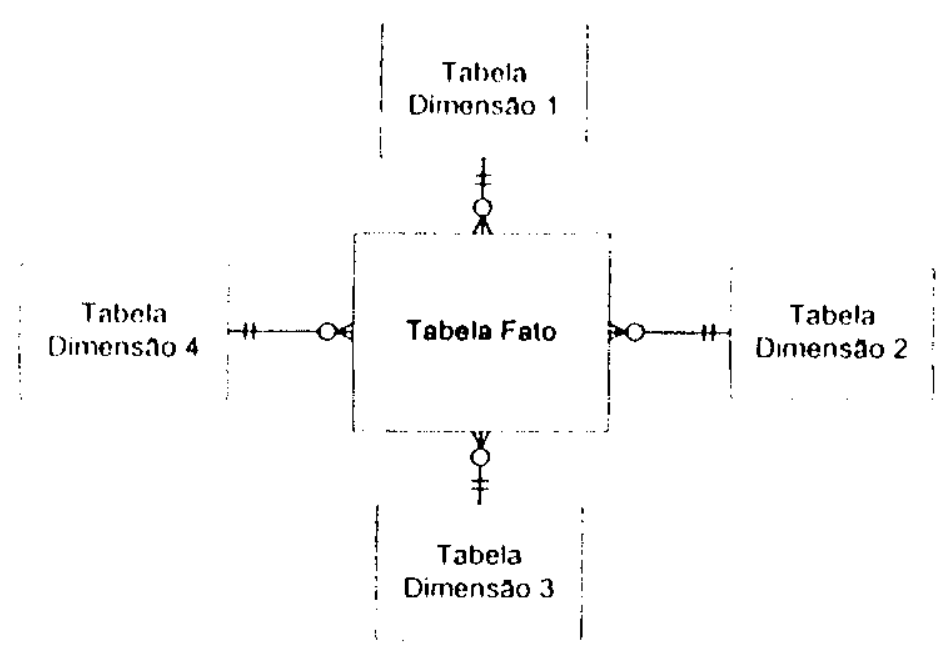

Figura 3-3 Estrutura genérica de um esquema estrela.

A tabela fato contém "medidas" (tais como preços, quantidades, etc.) que podem ser agregados de múltiplas maneiras, enquanto que as tabelas dimensão fornecem as formas de agregação para as medidas contidas na tabela fato. Além disso, a tabela fato deve estar está relacionada com todas suas tabelas dimensão através de relacionamentos "um a muitos", sendo que a chave primária da tabela fato é a concatenação das chaves primárias de todas as tabelas dimensão que estão relacionadas com ela.

As tabelas dimensāo sāo tabelas altamente "denormalizadas", e geralmente consistem de hierarquias agregadas. No exemplo mostrado na Figura 3-4 a tabela fato Web Site está relacionada com três tabelas dimensão, a primeira delas define uma hierarquia de tempo, fornecendo três niveis de agregação: ano, mês e dia. Da mesma maneira, as outras duas dimensões estão organizadas de forma similar.

A vantagem de utilizar o modelo estrela é que o número de relacionamentos na base de dados fica reduzido e por tanto, as consultas nela requerem um número menor de cálculos. Kimball [KIM96] conclui que o uso deste tipo de esquema no projeto de um data warehouse faz com que aproximadamente o $80 \%$ das consultas feitas na base de dados sejam feitas em uma única tabela. Outra vantagem é que elas podem ser implementadas utilizando ferramentas especialistas de OLAP. como também bancos de dados relacionais. 


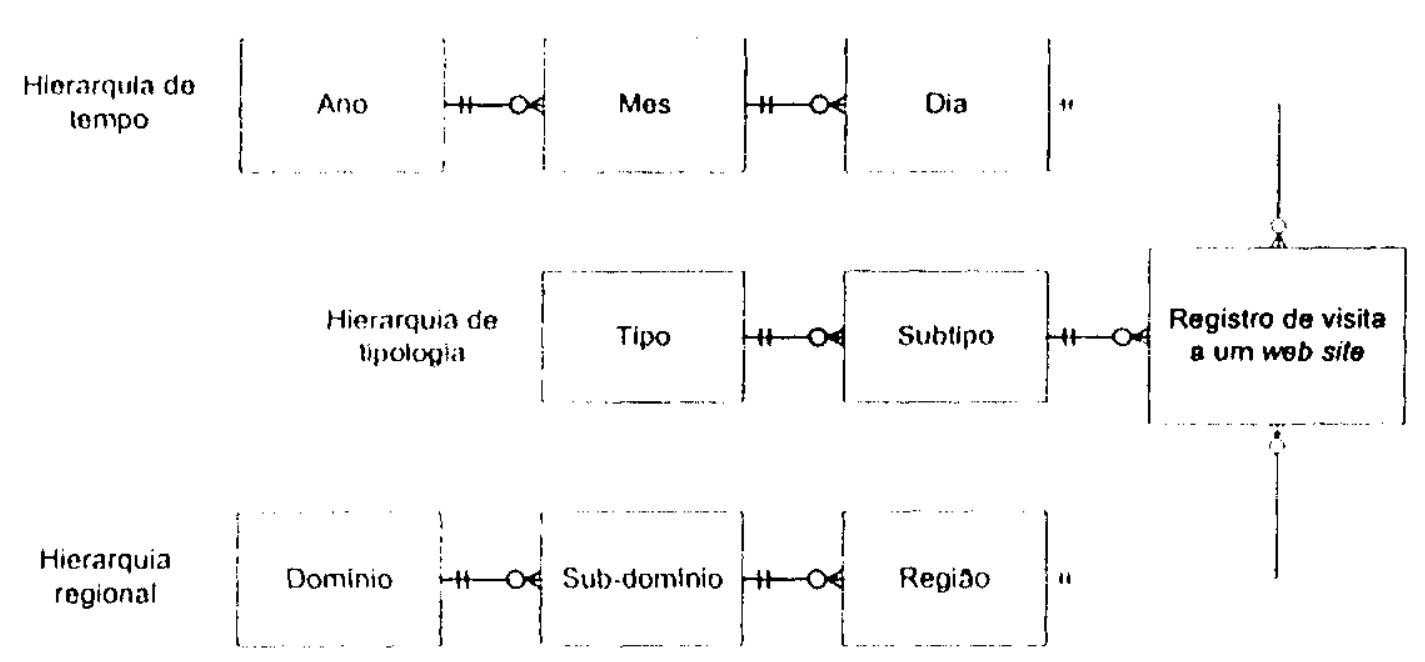

Figura 3-4 Exemplo de um esquema estrela para análise de visitas a um web site.

\subsection{Data marts}

Um data mart representa u $\mathrm{m}$ detalhe do produto final de um data warehouse. Os dados são extraidos do data warehouse central para os de data marts com a finalidade de dar o suporte a análises particulares. O mais importante requisito neste nivel é que os dados estejam estruturados de forma a facilitar sua interpretação por parte dos usuários finais. Por tal motivo, as técnicas de modelagem dimensional são mais apropriadas neste nivel. Isto garante que as estruturas de dados sejam tão simples quanto possiveis de tal forma que elas simplifiquem as consultas dos usuários.

\subsection{OLAP e cubos de dados}

As aplicações de OLAP precisam visualizar os dados desde pontos de vista diferentes (as dimensões, descritas no parágrafo 3.5), o cubo de dados, definido formalmente por Gray et al. [GRA97] é uma visão multidimensional de um banco de dados onde um valor crítico, é organizado por múltiplas dimensões. No exemplo dado na Figura 3-4, o valor critico seria a contagem do número de referências à um determinado web site (a tabela fato), organizada pelas diferentes hierarquias relacionadas.

A Figura 3-5 apresenta um cubo de dados correspondente ao exemplo citado no parágrafo 3.6. cada célula do cubo de dados corresponde a um único conjunto de valores para as diferentes dimensōes e contem os valores das medidas para esse conjunto. Para representar esla visāo multidimensional, os dados são geralmente armazenados na forma de "tabelas sumário", correspondentes aos sub-cubos do 
cubo de dados. Tal abordagem é conhecida também como ROLAP (Relational OLAP), outra abordagem para armazenar o cubo de dados é através de arranjos multidimensionais, tal abordagem é conhecida como MD-OLAP (Multidimensional OLAP), a qual consome muito espaço para cubos de dados esparsos e atualmente é pouco utilizada [GUP97].

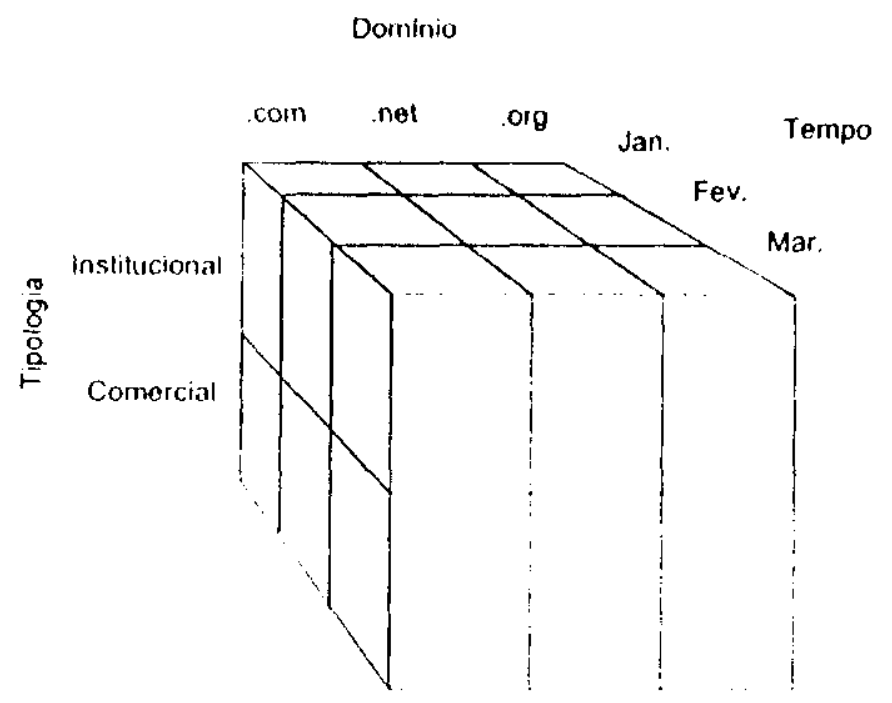

Figura 3-5 Cubo de dados correspondente ao exemplo da Figura 3-4

\subsection{Considerações finais}

A modelagem dimensional è a técnica mais utilizada na modelagem do data warehouse, ela fornece a base para analises mais exaustivas através da extração de dados em data marts especializados cuja finalidade é apresentar os dados ao usuário final da forma mais simple possivel. Embora existam várias ferramentas no mercado, a modelagem conceitual de dados continua a ser a base do desenvolvimento de um data warehouse. 


\section{Data Mining}

\subsection{Considerações iniciais}

Enquanto que as tecnologias de processamento da informaçăo evoluiram separadamente dos sistemas analiticos, o processo de data mining tenta fornecer um nexo entre ambos.

O objetivo primordial do processo de data mining é a previsão - e conseqüentemente, a mineração de dados de previsão (predictive data mining), é o tipo mais comum de mineração de dados.

\subsection{O Conceito de Data Mining}

Data mining é um processo analitico projetado para a descoberta de padrões previamente desconhecidos e potencialmente interessantes dentro de grandes bancos de dados [PIA91]. Estes padrões representam relações sistemáticas entre variáveis, e são logo validadas por meio da sua aplicação em novos conjuntos de dados.

A análise dos dados é realizada geralmente através de ferramentas ou bibliotecas de software especializadas. Tais ferramentas realizam análises das relaçōes e padrōes dentro dos dados transacionais armazenados nos repositórios de dados, utilizando consultas ao nivel de usuário. As relações encontradas dentro dos conjuntos de dados fornecem uma base para a expressão de conhecimento acerca dos mesmos.

\subsection{Marco de Trabalho}

Desde um ponto de vista prático, vários autores [INM96, MOD00], consideram que o uso de OLAP ajuda ao processo de data mining, isto devido ao variado conjunto de funções e operadores disponiveis nele. Na Figura 4-1 podemos ver que a arquitetura geral de um esquema de integração consiste dos seguintes componentes: (1) o data warehouse, (2) o cubo de dados ou os data marts, e (3) o motor de mineração.

- O data warehouse permite realizar as operações de consolidação, preparação e limpeza dos dados, servidor como uma implementação física de um modelo de suporte às decisões também como um repositório de informação. Inclui-se nele dados históricos, as visões materializadas dos cubos e metadados para descrever os dados armazenados nele. 
- O cubo de dados. Em um processo de mineração envolvendo as dimensões $A_{1}, A_{2}, \ldots, A_{1}$ é possivel pré-processar e materializar os dados relevantes ao problema em um cubo n-dimensional. O pré-procesamento é feito geralmente utilizando o motor de OLAP.

- O motor de data mining possibilita realizar a exploração analítica dos dados para tentar extrair as informações e relacionamentos que os usuários precisam. Tal exploração pode ser automatizada, interativa ou uma combinação de ambos.

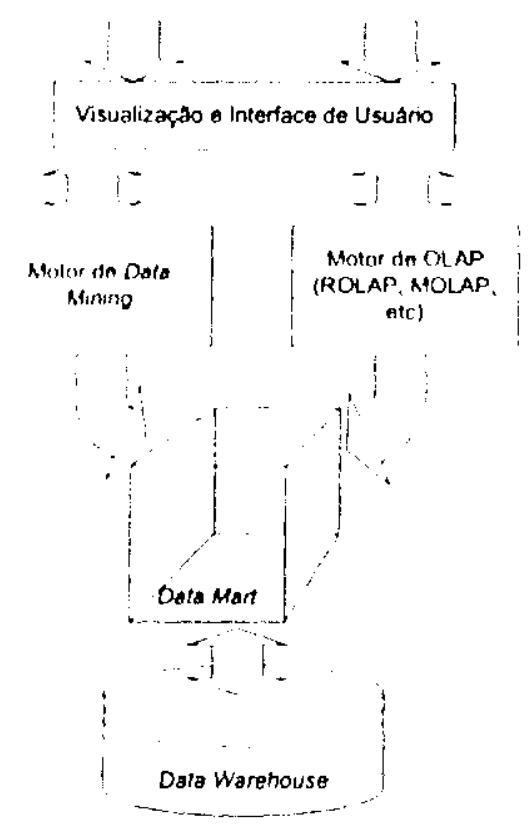

Figura 4-1 Arquitetura geral para integração de data warehouse e data mining

\subsection{O processo de Data Mining}

O processo pode ser visualizado como consistindo de três estágios principais:

- Exploração inicial. Este estágio usualmente é iniciado com a preparação dos dados, o qual pode implicar um processo de "limpeza", transformação, seleção de sub conjuntos de registros e - no caso de grandes quantidades de variáveis (ou campos) - a execução de algumas operaçōes de seleção preliminar do número de variáveis. Dependendo da natureza do problema analitico, este primeiro estágio do processo de mineraçăo pode abranger desde uma seleção simples de elementos de previsão extraidos de um modelo de regressão, até a elaboração de análises exploratórias utilizando uma grande variedade de métodos gráficos e estatísticos.

- Modelagem e validação. Este estágio envolve a consideraçāo de vários modelos $e$ a escolha do mais adequado baseado na sua performance de 
previsão dos resultados. Existe uma grande variedade de técnicas desenvolvidas para conseguir este objetivo - muitas das quais estão baseadas nos também chamados "modelos de avaliação competitiva", isto é. a aplicação de diferentes modelos dentro do mesmo conjunto de dados e então a comparação da sua performance para a escolha do mais acertado. Estas técnicas incluem Bagging (escolha, calculo médio, etc.), Boosting. Stacking e Mela-learning (vide Apêndice A).

- Aplicação do modelo (deployment). O estágio final implica a utilização do modelo selecionado no estágio precedente e sua aplicação em dados novos, para a geração de previsões ou estimativos. Aspectos relativos à aplicação do modelo (ou modelos) obtidos em um ambiente de e-commerce, incluindo escalabilidade, performance, e disponibilidade em tempo real são abordados em [SCH01].

A maioria dos métodos de data mining encaixa-se no processo geral descrito anteriormente. A seguir, é feita uma revisão dos principais métodos de mineração e sua natureza funcional.

\subsection{Métodos mais comuns de Data Mining}

De uma forma mais geral, existem métodos de mineração para criar modelos analiticos de previsão, descrição ou ambos [FRE98].

Um modelo de previsão pode responder perguntas do tipo "qual o retorno esperado do investimento" por exemplo. Os modelos descritivos, por outro lado, fornecem informações acerca dos relacionamentos entre os dados, informação do tipo "Um cliente que compra um computador no crediário é três vezes mais propenso a comprar também uma impressora". A maioria dos modelos de previsão cai também na categoria de modelos descritivos, entre os mais comuns encontram-se os seguintes:

- Clustering (descritivo)

- Classificação (previsão) e regressão (previsão).

- Descoberta de regras de associação (descritivo) e descoberta de padrões seqüenciais (previsão).

\subsubsection{Clustering}

Clustering è um método que cria grupos de entidades semelhantes baseando-se nas caracteristicas e similitudes comuns dos dados tratados. A similaridade é 
parametrizada utilizando uma função de medida de distância, sendo que a disposição final dos clusters é dependente da função escolhida. Esta técnica requer da participação de um experto para determinar a métrica de distância adequada ao dominio do problema. Na Figura 4-2 podemos observar que são criados grupos com valores de atributos "semelhantes", entanto que as entidades que não podem ser classificadas são simplesmente descartadas.

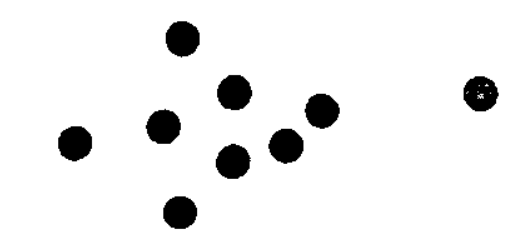

Figura 4-2 Dados organizados em grupos de valores similares.

Inclui-se neste método as técnicas de k-nearest neighbours (k-NN) e um tipo especial de rede neural chamada rede de Kohonen ou Self Organizing Maps (SOM).

- k-Nearest Neighbor. É uma técnica de previsão aplicável a modelos de classificação. $k$ representa um número de casos semelhantes ou o número de elementos dentro do grupo. Com a técnica de k-NN, os dados de treinamento é o modelo. Quando um novo caso é a presentado a o modelo, o algoritmo procura todos os dados para encontrar um subconjunto de casos que sejam o mais semelhante a ele para tentar predizer o resultado da classificação. $O$ algoritmo utiliza como parâmetros principais o número de casos semelhantes a ser utilizado $(k)$ e a métrica para medir tal semelhança.

O algoritmo de k-NN está baseado em um conceito de distância, e precisa do estabelecimento de uma métrica para determinar dita distância. Para valores continuos, a distância euclidiana é geralmente utilizada; para variáveis categóricas, deve encontrar-se uma forma adequada de medir tal distância. A principal desvantagem desta técnica é que o número de cálculos necessários cresce proporcionaimente ao fatorial do número total de pontos.

- SOM - Self Organizing Map. Em um SOM [KOH82], os clusters são geralmente organizados em um arranjo de células, usualmente bidimensional, podendo ser unidimensional ou multidimensional. O SOM tenta encontrar clusters de tal forma que dados dois clusters, um perto do outro no arranjo. encerram outros clusters no espaço do arranjo. A principal vantagem 
desta técnica é que não precisa supervisão do treinamento, como no caso das redes neurais.

\subsubsection{Classificação e Regressão}

Classificação e regressão constituem uma grande parte dos problemas nos quais data mining é aplicado, criando modelos para prever a classe de uma entidade (classificação) ou seu valor (regressåo).

Uma variação dos modelos de regressão é a chamada regressão logistica, a qual é utilizada para prever um valor binário. Ela é uma generalização da regressão linear devido ao fato de que uma variável binária dependente não pode ser modelada diretamente pela regressão linear. A regressão logistica comporta-se como ferramenta de classificaçāo quando utilizada para prever variáveis categóricas (discretas), como no caso no qual um cliente está afim ou não de comprar determinado produto, enquanto que é vista como ferramenta de regressão quando utilizada para predizer variáveis continuas, tais como a probabilidade de que um cliente realize uma determinada compra.

Entre as técnicas de classificação e regressão mais utilizadas incluem-se as árvores de decisão, redes neurais, Naïve-Bayes e nearest-neighbor.

- Redes neurais artificiais. As redes neurais são uma tecnologia cada vez mais utilizada em data mining. Sua grande vantagem é basicamente sua habilidade de aprendizagem a partir das experiências, não ficando restritas a uma ordem seqüencial pré-fixada. Elas consistem em algoritmos e procedimentos computacionais que imitam a capacidade de aprendizagem do cérebro.

Uma definiçāo de rede neural, fornecida por Aleksander e Morton [ALE90] é a seguinte: "Uma rede neural é um processador paralelo massivo e distribuido consistindo de unidades de processamento simples, que tem uma propensão natural para armazenar conhecimento a partir da experiência, ademais de disponibilizar seu uso".

Esta técnica é formada de nódulos cujo processamento se assemelha ao dos neurônios, dai seu nome. Não oferece indicadores definidos e o comportamento de uma rede neural, com certa massa de dados, nem sempre se repetirá com outra. No entanto, é um recurso que permite o emprego de estatistica em modelos não lineares. 
A Figura 4-3 mostra como são constituidas as Redes Neurais. Os nódulos são conectados como uma rede e funcionam paralelamente. A primeira fase de nódulos é composta pelos nódulos de entrada. Eles recebem o input das variáveis fornecidas pelo banco de dados, transformam-no de acordo com uma função (chamada funçăo de ativação), produzindo uma informação de saida que será enviada à próxima fase de nódulos. Esta, por sua vez, receberá diversas informações dos nódulos de entrada como seu input. Essa fase é formada pelos nódulos ocultos, que, em redes neurais mais complexas, podem formar diversas camadas. Por fim, têm-se nódulos de saida. Estes processam as informaçōes recebidas e produzem uma resposta, mas não a enviam para outro nódulo, pois esta saida já é o resultado final da rede. Se a rede é de classificação, o nódulo de saida já é a classe final. Para o caso de modelos de previsão, o nódulo de saida representa um valor de previsão.

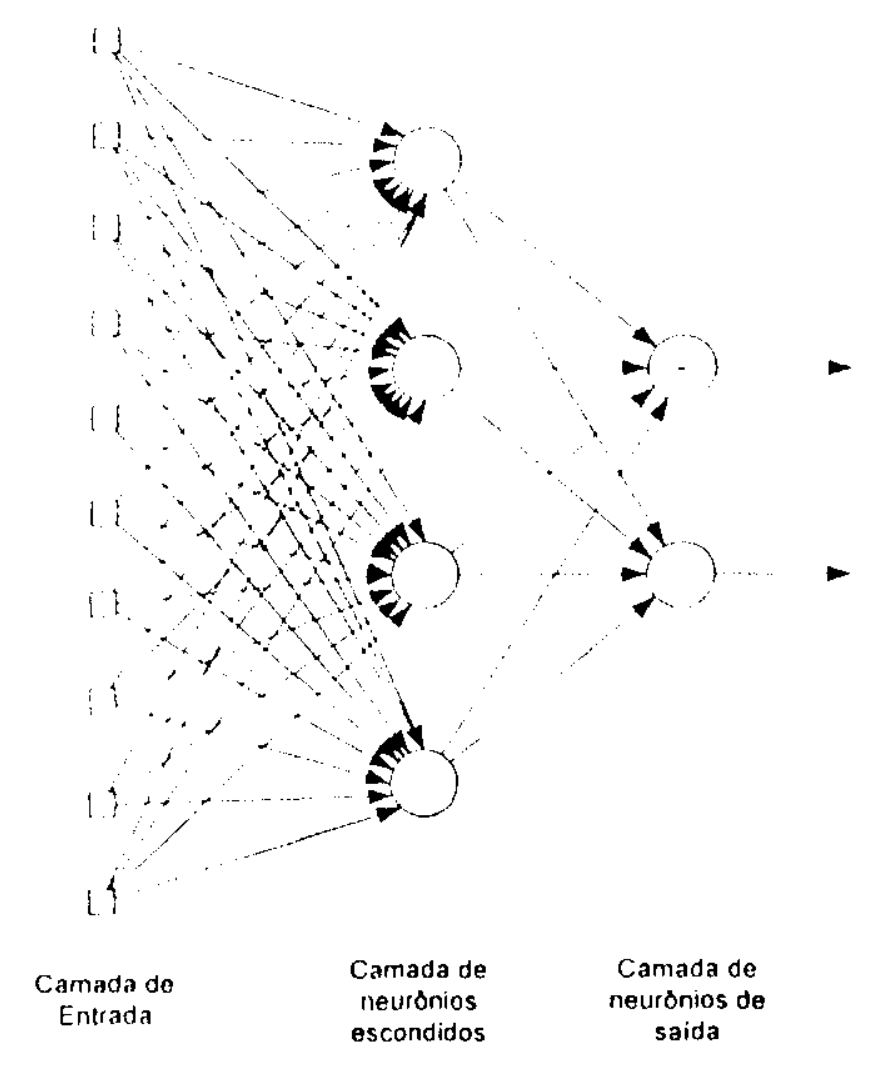

Figura 4-3 Visão esquemática de uma rede neural [HAY99]

Para entender c omo funciona cada nódulo, a Figura 4-4 mostra que o ele recebe uma quantidade de informação de entrada, $x_{1}, x_{2}, \ldots, x_{m}$, ponderada, respectivamente, por $w_{k,} w_{1}, \ldots, w_{k, k}$. A função de ativação $\varphi$ transforma as entradas recebidas em uma informaçāo de saida que servirá de entrada para a próxima fase de nódulos. Portanto, a saida final da rede neural é a soma 
ponderada dos nódulos ocultos. As funções de ativação são geralmente não lineares, o que dificulta a interpretação dos modelos de Redes Neurais.

Geralmente só são permitidas conexões em um único sentido, ou seja, não há conexōes de volta.

As redes neurais precisam ser treinadas. Este treinamento consiste em estimar os valores dos parámetros das funções de ativaçāo $\varphi$ de tal forma que os valores previstos sejam o mais próximos possiveis dos valores observados. Isso é obtido por meio de uma amostra aleatória do conjunto de dados, contendo entradas ( $v$ e saidas (v). Para começar, escolhe-se um conjunto de valores iniciais, posteriormente, uma nova estimativa é obtida quando as observaçōes $\left(x_{i}, y_{i}\right)$ da amostra aleatória de treinamento são consideradas. Esse procedimento vai sendo repetido até se obter convergência, isto é, um ponto global ótimo.

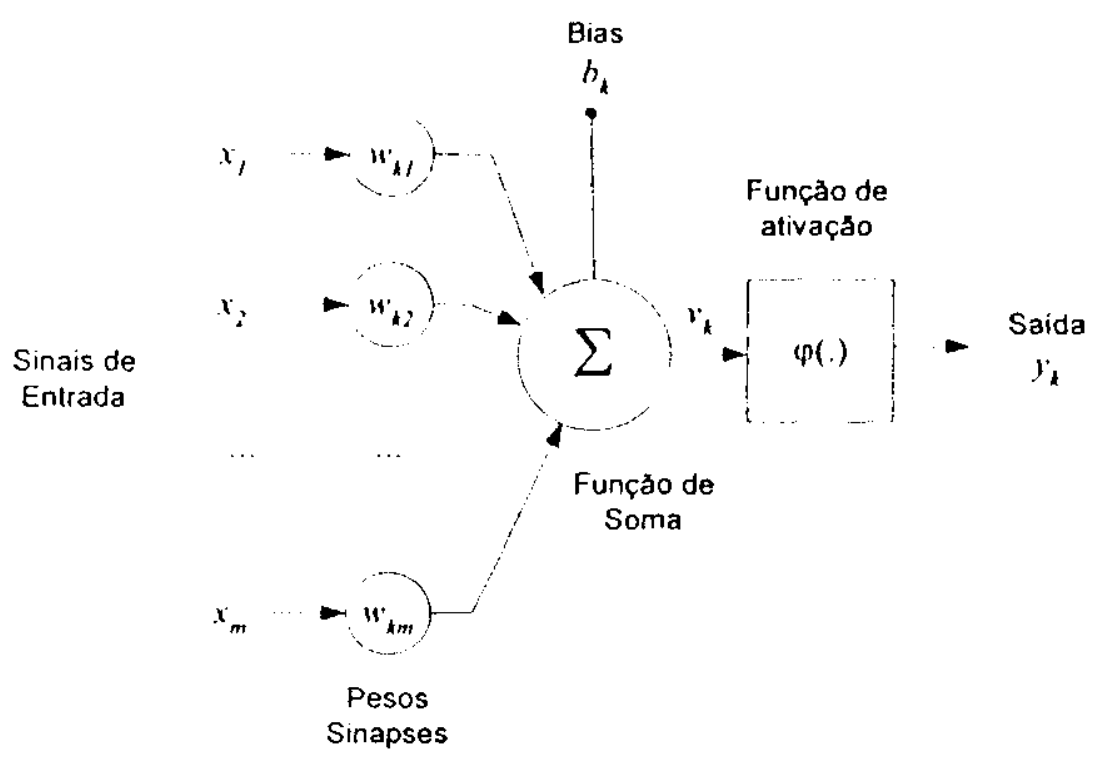

Figura 4-4 Visão esquemática de um nódulo de Rede Neural.

A partir das estimativas dos parâmetros, obtidas da amostra de treinamento, ajusta-se o modelo com os dados completos. Tal modelo pode ser avaliado com uma amostra de validação, possibilitando a verificação do ajuste de forma independente.

O analista deve tomar cuidado para que a rede neural na sofra uma 'sobredose' de treinamento, ou seja, para que a rede não comece a explicar todas as relaçōes entre os nódulos e acabe representando até o erro aleatório no modelo. Já que sempre irá existir um erro, um ruido nos dados, o importante é tentar controlá-lo, e não esperar que ele desapareça. Este problema de 
supertreinamento pode ser evitado simplesmente determinando-se um limite máximo de erro tolerado. Quando a rede atingir este limite, o treinamento é dado como finalizado.

- Árvores de classificação. É uma técnica que, a partir de uma massa de dados, cria e organiza regras de classificação e decisão em uma estrutura de árvores. Se os dados estiverem divididos em classes dicotômicas, como assinantes e não-assinantes, infectados contra não-infectados, etc., uma árvore de classificação pode ser construida para criar regras que classifiquem casos já existentes ou casos novos, com uma determinada precisão (por exemplo, regras de indução).

Cada nivel da árvore representa um estágio de decisão. Tais decisões geram regras que servem para classificar conjuntos de dados. Métodos específicos deles incluem: Classification and Regression Trees (CART) [BRE84], e ChiSquared Automatic Interaction Detection (CHAID) [MAG94]. CART e CHAID são técnicas de árvores de classificação utilizadas para classificação de conjuntos de dados. Eles fornecem um conjunto de regras que podem ser aplicadas a um novo (não classificado) conjunto de dados para prever um provável resultado dado um conjunto de registros de entrada.

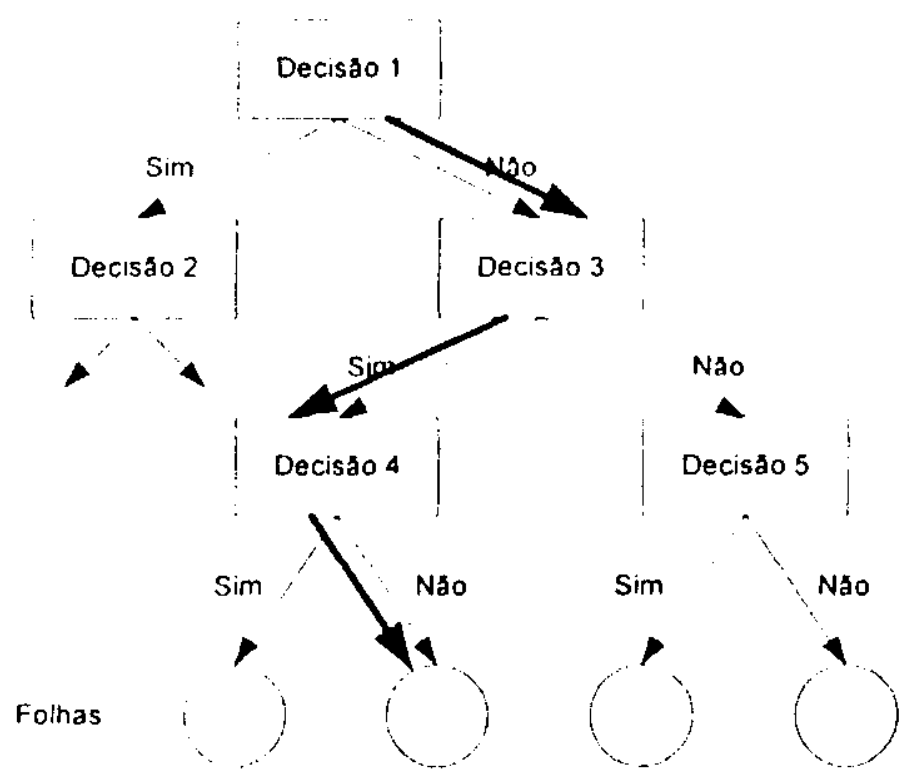

Figura 4-5 Uma ârvore de classificação.

Na Figura 4-5 è possivel observar que uma árvore de classificação vai se expandindo a partir da raiz, até alcançar um nó que não pode ser mais expandido. Atravessar a árvore desde a melhor folha (a melhor escolha) até a raiz fornece a regra que classifica a variável sendo estudada. 


\subsubsection{Regras de associação}

A mineraçăo de regras de associação em um conjunto de dados é uma forma de data mining para descobrir relacionamentos que possam ser interessantes para a aplicação. A descoberta de regras pode ajudar no marketing. toma de decisōes, e gerenciamento de negócios. Dađo que as regras obtidas sắo bem simples e fáceis de serem compreendidas, explicadas e aplicadas, elas têm constituido o foco de várias pesquisas na área de data mining.

Uma definição formal de uma regra de associação é mostrada na Figura 4-6, onde $A_{i}$ e $B_{j}$ são predicados ou ilens. Tais regras são interpretadas como "Quando os itens $A_{1}, A_{2} \ldots, A_{1 !}$ acontecerem, é muito provável que os itens $B_{1}, B_{2}, \ldots, B_{n}$ acontecerem lambém na mesma transaçăo".

$$
A_{1}, A_{2}, \ldots, A_{m} \rightarrow B_{1}, B_{2}, \ldots, B_{n}
$$

Figura 4.6 Modelo de regra de associaçăo

Como exemplo de uma regra de associação podemos considerar o exemplo mostrado na Figura 4-7. A regra diz que si um comprador leva papel e caneta, muito provavelmente ele esteja interessado também em comprar borracha.

$$
\text { Produto(.Y."Papel"), Produto(X."Cancta") } \rightarrow \text { Produto(X,"Borracha") }
$$

Figura 4-7 Exemplo de regra de associaçăo.

De [DAS01], extraímos as seguintes definições: seja $l=\left\langle i_{1}, \ldots, i_{n}\right\rangle$ um conjunto de itens, e seja $D$ o banco de dados que armazena as transaçōes, onde cada transação $T$ é conformado por um conjunto de itens tal que $T \subseteq 1$. Um identificador único, TID, é associado a cada transação. Dizemos que cada transação $T$ suporta $X$, um conjunto de itens em $I$, se $T \subseteq 1$. Dizemos que a regra de associação da forma $A \rightarrow B$ é mantida no banco de dados com nivel de confidência $c$, se $\left|X \cup Y^{\prime}\right| /|X| \geq c$ (onde $|A|$ é o número de ocorrências de um co njunto de itens $A$ no conjunto de transações $D$ ). Dizemos também que a regra $A \rightarrow B$ possui um suporte $s$, se $|X \cup \gamma| /|N| \geq s$, onde $N$ é o número de transaçōes em $D$. Podemos notar que enquanto o suporte é uma medida de freqüência de uma regra, a confidência é uma medida da força da relação entre conjuntos de itens.

A mineração de regras de associação teve sua origem no problema de market basket analysis (vide Apêndice A), podendo ser aplicada no dominio de outras áreas como negócios, engenharia, medicina e finanças [FAY96]. 


\section{- Market Basket Analysis}

Compreender os hábitos dos consumidores e suas preferências é um ponto essencial para que os abastecedores possam tomar decisðes. Decisões que incluem: quanto colocar à venda, em que época do ano e como aplicar o merchandising dos seus produtos para maximizar o retorno dos investimentos. Nesse caso, uma aplicação de mineração eficaz teria que apresentar ao consumidor ofertas atraentes na medida que ele interage com o portal de venda.

- Cross-sale

O término cross-sale é aplicado ao problema de impulsionar a venda de um determinado produto a consumidores da companhia que não são consumidores desse produto em particular. Tal problema se justifica pelo fato de que muitas empresas fornecem mais de um tipo de produto ou serviço a uma ampla gama de consumidores.

- Classificação parcial.

Os classificadores convencionais são ineficazes quando existe u ma grande coleção de atributos no conjunto de dados, sendo que às vezes, muitos dos valores de alguns atributos estão vazios. O problema pode ser resolvido utilizando uma análise associativa.

- Serviços financeiros.

As regras de associação são extensivamente utilizadas pelas indústrias de serviço financeiro. Analistas de seguros usam-se delas para analisar conjuntos de dados com o objetivo de criar modelos de risco para o desenvolvimento de estratégias de investimento.

\subsection{Considerações finais}

Neste capitulo, foi descrito o processo de data mining como um passo intermediário na extraçāo de conhecimento, e como uma forma para encontrar relações não triviais em grandes repositórios de dados. Foram discutidos os requisitos para a execução do processo, que destacam a importância da necessidade de um alto grau de interação com a finalidade de re-alimentar o modelo. 


\section{Integração DW e DM no projeto DEEPSIA}

\subsection{Considerações iniciais}

O DEEPSIA (Dynamic on-linE IntErnet Purchasing System based on Intelligent Agents) é um consórcio para o desenvolvimento de uma ferramenta que possibilite a extraçāo de informação dos produtos à venda em nos portais de comércio eletrônico disponiveis na Internet. O sistema está composto de vários outros subsistemas, cada um dois quais está encarregado de uma tarefa distinta: aquisição, processamento e extração de informações úteis. Várias frentes de trabalho foram criadas, e em cada uma delas com foi estabelecido um conjunto de objetivos primários para a exploraçăo das potencialidades do sistema.

A Figura 5-1 mostra a arquitetura global do sistema DEEPSIA como um sistema multi-agentes atuando sobre a Internet e coletando e classificando as informaçóes obtidas através do Catálogo. Existe também outro tipo de fonte de informação, chamado de PIA (Portal Agent Interface), o qual é um ponto de integração com parceiros comerciais do consórcio para a inserção direta de dados no catálogo através de protocolos preestabelecidos.

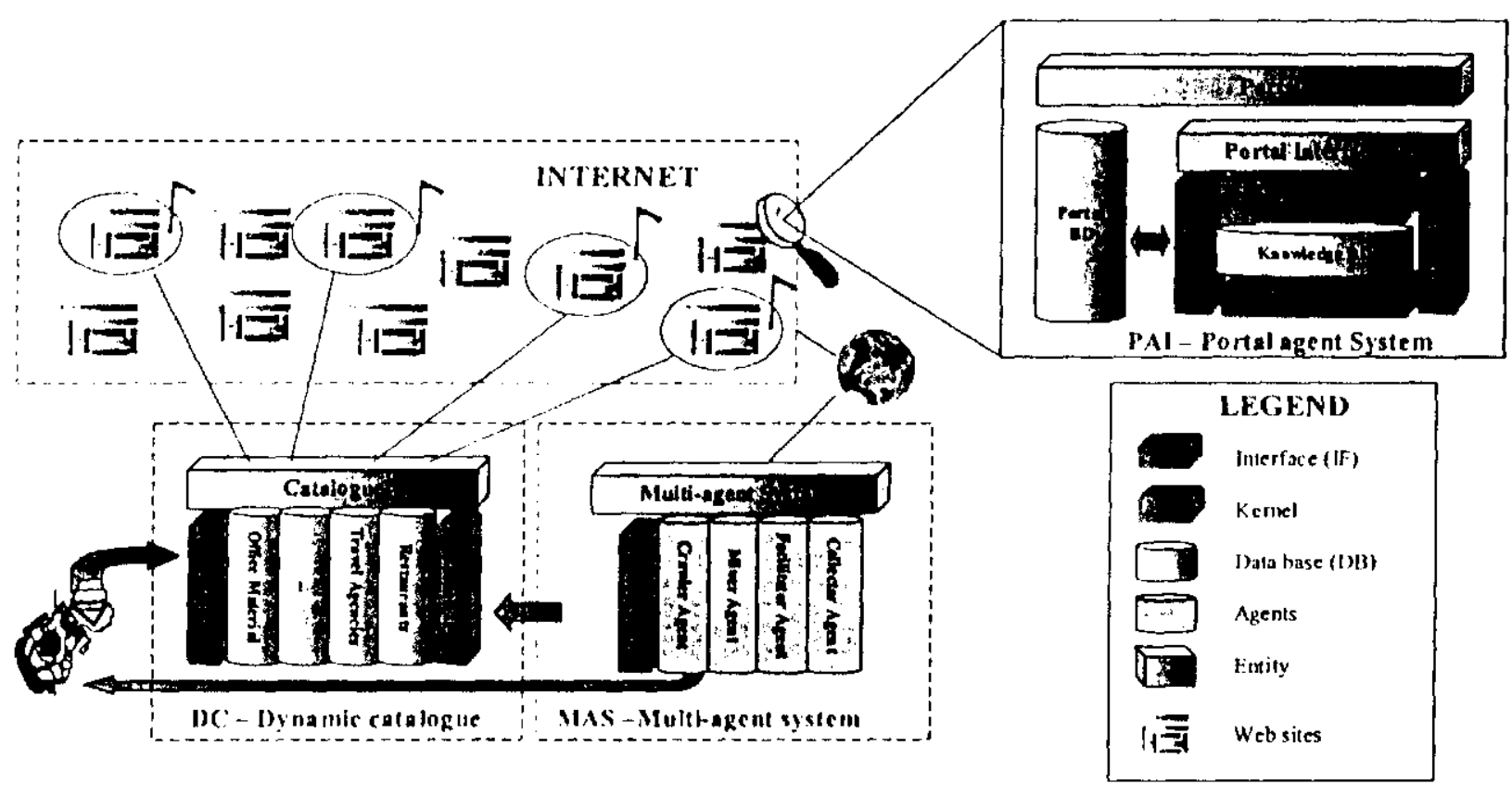

Figura 5-1 Arquitelura do sistema DEEPSIA

Neste capitulo, fazemos um resumo do trabalho realizado para o projeto, explorando a parte de integração de data warehousing e data mining. 
A existencia de vários grupos de trabalho, cada um deles utilizando tipos e fontes de dados diferentes, gerou uma das primeiras dificuldades devido à heterogeneidade das mesmas. Equipes de vários paises, entre eles Espanha, Portugal e Polônia tiveram a seu cargo a realização de diferentes partes do projeto. Na hora de realizarmos o processo de integração, foi derivado um ponto relativo à consolidação de tais fontes, o que nem sempre foi possivel em todos os casos, como será observado no processo de análise.

\subsection{Análise do processo integração}

Vários problemas foram abordados pelo grupo de pesquisa, dentre eles podemos mencionar: (1) a melhora nos processos de classificação das informações no catálogo, (2) o impacto social do sistema no mercado local e (3) a melhora da experiência do usuário na sua interação com o sistema. Tal tarefa envolveu a construçăo de um protótipo para o estudo e tentativa de resoluçảo de potenciais problemas.

\subsubsection{Fontes de dados heterogêneas}

O nosso primeiro problema foi integrar todas as fontes de dados presentes nos subsistemas que conformam o sistema geral (Figura 5-2), tal diversidade é produto, como mencionado anteriormente, da heterogeneidade das equipes de trabalho $\mathrm{e}$ das ferramentas utilizadas por cada um deles.

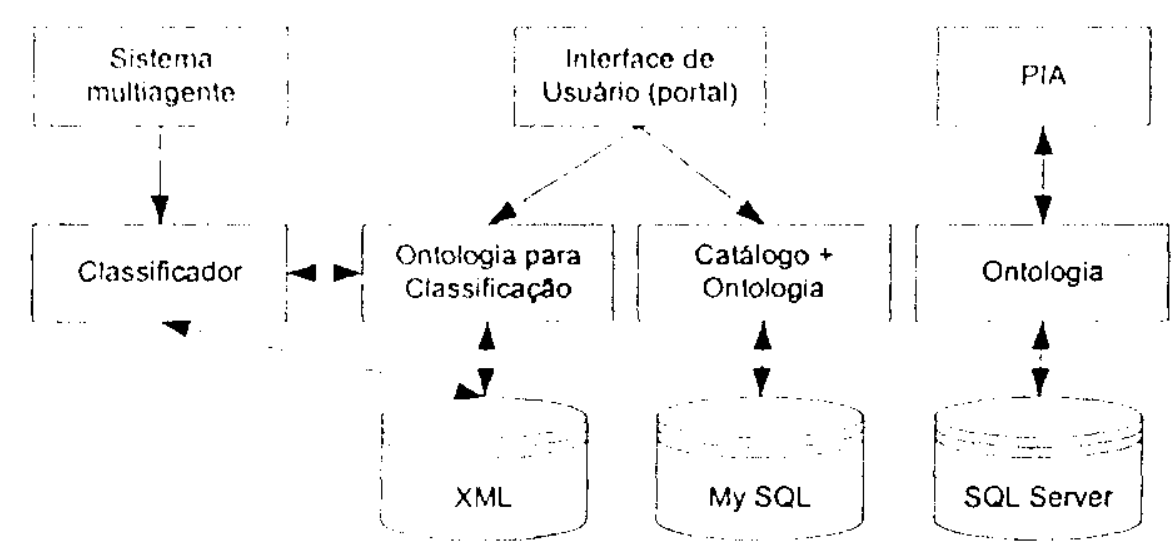

Figura 5-2 Fontes de dados presentes no sistema original.

Observando a Figura 5-2, podemos ver que existem elementos redundantes nas diferentes fontes de dados. Por exemplo, a ontologia está presente em praticamente lodas elas. O processo de consolidação visa a eliminação deste tipo de redundâncias. No caso, do classificador no sistema multi-agente, ele continua a utilizar a estrutura da ontologia em XML, já que o processo de classificação foge do 
escopo do presente trabalho. A estrutura projetada do banco de dados e detalhada no parágrafo 5.4.1 foi implementada inteiramente em um servidor SQL Server da Microsoft ${ }^{\mathrm{r}}$, que veio a ser o servidor transacional do protótipo projetado.

\subsubsection{Modelagem conceitual}

A modelagem conceitual do protótipo foi desenvolvida utilizando UML (Unified Modelling Language) como ferramenta de análise. O universo do problema foi dividido em pacotes (packages), cada um deles contendo conjuntos de classes e relacionamentos adequados a um elemento em particular, como mostrado na Figura 5-3.

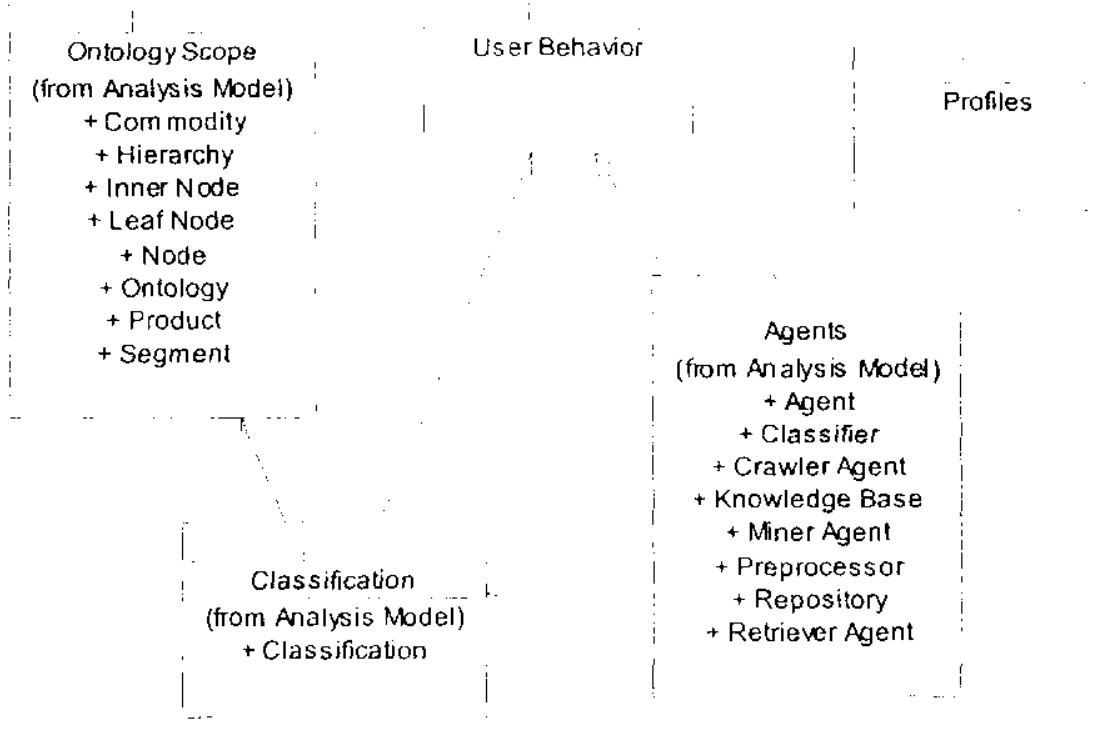

Figura 5-3 Pacotes presentes no modelo conceitual

A ontologia é o ponto de partida de vários processos dentro do sistema, podemos enxergar ela como sendo uma hierarquia (ou taxonomia) incluindo outros relacionamentos além das associações pai-filho inerentes. Nesse caso, o processo de classificação cria relacionamentos entre os nós da ontologia e os produtos coletados da Internet através dos agentes de software.

Na Figura 5-4 podemos observar em detalhe a interação entre os agentes do sisterna para a coleta e processamento de informaçōes.

- O Crawler coleta as páginas da Internet a partir de pontos de saída prédeterminados (por exemplo, um conjunto conhecido de portais de venda) e coloca tais páginas no Repository. 
- O Retriever tem a função de pegar cada uma das páginas coletadas do repositório (não necessariamente em sincronia com o Crawler) e depois, realizar uma pré-classificação para determinar se a página possui informação de produtos à venda.

- Finalmente, o Miner tem a função de processar a página e criar os relacionamentos entre a página e a ontologia.

- Além dos agentes mencionados anteriormente, fazemos uma menção à Ontologia. Ela está composta de quatro niveis, a saber: segmento, familia, classe e commodity, sendo que este último nivel corresponde aos produtos e serviços propriamente ditos.

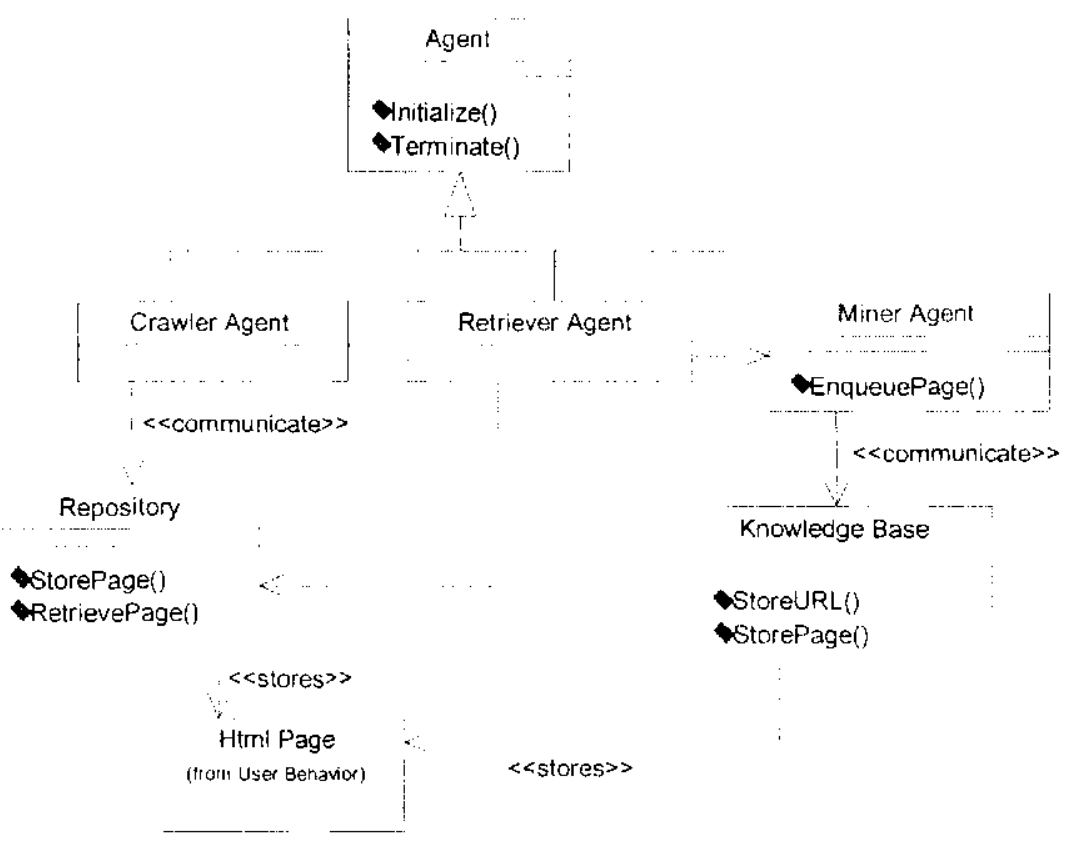

Figura 5-4 Interação dos agentes no sistema DEEPSIA

Como mencionado no parágrafo 5.2.1, os agentes utilizam diferentes fontes e repositórios de dados para a realizaçăo das suas tarefas. A eliminação das redundâncias implicou em pequenas modificaçōes em alguns dos agentes, por exemplo, fazendo com que todos eles utilizassem o mesmo banco de dados para consulta da ontologia (com a exceção mencionada no parágrafo 5.2.1).

\subsubsection{Sistemas legados}

Devido ao escopo deste trabalho (a melhora da interface do usuário), outros subsistemas continuariam a ser utilizados, sendo que foi preciso estabelecer camadas de acesso e/ou transferência de dados entre e les e o nosso protótipo. 
Basicamente, elementos tais como o Crawler, o Retriever (classificador) e o Catálogo permaneceram inalterados na sua estrutura geral. Outros trabalhos do grupo de pesquisa como [MAR03] estiveram focados na melhoria do processo de classificação e, portanto, algumas modificações foram introduzidas nesse sentido.

\subsubsection{Avaliaçio de tecnologias e ferramentas}

Outro ponto a analisado foi a escolha da tecnologia e das ferramentas para a realização do protótipo. Existem diversas ferramentas no mercado, sendo que a principal condição na escolha foi a disponibilidade de interfaces para facilitar os procedimentos de integração. A Figura 5-5 resume a avaliação e escolha das ferramentas utilizadas.

\begin{tabular}{|c|c|c|c|}
\hline Ferramenta & Propósito & Licenciamento & $\begin{array}{c}\text { Avaliação Geral \& } \\
\text { Comentários }\end{array}$ \\
\hline $\begin{array}{l}\text { MS SQLServer } \\
2000\end{array}$ & $\begin{array}{l}\text { Banco de Dados } \\
\text { transacional }\end{array}$ & Pago (fonte: USP) & Bom para prototipagem \\
\hline Oracle $9 i$ & $\begin{array}{l}\text { Motor de OLAP e Data } \\
\text { Mining }\end{array}$ & $\begin{array}{l}\text { Livre para } \\
\text { desenvolvimento e } \\
\text { leste. }\end{array}$ & $\begin{array}{l}\text { Interface, ferramentas e } \\
\text { API simples de usar. }\end{array}$ \\
\hline PolyAnalyst 4.5 & Data mining visual & Shareware & $\begin{array}{l}\text { Bom para análise visual } \\
\text { e exploração inicial. }\end{array}$ \\
\hline ERWin & $\begin{array}{l}\text { Modelagem de banco } \\
\text { de dados relacional. }\end{array}$ & Shareware & $\begin{array}{l}\text { Excelente, tanto para o } \\
\text { modelo lógico como } \\
\text { fisico da base de dados. }\end{array}$ \\
\hline Rational Rose & Análise e Modelagem & $\begin{array}{l}\text { Licencia para } \\
\text { desenvolvimento }\end{array}$ & $\begin{array}{l}\text { Integração do projeto de } \\
\text { classes em UML. e } \\
\text { documentação com Java }\end{array}$ \\
\hline NetBeans 3.4 & Programaçāo Java & GNU & $\begin{array}{l}\text { Ambiente integrado para } \\
\text { programação Java }\end{array}$ \\
\hline TomcatApache & $\begin{array}{l}\text { Portal e interface de } \\
\text { usuário }\end{array}$ & GNU & $\begin{array}{l}\text { Integraçăo funcional com } \\
\text { Java e JSP. }\end{array}$ \\
\hline
\end{tabular}

Figura 5-5 Resumo das ferramentas utilizadas neste trabalho.

Cabe ressaltar que a escolha de Java como linguagem de prototipagem e desenvolvimento neste casso foi dada pelas razóes de que ela pode ser utilizada em várias frentes, tais como no motor de data mining, na programação das páginas (JSP - Java Server Pages) do portal e na geraçāo do código, que pode ser sincronizada com as ferramentas de análise e documentação como o no caso do Rational Rose 'v.

Os processos de dala warehousing e data mining foram utilizados principalmente na melhora da experiência do usuário no sistema. A seguir, fazemos uma revisão 
do processo de desenvolvimento do protótipo antes de entrar nos detalhes da solução do problema (2) mencionado no parágrafo 5.2.1.

\subsection{Consideraçōes para o projeto do protótipo}

O primeiro passo para o projeto do protótipo foi a construção do modelo físico de interaçåo entre as classes que iriam conformar o corpo dos programas. Algumas consideraçōes foram necessárias nesta etapa:

- Interface de usuário. Sendo que a melhora da interface de usuário é um dos principais objetivos do protótipo, o projeto de interface foi um dos primeiros pontos de discussão do grupo de pesquisa.

- Tratamento de exceções. As exceções constituem a ferramenta com a qual um sistema compulacional lida com situaçōes inesperadas. Por exemplo, quando acontece um acesso a uma locação de memória não válida ou quando existe um erro de conexão a um determinado serviço.

- Idioma. Devido ao alcance do projeto, e em geral devido ao fato de que as Internet é a fonte dos dados coletados, faz-se necessário fornecer um suporte multilingual no protótipo.

- Estruturas de dados. A ontologia é, na sua forma básica, uma floresta (conjunto de árvores) de quatro niveis. Muitas das estruturas de dados projetadas utilizam esse paradigma para a manipulação das mesmas, incluindo sua utilizaçāo na interface do usuário.

- Data mining. O protótipo deve servir para lestar a aplicação e integração de data mining no escopo da melhora da navegabilidade para o usuário. A coleta de eventos foi centralizada na camada de acesso ao banco de dados.

\subsection{Projeto}

O esquema do projeto de software completo pode ser apreciado na Figura 5-6, ele composto pelos seguintes elementos:

- Operational Artifacts. Classes para a interação entre o usuário e o sistema, estruturas de informação para autenticação e acesso e classes utilitárias para diversos processos.

- Database Artifacts. Classes para conexão com o banco de dado transacional e escolha do idioma. 
- Mining Artifacts. Classes para o controle dos processos de mineração, extração de regras de associação e outras informações de data mining.

- Ontology Layer. Classes de acesso e manipulação da ontologia. Inclui estruturas de dados e controladores para navegação dentro da mesma.

- Catalogue. Objetos para recuperação das informações do catálogo, na forma de listas de produtos e suas propriedades. Os dados do catálogo sāo importados da fonte de dados original do subsistema do Miner mencionado na modelagem conceitual (parágrafo 5.2.2).

- Exceptions. Tratamento de exceções, foi projetada uma hierarquia particular a partir da classe padrão java.lang.Exception.

- Trace Engine. Um conglomerado de objetos e procedimentos para a depuração dos programas que utilizam os pacotes mencionados anteriormente.

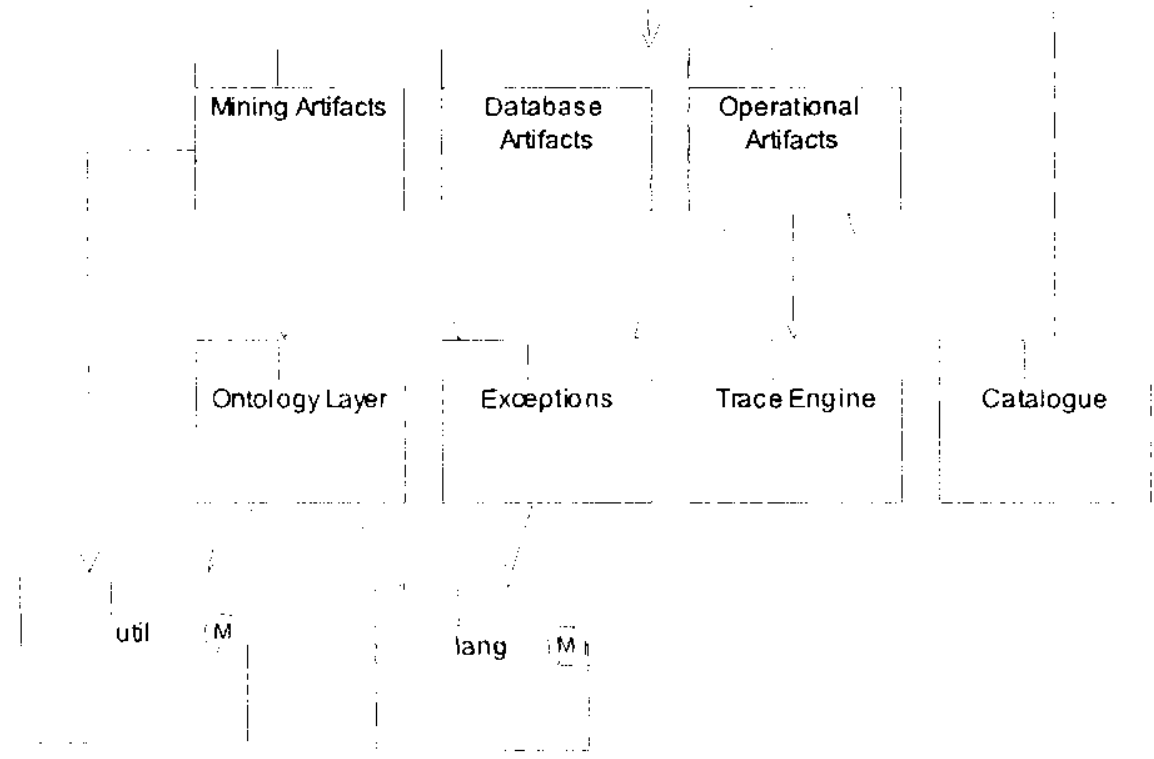

Figura 5-6 Arquitetura dos componentes de software do protótipo.

Podemos observar também que o pacote de Mining Artifacts está diretamente relacionado com o pacote Ontology Layer. De acordo com o objetivo do presente trabalho, o processo de integração de data mining está diretamente relacionado com a interação usuário-ontologia.

\subsubsection{Estrutura do banco de dados}

A Figura 5-7 apresenta parte do esquema relacional correspondente ao sistema de navegação da ontologia utilizada no protótipo. A ontologia está contida dentro da 
tabela D4OntologyNode, pode-se observar que existe uma relação recursiva nesta tabela conectando os atributos pnOntologyNode (chave primária) e pnParentNode (nó pai do registro em questão). Tal relação é necessária para manter a integridade referencial quando se interconectam dois elementos pertencentes a niveis diferentes (segmento-familia, familia-classe ou classe-commmodity). Por sua vez, os u suários cadastrados no sistema são a rmazenados dentro da tabela D 4User Para efeitos de análise do comportamento do usuário, foi criada a tabela D4OntologyNodeRecord, a que registra todas as ocorrências nas que o usuário acessou um determinado segmento, família, classe ou commodity.

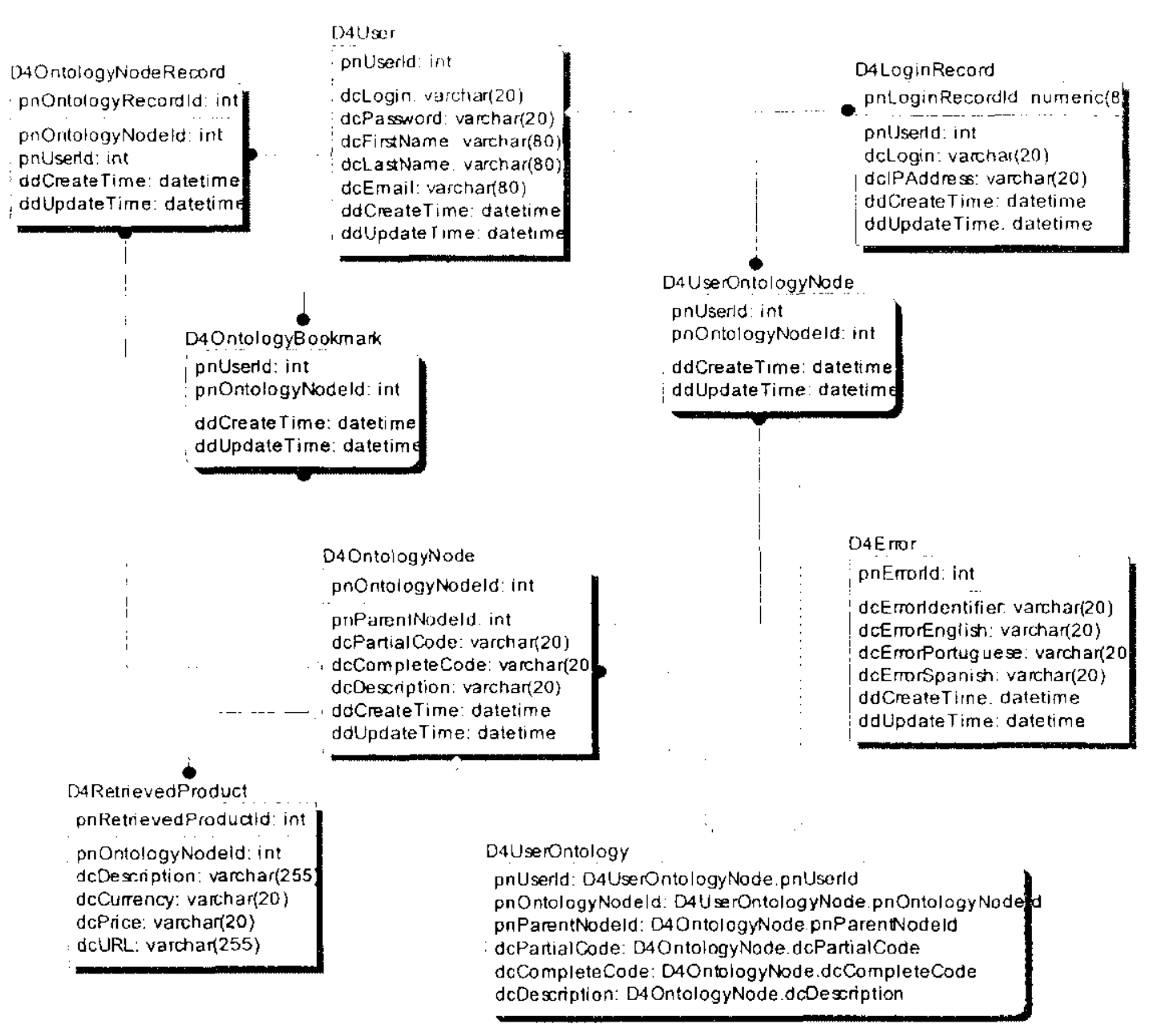

Figura 5-7 Parte do modelo relacional do banco de dados do protótipo.

A Figura 5-8 resume a função de cada tabela:

\begin{tabular}{l|l}
\hline Tabela & Descrição \\
\hline D4User & $\begin{array}{l}\text { Dados do usuário, para autenticação e seguimento } \\
\text { de eventos. } \\
\text { D4LoginRecord }\end{array}$ \\
D4OntologyNode & $\begin{array}{l}\text { Tabela para o seguimento de acessos ao sistema. } \\
\text { Tabela para armazenamento da ontologia, ela }\end{array}$
\end{tabular}




\begin{tabular}{l|l} 
D4UserOntologyNode & $\begin{array}{l}\text { contem aproximadamente } 16000 \text { registros. } \\
\text { O usuário pode definir os segmentos de trabalho em } \\
\text { uma ontologia particular a modo de facilitar o } \\
\text { acesso. Esta tabela contem tais segmentos } \\
\text { Tabela para armazenamento dos eventos de acesso } \\
\text { dos usuários aos nós da ontologia através do tempo. } \\
\text { D4OntologyBookmark } \\
\text { Os bookmarks (marcadores) de commodities } \\
\text { individuais definidos pelo usuário são armazenados } \\
\text { nesta tabela. } \\
\text { Catálogo dos produtos já classificados, o Retriever. } \\
\text { Um processo de sincronia deposita os novos } \\
\text { produtos (referências) recuperados e classificados } \\
\text { nesta tabela. } \\
\text { Visão da ontologia particular do usuário. Baseada } \\
\text { nas tabelas D4User e D4UserOntologyNode. } \\
\text { Tabela de mensagens de erro, em vários idiomas. }\end{array}$ \\
\hline
\end{tabular}

Figura 5-8 Descrição das tabelas utilizadas no protótipo

Todas as tabelas possuem atributos com as datas de criação e modificação dos registros, sendo que tanto a nomenclatura dos campos como das relaçōes seguem um padrão pré-definido, conforme à tabela da Figura 5-9. A implementação do sistema transacional foi feita utilizando o SQL Server da Microsoft como servidor banco de dados (vide parágrafo 5.2.4).

$\begin{array}{ll}\text { Prefixo } & \text { Tipo de atributo } \\ \text { pn } & \text { Chave primária de tipo numérico } \\ \text { dn } & \text { Atribulo de tipo numérico } \\ \text { dc } & \text { Atributo de tipo caractere. } \\ \text { dd } & \text { Atributo de tipo data } \\ \text { fn } & \text { "flag" de tipo numérico } \\ \text { fc } & \text { "flag" de tipo caractere. }\end{array}$

Figura 5-9 Nomenclatura dos atributos fisicos no banco de dados.

\subsubsection{Navegação dentro da ontologia}

Existem mais de 16000 elementos na ontologia fornecida pelo ECCMA, e mais ou menos 10000 commodities, sendo que cada um deles pode estar associado com um conjunto de páginas que oferecem o produto ou serviço descrito pelo commodity.

A visão da estrutura da interface de usuário pode ser apreciada na Figura 5-10. Ela está composta dos elementos de navegação através da ontologia e do catálogo de 
produtos, das ferramentas e utilitários de busca e histórico de acessos e a área de apresentação de itens previstos, para ajuda na navegaçăo.

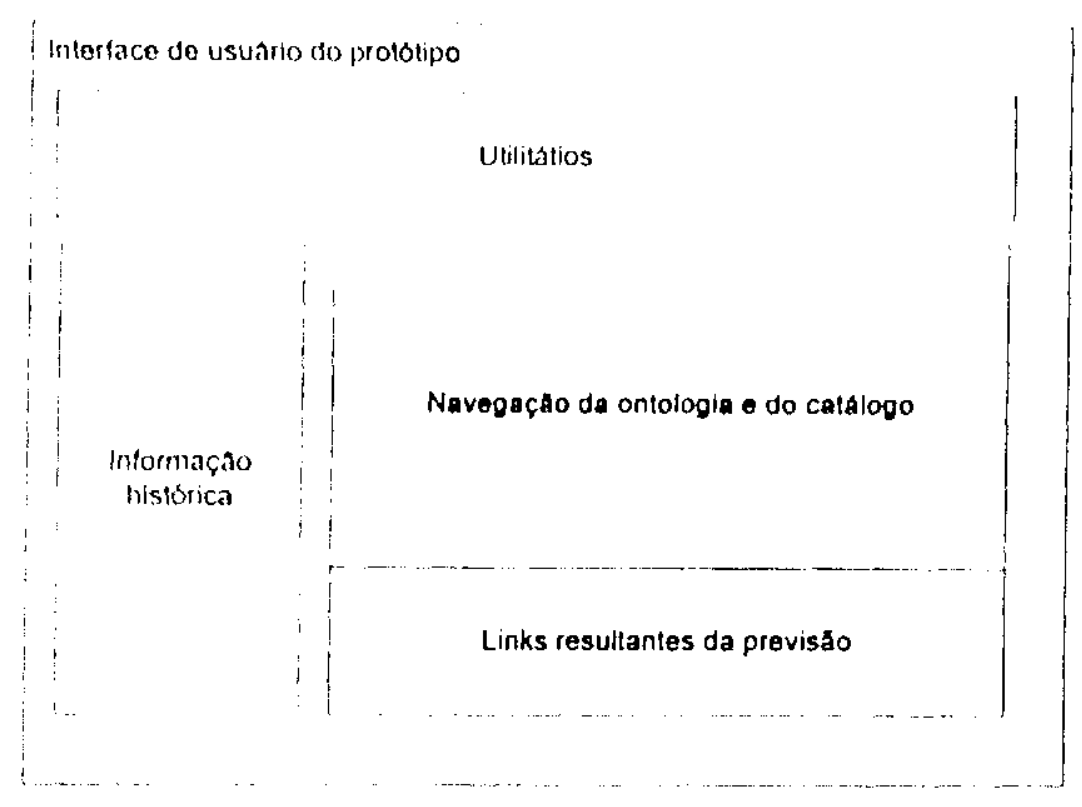

Figura 5-10 Visão da interface de usuário proposta no projelo DEEPSIA

Mostraremos que é possivel utilizar um processo de data mining para tentar realizar a previsāo mencionada nos parágrafos anteriores.

De fato, para realizar um trabalho de desenvolvimento ordenado, foram estabelecidas algumas normas que prevaleceram durante o processo todo. Entre elas podemos mencionar: (1) A interface não tem acesso de forma explícita ao banco de dados; (2) Para fornecer acesso aos dados foi criada uma camada intermediária refletindo a estrutura hierárquica da ontologia e (3) A coleta de dados, incluindo os fatos u tilizados $p$ ara o processo de mineração, foi realizada a través dos componentes que conformam a camada mencionada em (2). Os componentes dessa camada, conforme mostrado na Figura 5-11 são:

- EntityController e EntityHelper. Ambas classes constituem a base da maioria das classes implementadas no protótipo. A primeira é um modelo de controlador genérico para extração de dados de u m conjunto de e ntidades com propriedades similares, a segunda possui alguns atributos comuns à entidade como, por exemplo, sua chave primária (no modelo, consideramos todas as chaves primárias como sendo números inteiros).

- OntologyController e User OntologyController. Estas classes servem para recuperar os dados de um conjunto de nós da ontologia. A classe 
UserOntologyController possibilita o rastreamento do acesso dos usuários durante sua navegação na ontologia através da interface.

- OntologyNode e UserOntologyNode. São estruturas de dados que contêm a informação de um nó da ontologia em particular. São utilizados pelos controladores para armazenar e transferir conjuntos de dados entre o banco de dados e a interface de usuário.

Outros relacionamentos não são mostrados na figura por questōes de simplicidade. Todo controlador, ou seja, toda classe derivada de EntityController, precisa ter um meio de se comunicar com o banco de dados. Isto é feito através do método SetConnection/nfo que permite o passo dos argumentos de conexão ao banco.

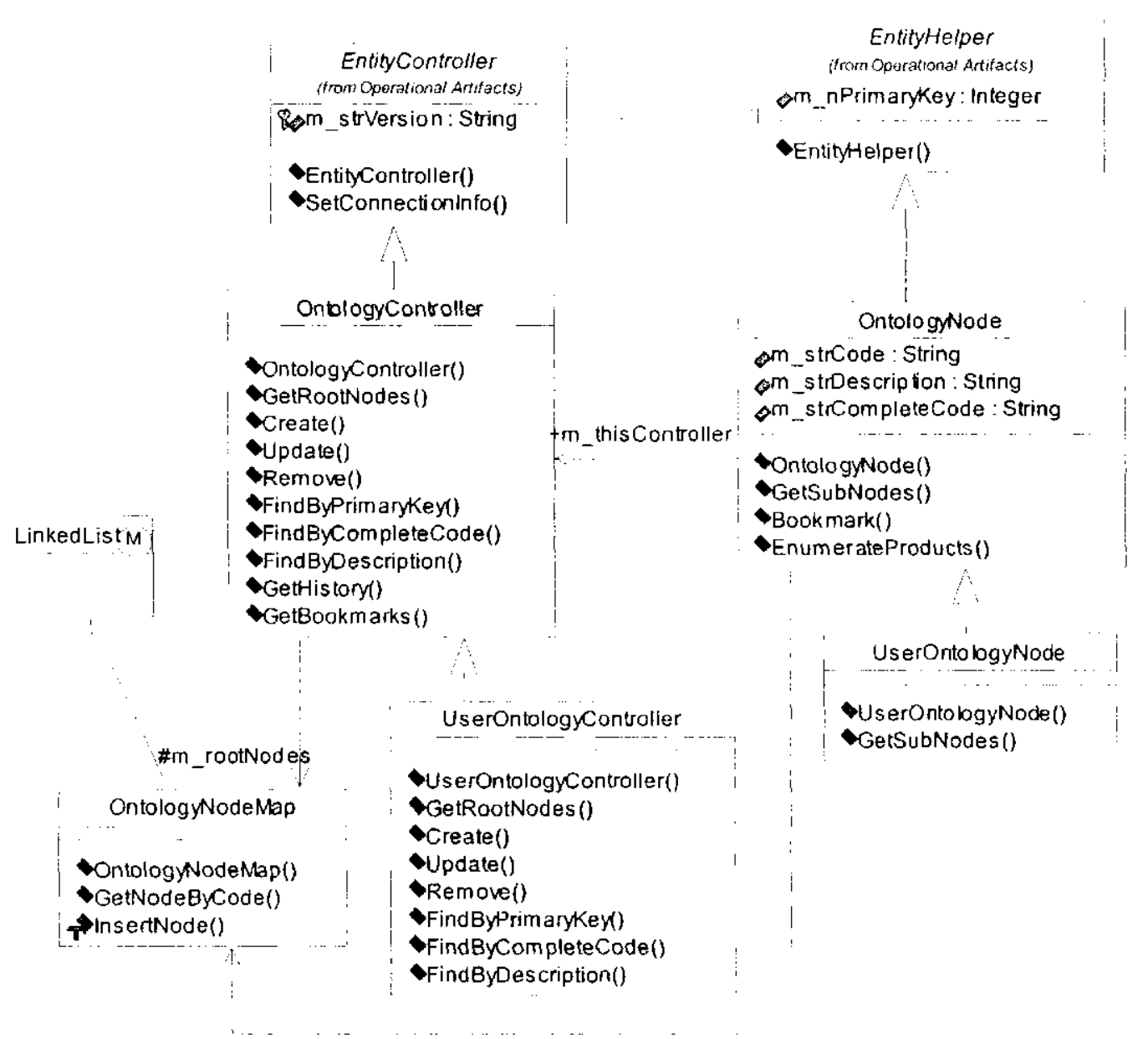

Figura 5-11 Arquitetura da camada de software para manipulação da ontologia.

Utilizando o modelo apresentado, a coleta de dados é realizada através da chamada aos métodos das classes pela interface do usuário. Como exemplo, consideremos o caso de desejarmos armazenar os toques do mouse (clicks) dos usuários na interface para realizar algum processo posterior. Nesse caso especifico, sabemos que a interface chama o método FindByPrimaryKey ou 
FindByCompleteCode cada vez que o usuário clica em um nó da ontologia, e portanto, podemos inserir códigos de rastreamento nesses métodos para registrar tais eventos.

\subsubsection{População do Catálogo}

O Catálogo é composto por um conjunto de páginas classificadas de acordo com a informação dos produtos à venda que eles contêm. $O$ acesso ao catálogo é feito através da interface da ontologia, conforme ao esquema mostrado na Figura 5-12. Os dados são obtidos através de um processo de importação do Retriever e centralizados no banco de dados do protótipo. A informação coletada inclui a data de coleta, o agente coletor, o portal e página de origem.

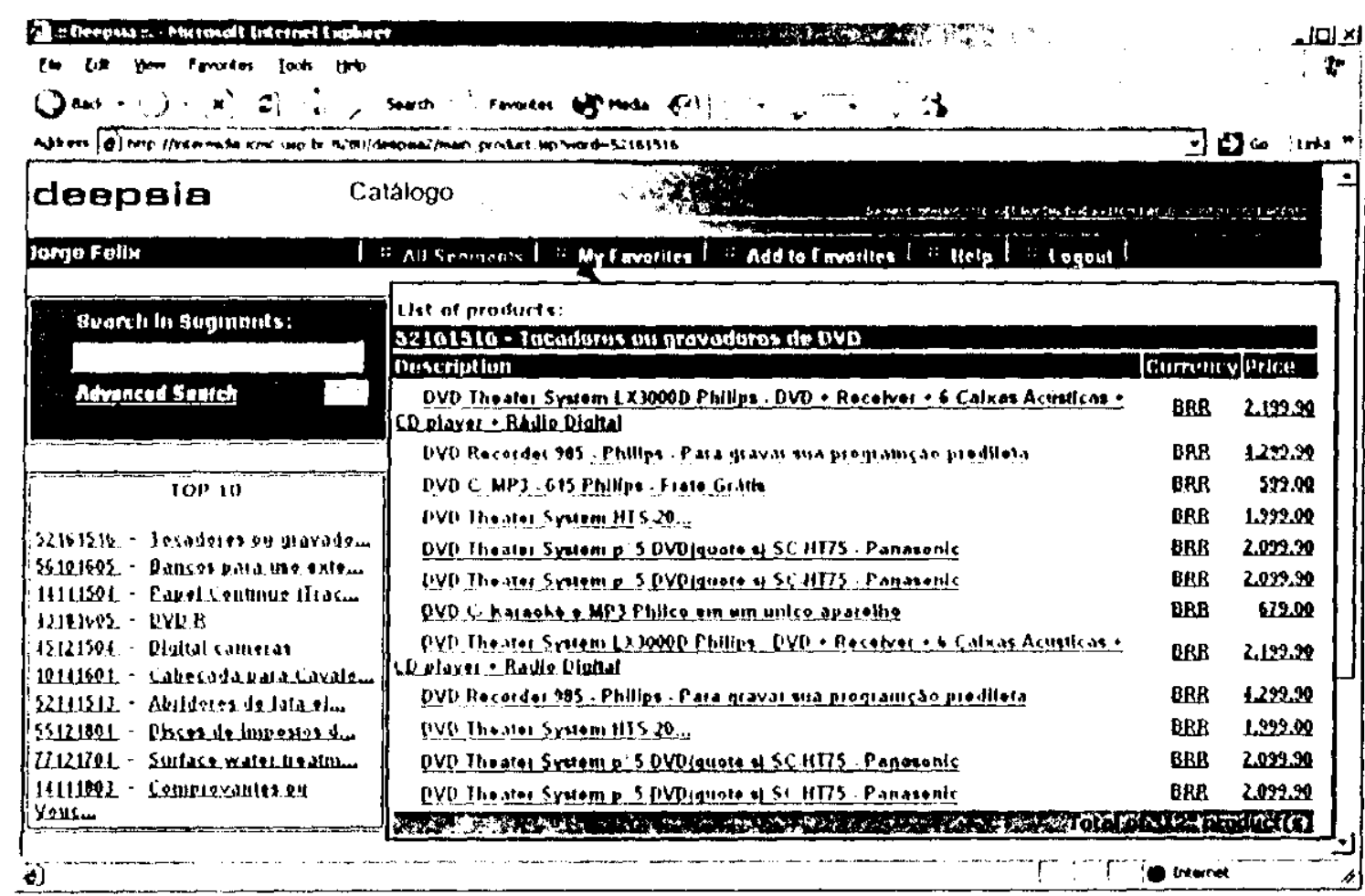

Figura 5-12 Catálogo de produtos para o commodity 52161516.

Os componentes da camada de manipulação do catálogo, conforme ao esquema mostrado na Figura 5-13 são:

- ProductCatalogue. Controlador de acesso ao catálogo de um determinado commodity. Dado um nó da ontologia, possibilita a extração de um conjunto de informaçōes de produtos associados ao mesmo.

- ProductHelper. Estrutura de dados contendo a informação de uma instância particular de um produto. Os dados incluem nome, preço, moeda e URL de origem e data de aquisição dos dados. 

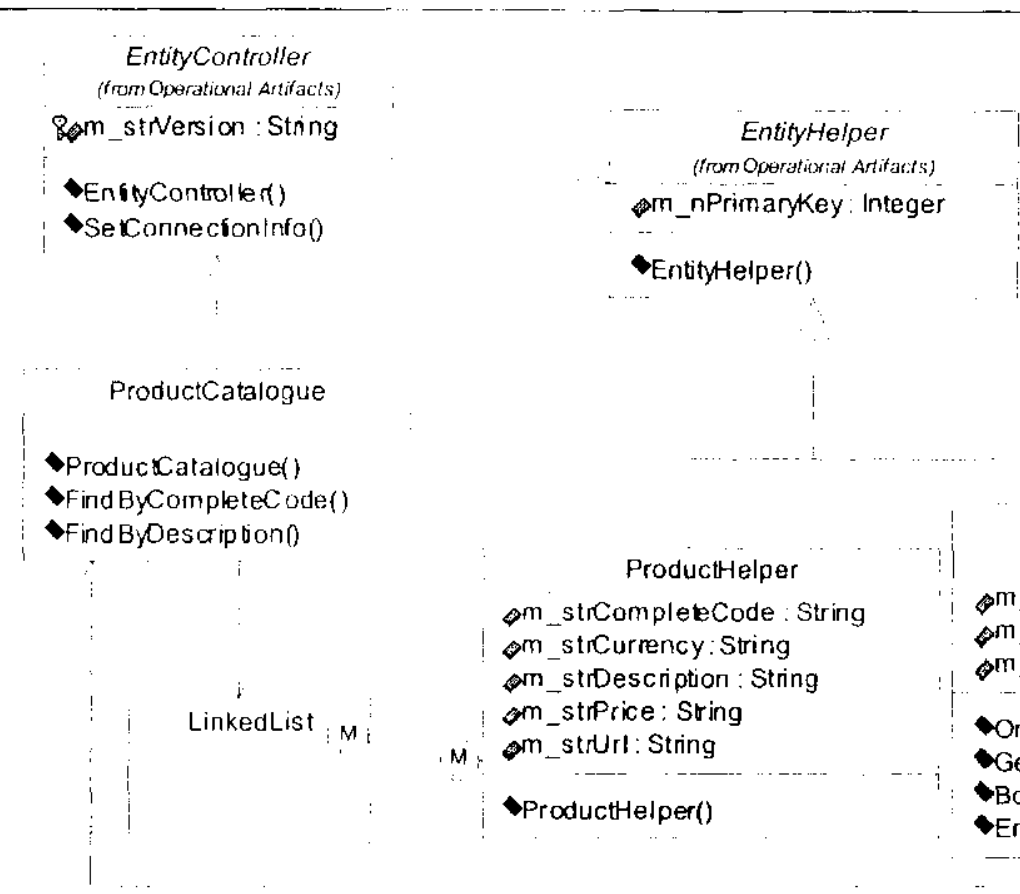

EntityHelper()

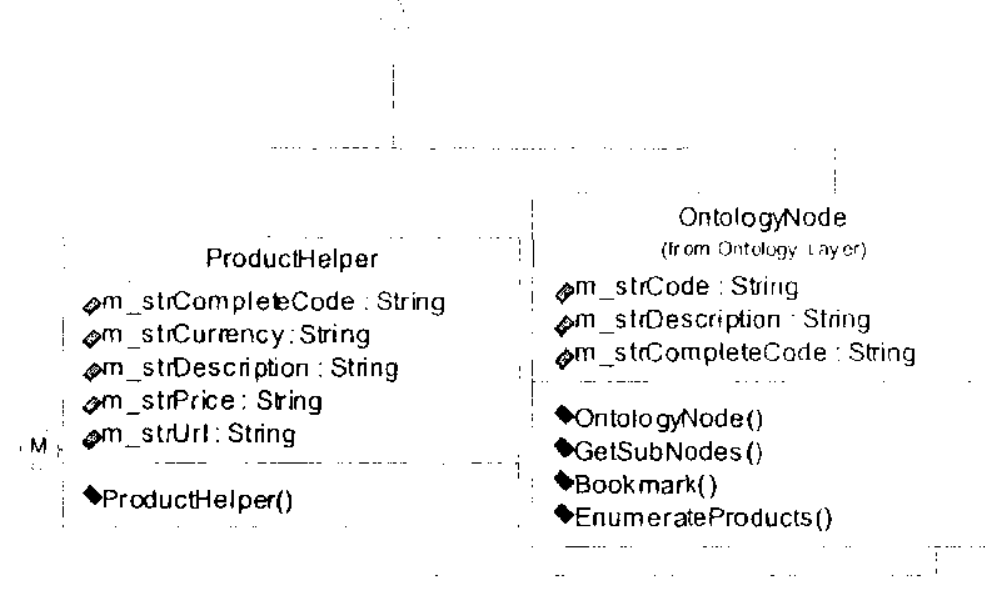

Figura 5-13 Arquitetura da camada de software para manipulação do catálogo

\subsubsection{Considerações do idioma}

Como mencionado no parágrafo 5.3, o controle da parte idiomática da interface constitui é tratado pelo protótipo, incluindo-se o caso da ontologia. Para tal, forneceu-se um componente de seleção idiomática na hora de realizar a conexão com o banco de dados. A partir dessa informação, os controladores possuem informação acerca da linguagem em que os dados devem ser devolvidos para a interface cada vez que um método é invocado.

A classe LanguageEngine (Figura 5-14) fornece uma enumeração dos idiomas disponiveis. Quando o controlador precisa ter acesso ao banco, uma instância da

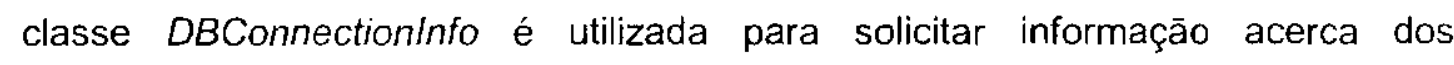
parâmetros de conexão e do idioma a ser utilizado durante a sessão do usuário. 
on_strDriverName : String

om_stroatabaseURL : String

m.strUsemame : String

Q

-DBConnectioninfo()

-DBConnectioninfo()

- Loadfromfile()

- Sellanguage()

-GetLanguage()

$1: \# m_{-} d b C o n$ nectioninfo

DBErrorlnfo

- DBerrorinoul)

- GetErrorDescriptiono

LanguageEng ine

DLANGUAGE ENGLISH: int $=1$

LANGUAGE PORTUGUESE: int $=2$

$\checkmark L A N G U A G E$ SPANISH : int $=3$

Figura 5-14 Componentes para suporte de conexāo e idioma no banco de dados,

\subsection{Utilizando data warehousing e data mining}

Para começar a discussão acerca do uso de data warehousing e data mining neste projeto, fazemos uma revisão dos objetivos do uso dessas ferramentas no protótipo.

- Melhora da interface de usuário. Devido a que a ontologia possui mais de 16000 nós e mais de 10000 categorias de commodities, é preciso reforçar a interface, fazendo com que ela possua algum nível de adaptabilidade baseada na interação do usuário.

- Adaptabilidade da solução ao escopo geral do sistema. Determinar se a solução pode ser utilizada no projeto global.

- Integração das ferramentas no projeto. Determinar se as ferramentas possuem um grau de integração aceitável para seu uso tanto no processo de análise como de uso contínuo da interface.

Tomando-se em consideração o conjunto de dados disponivel, o objetivo escolhido para o uso de data warehousing e integração de data mining no protótipo foi a previsão do comportamento do usuário através da extração de Regras de Associação (vide parágrafo 4.5.3). Para tal fim, de acordo com o esquema geral apresentado nos parágrafos 3.5 e 4.4 , foram realizados procedimentos de exploração inicial, preparação dos dados, criação de data marts, aplicaçāo do modelo de data mining e extração de regras para serem utilizadas diretamente na interface de usuário. 


\subsubsection{Exploração inicial}

A figura mostra um exemplo dos dados que são coletados diretamente do portal através da interface.

\begin{tabular}{|c|c|c|c|c|}
\hline No. & Commodity & Usuário & Data de criação & Data de atualização \\
\hline 276 & 27121501 & lase & $4 / 9 / 200220: 07: 33$ & $4 / 9 / 200220: 07: 33$ \\
\hline 277 & 27 & lase & $4 / 9 / 200220: 07: 33$ & $4 / 9 / 200220: 07: 33$ \\
\hline 278 & 2712 & lase & $4 / 9 / 200220: 07: 33$ & $4 / 9 / 200220: 07: 33$ \\
\hline 279 & 271215 & lase & $4 / 9 / 200220: 07: 33$ & $4 / 9 / 200220: 07: 33$ \\
\hline 280 & 56 & lase & $4 / 9 / 200220: 07: 45$ & $4 / 9 / 200220: 07: 45$ \\
\hline 281 & 56 & lase & $4 / 9 / 200220: 07: 46$ & $4 / 9 / 200220: 07: 46$ \\
\hline 282 & 56 & lase & $4 / 9 / 200220: 12: 28$ & 4/9/2002 20:12:28 \\
\hline
\end{tabular}

Figura 5-15 Lislagem de eventos na interface

Observando a coluna commodity e a data de inserção do evento, podemos ver que, os eventos 276 a 278 aparecem registrados como eventos separados que. aparentemente, aconteceram ao mesmo tempo para o mesmo usuário. Mas, acontece que raramente um usuário iria clicar tão rapidamente em três links para que $o$ registro ficasse dessa forma. A resposta a esse aparente problema é que quando o usuário escolhe um commodity na interface, ela realiza uma série de consultas através do método FindByCompleteCode do controlador OntologyController. Assim, as consultas sucessivas ficam registradas como se existissem vários eventos do mesmo usuário quando na realidade eles constituem um único evento. Precisamos realizar uma filtragem dos dados antes de prosseguir com a análise.

\subsubsection{Preparação dos dados}

Para realizar as operações de filtragem e preparação, utilizamos o data warehouse onde criamos tabelas auxiliares para os procedimentos intermediários de análise. A Figura 5-16 mostra um esquema da operação de filtragem realizada para eliminar as redundâncias mencionadas anteriormente. O utras operaçōes de consolidação foram também necessárias neste estágio, sendo que algumas foram realizadas após da criação das dimensões e tabelas fato do data warehouse. 


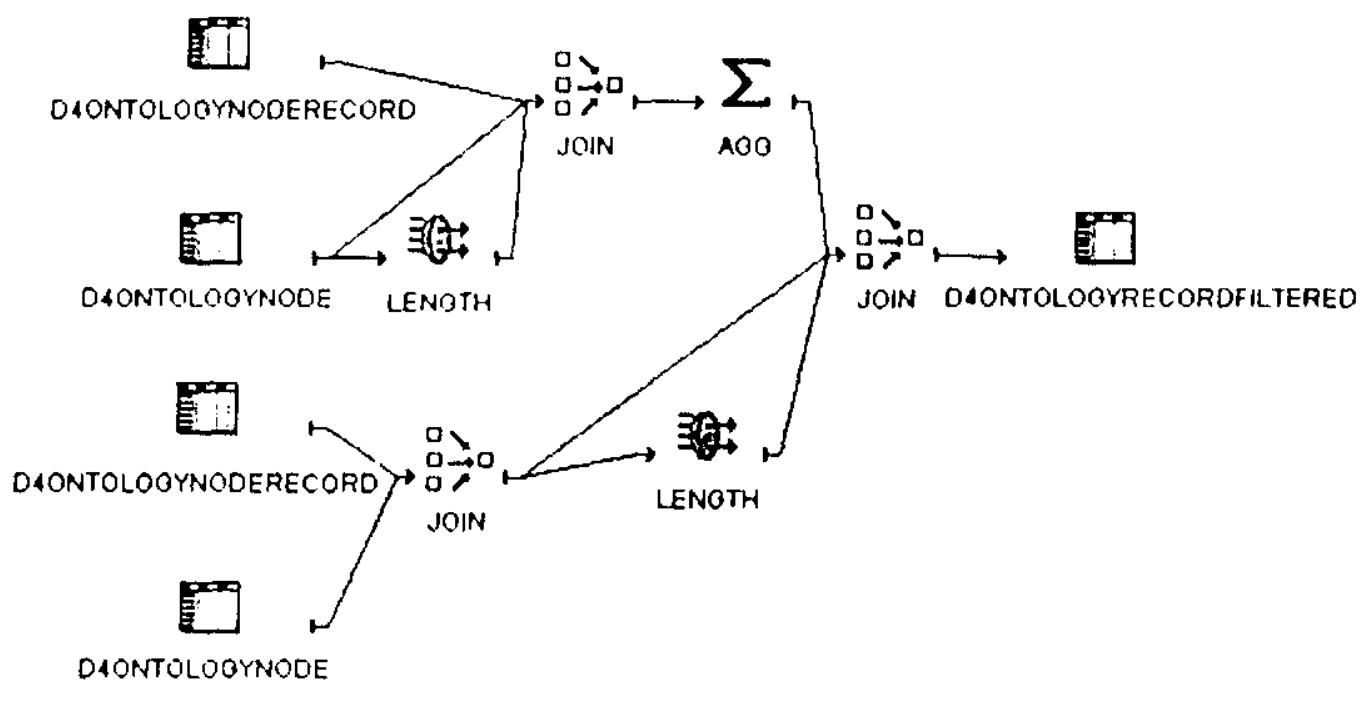

Flgura 5-16 Operação de filtragem dos eventos coletados na interface

\subsubsection{Dimensioes e tabelas fato}

Para realizar a análise comportamental na navegação dos usuários através da ontologia, foram criadas duas dimensōes: USER_SESSION e D4TIME.

A dimensão USER_SESSION possui uma hierarquia, SESSION_HIERARCHY que agrupa dois niveis: P_USER, identificando um usuário do sistema, e P_SESSION para referência temporal (diária) da sessões do mesmo no sistema. A dimensão D4TIME é uma dimensão de tempo, utilizada para a análise dos fatos em intervalos discretos. Ambas dimensões são mostradas na Figura 5-17.

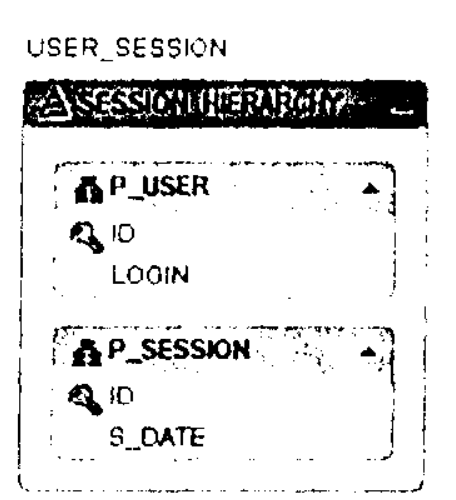

DATIME

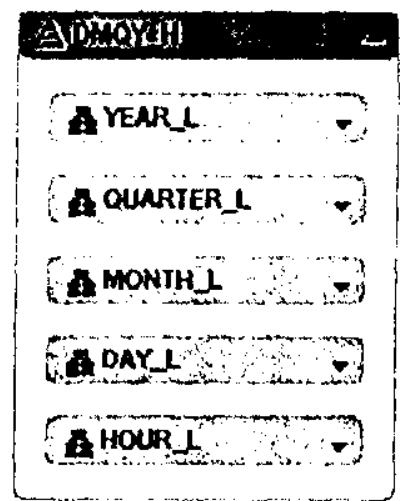

Figura 5-17 Dimensões utilizadas na análise de navegaçăo.

Para $O$ armazenamento dos eventos já filtrados, foi criada uma tabela fato chamada NAVIGATION, ela possui os atributos CHECK_VALUE, ONTOLOGY_SEGMENT e SESSION_ID. A Figura 5-18 mostra o esquema estrela desta tabela e a Figura 5-19 mostra a disposiçăo fisica no banco de dados. As chaves estrangeiras para 
relacionamento da tabela fato com as dimensões são SESSION_ID e DA_ACTUAL_DATE.

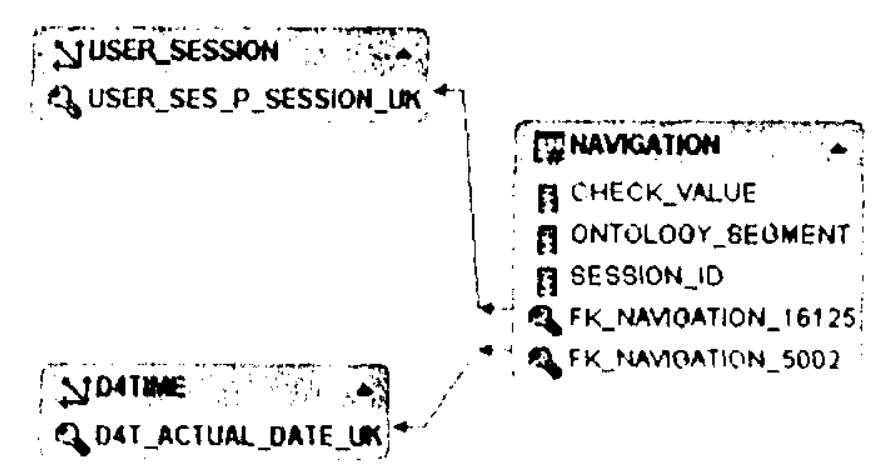

Figura 5-18 Esquema estrela do data mart para análise da navegaçăo na interface.

\begin{tabular}{lll}
\hline Coluna & Típo & Descrição \\
\hline ONTOLOGY_SEGMENT & Caractere & $\begin{array}{l}\text { Código do nó da ontologia } \\
\text { associado ao evento }\end{array}$ \\
CHECK_VALUE & Sim/Não & $\begin{array}{l}\text { Sempre verdadeiro } \\
\text { Identificador único da } \\
\text { SESSION_ID }\end{array}$ \\
& Numérico & $\begin{array}{l}\text { sessão do usuário no } \\
\text { sistema e relacionamento } \\
\text { com a dimensão } \\
\text { USER_SESSION. }\end{array}$ \\
& & $\begin{array}{l}\text { Chave para } \\
\text { relacionamento com a } \\
\text { dimensão de tempo } \\
\text { D4TIME. }\end{array}$ \\
\hline
\end{tabular}

Figura 5-19 Disposiçăo fisica da tabela fato NAVIGATION.

A resultante desta transformação é uma matriz esparsa de zeros e uns contendo o conjunto de iterações nas sessões dos usuários através do tempo. A maioria dos algoritmos para extração de regras de associaçāo consegue trabalhar sem problemas com esse tipo de matriz.

\subsubsection{Aplicando o modelo}

Um dos p rimeiros p roblemas p ara a plicar o a lgoritmo de e xtração de Regras de Associaçāo foi determinar o conjunto de atributos que seriam utilizados no processo. Se quisermos aplicar o algoritmo a todo o conjunto teriamos mais de 16000 atributos por linha na matriz de trabalho. No entanto, alguns elementos da matriz (e, portanto, da ontologia) são mais referenciados que outros.

Na Figura 5-20 podemos observar uma distribuição de densidade da freqüência relativa acumulada de acesso à ontologia. O eixo horizontal representa os 
diferentes nós da ontologia, ordenados do nó com maior ao nó com menor número de acessos, enquanto que o eixo vertical representa a distribuição de freqüência relativa acumulada

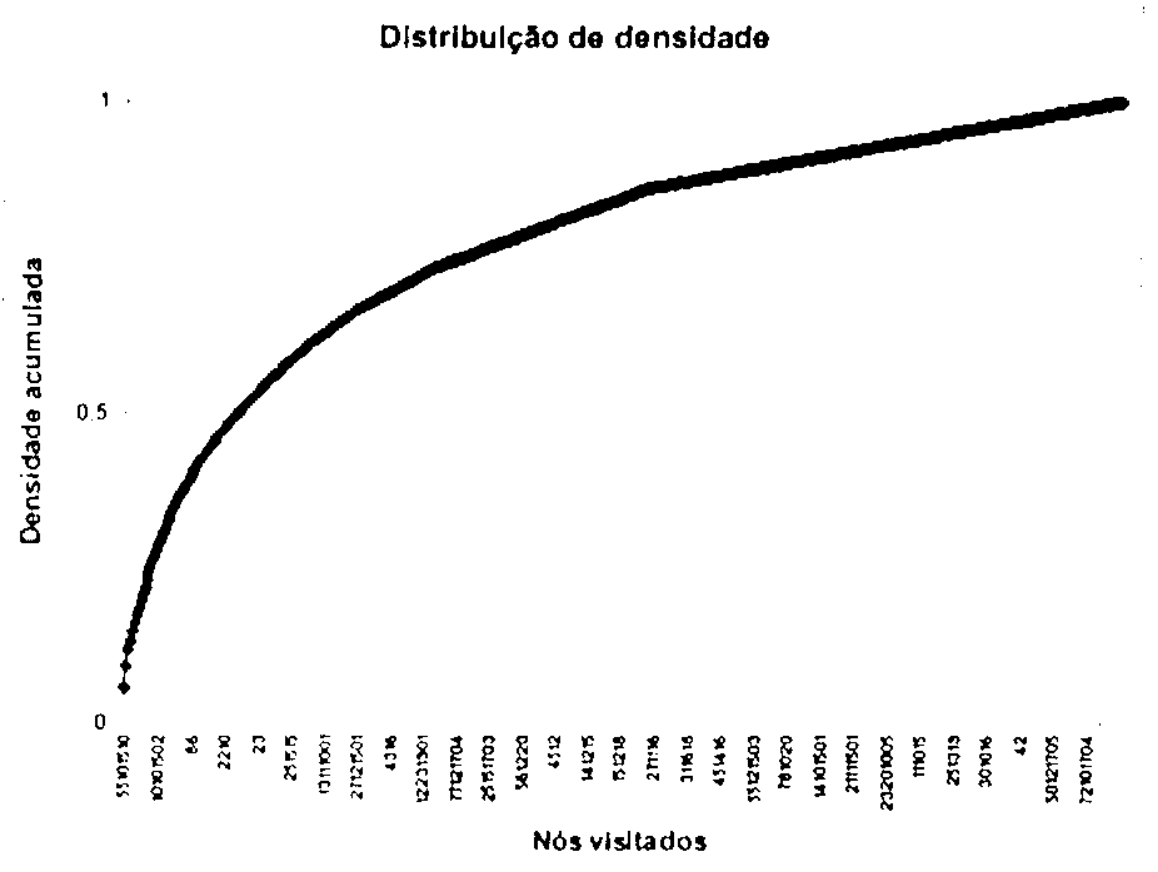

Figura 5-20 Distribuição de densidade da freqüência de acesso aos nós

Realizando uma série de testes com diferentes conjuntos de amostras de acesso à ontologia com intervalos de tempo diferentes, obteve-se a uma interessante relação nos dados mostrados no gráfico: a curva assemelha-se a uma função de escala logaritmica, sendo que a equação da Figura 5-21 descreve a mesma com um coeficiente de correlação bastante aproximado de 1. Na curva da Figura 5-20, por exemplo, tomada durante um estágio tardio de utilizaçāo do protótipo, obteve-se um coeficiente $\alpha$ da ordem de 0,003374 e um coeficiente $\beta$ de 0,9509 , sendo que a curva teve um coeficiente de correlação de 0.99882.

$$
h=\sqrt[3]{\ln (x n+\beta)}
$$

Figura 5-21 Modelo para a distribuição de densidade de acessos.

Utilizando a equação da Figura 5-21, poderia-se estimar o número de elementos da ontologia que representarão uma determinada porcentagem de dados amostrais para o processo de extraçāo de regras de decisāo. Por exemplo, se no modelo apresentado anteriormente quiséramos trabalhar com $030 \%$ dos nós mais representativos, sabendo que temos na tabela fato NAVIGATION um total aproximado de 500 nós representativos, obteriamos que, aproximadamente os 25 
primeiros nós da distribuição de frequêencia possuem tal porcentagem de referências na tabela, utilizando os valores de $\alpha$ e $\beta$ do exemplo.

O passo seguinte é a aplicação do algoritmo de extração de regras, para nosso caso utilizamos o API de data mining da Oracle Corp. (Oracle Data Mining), disponivel a partir da versão 9 i do motor de banco de dados

Na sua forma mais simples, o motor de data mining recebe os processos de mineração de forma seqüencial, sendo que as tarefas são enfileiradas através de uma interface centralizada. Isto não quer dizer que os processos são realizados de forma seqüencial necessariamente, mas é possivel decidir se a exploração será realizada de forma sincrona ou assíncrona. Com base no API de mineração, foram construidas várias classes para o controle dos processos (a Figura 5-22 mostra um exemplo de uma classe para a extração de regras de associação).

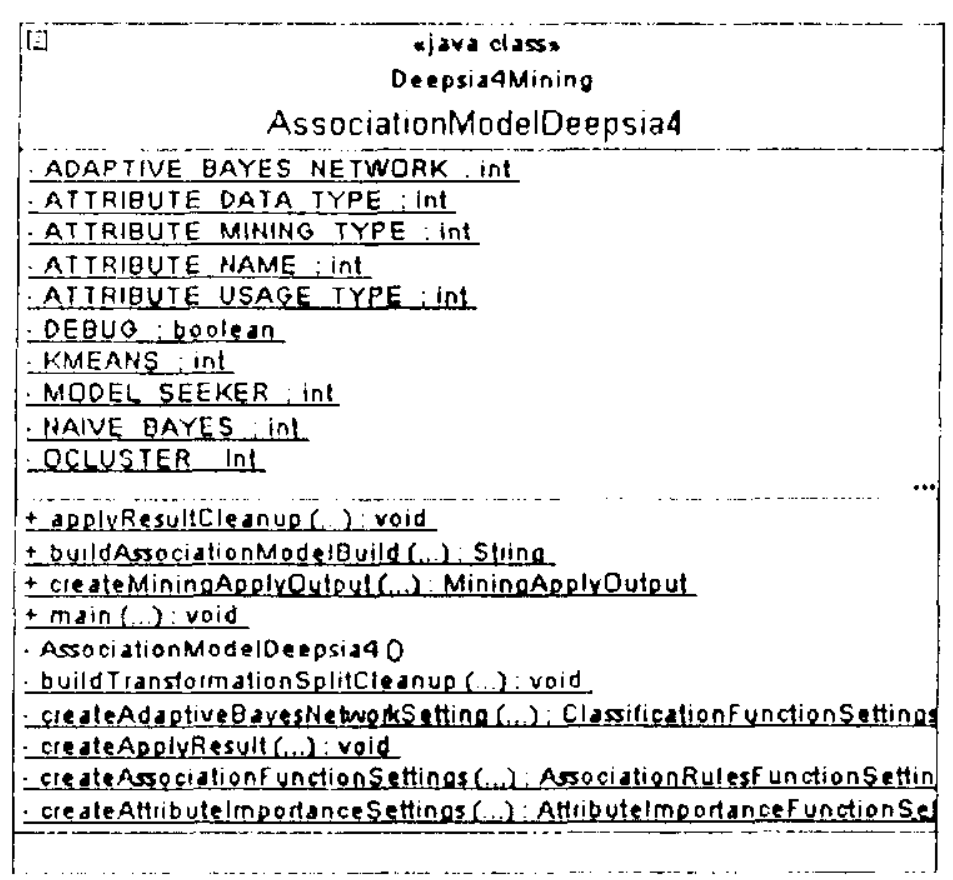

Figura 5-22 Classe em Java para a execução da tarefa de mineraçăo.

As classes de controle dos processos de mineração ficam dentro do espaço de trabalho do motor de mineração, já que o próprio motor possui a capacidade de execução de máquinas virtuais Java segundo a carga de trabalho.

Após a execução das tarefas de mineração, os resultados são depositados em várias tabelas de acordo com o modelo fornecido pelo API. No casso das regras de associação, quatro tabelas descritivas e duas resultantes são obtidas. Condensando a informaçāo resultante obtemos uma tabela parecida com a da Figura 5-23. 


\begin{tabular}{|c|c|c|c|c|c|c|}
\hline Regra & Pred 1 & Pred 2 & Pred3 & Resultado & Suporte & Confidencla \\
\hline 1 & 52161516 & & & 45121504 & 0,0449438 & 0,5714286 \\
\hline 2 & 55101514 & & & 55101510 & 0,0561798 & 0,6250000 \\
\hline 45 & 1010 & 10101501 & & 101015 & 0,0337079 & 1,0000000 \\
\hline 46 & 55101514 & 23181509 & & 10101501 & 0,0337079 & 0,5000000 \\
\hline 47 & 10 & 1010 & & 101015 & 0,0786517 & 0,7000000 \\
\hline 48 & 10 & 10101501 & & 101015 & 0,0337079 & 0,7500000 \\
\hline 49 & 101015 & 10101501 & & 1010 & 0,0337079 & 1,0000000 \\
\hline 50 & 101015 & 10101501 & & 10 & 0,0337079 & 1,0000000 \\
\hline 3 & 101015 & & & 10 & 0,0786517 & 1,0000000 \\
\hline 4 & 101015 & & & 1010 & 0,0786517 & 1,0000000 \\
\hline 5 & 10101502 & & & 10101501 & 0,0337079 & 0,5000000 \\
\hline 6 & 10101502 & & & 55101514 & 0,0337079 & 0,5000000 \\
\hline 7 & 55101514 & & & 23181509 & 0,0674157 & 0,7500000 \\
\hline 8 & 10101502 & & & 55101510 & 0,0337079 & 0,5000000 \\
\hline 15 & 45121504 & & & 52161516 & 0,0449438 & 0,5714286 \\
\hline 16 & 1010 & & & 101015 & 0,0786517 & 0,7000000 \\
\hline 17 & 10101501 & & & 55101510 & 0,0449438 & 0,5714286 \\
\hline 18 & 23181509 & & & 55101514 & 0,0674157 & 0,6666667 \\
\hline 19 & 1010 & & & 10 & 0,1123596 & 1,0000000 \\
\hline 20 & 10101501 & & & 10 & 0,0449438 & 0,5714286 \\
\hline 21 & 23181509 & & & 55101510 & 0,0674157 & 0,6666667 \\
\hline 29 & 10101501 & 23181509 & & 55101510 & 0,0337079 & 1,0000000 \\
\hline 30 & 55101514 & 10101501 & & 55101510 & 0,0337079 & 1,0000000 \\
\hline 31 & 55101514 & 55101510 & & 23181509 & 0,0561798 & 1,0000000 \\
\hline 32 & 55101514 & 55101510 & & 10101501 & 0,0337079 & 0,6000000 \\
\hline 33 & 1010 & 10101501 & & 10 & 0,0337079 & 1,0000000 \\
\hline 34 & 10101501 & 55101510 & & 55101514 & 0,0337079 & 0,7500000 \\
\hline 35 & 10101501 & 55101510 & & 23181509 & 0,0337079 & 0,7500000 \\
\hline 36 & 55101514 & 23181509 & & 55101510 & 0,0561798 & 0,8333333 \\
\hline 37 & 10 & 10101501 & & 1010 & 0,0337079 & 0,7500000 \\
\hline 38 & 23181509 & 55101510 & & 55101514 & 0,0561798 & 0,8333333 \\
\hline 39 & 23181509 & 55101510 & & 10101501 & 0,0337079 & 0,5000000 \\
\hline 41 & 10101501 & 23181509 & & 55101514 & 0,0337079 & 1,0000000 \\
\hline 42 & 55101514 & 10101501 & & 23181509 & 0,0337079 & 1,0000000 \\
\hline 43 & 10 & 101015 & & 1010 & 0,0786517 & 1,0000000 \\
\hline 44 & 101015 & 1010 & & 10 & 0,0786517 & 1,0000000 \\
\hline
\end{tabular}

Figura 5.23 Regras de associaçáo extraidas da tabela fato NAVIGATION

As colunas Pred1, Pred2, Pred3 são os nós da ontologia (segmentos, familias classes ou commodities) utilizadas no lado direito dos predicado nas regras de associação. Por exemplo, a regra No. 29 diz que se um usuário seleciona o item 23181509 após ter selecionado o item 10101501, então existe uma probabilidade de e le e star interessado no item 55101510. O grau de suporte e de confidência desta regra é 0,0337079 e 1,0, respectivamente.

Agora, podemos utilizar os resultados mostrados na Figura 5-23 na interface de navegação do protótipo. 


\subsubsection{Integração dos resultados}

Depois de ter concluido o processo de mineraçåo è necessário realimentar o sistema com os resultados obtidos por tal. O esquema proposto da Figura 5-24 (segunda fileira) foi implementado utilizando o motor de data mining da Oracle. Devido a que a implementação das tabelas operacionais foi feila em SQL Server, foi necessária a criação um esquema de transferéncia entre ambos sistemas.

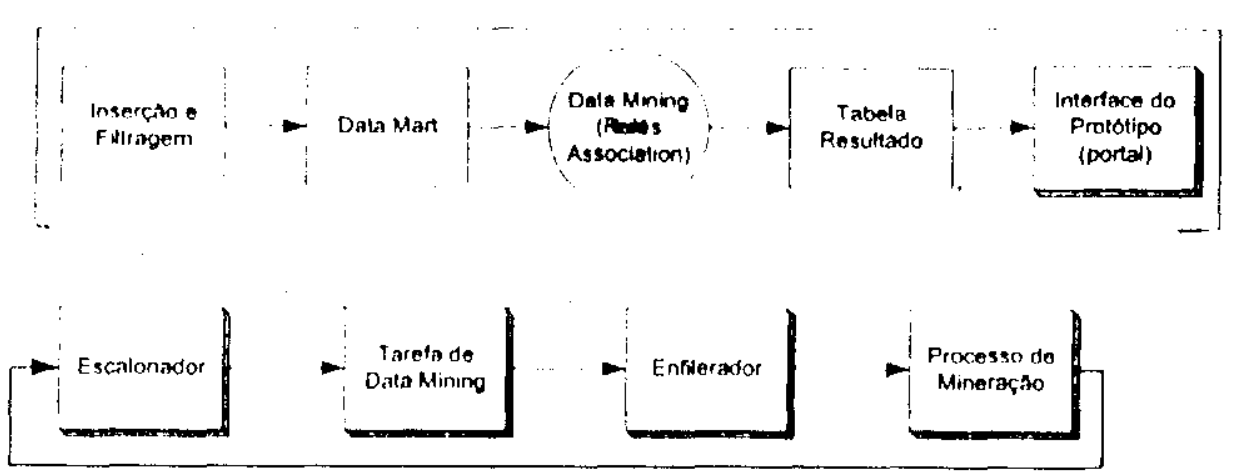

Figura 5-24 Esquema de integraçảo de dala mining no protótipo

- Do lado do motor de data mining. O pacote Java Deepsia4Mining (que contem os controladores de mineração) foi colocado no contexto do motor de data mining dentro do espaço de trabalho Java do banco de dados. Isto foi feito com o intuito de dispor dos controladores dentro do ambiente operacional do banco ao invés de criar dependēncias com ferramentas ou processos externos. Tal decisảo possibilitaria chamar o controlador desde. por exemplo, um procedimento armazenado (stored procedure) factivel de ser integrado com outros sistemas (através de pontes ODBC/JDBC, por exemplo).

- Do lado da base de dados transacional. É possivel exportar os conjuntos de dados em bruto para tabelas de trabalho no motor de data mining através de pontes ODBC (o Java não é suportado no contexto de execução de SQL Server).

Na Figura 5-25 podemos apreciar o processo de transferência de dados do servidor transacional para o motor de data mining. Alguns desses processos realizam transferências incrementais, isso quer dizer que só transferem os dados catalogados como sendo de recente acesso/criaçăo. 


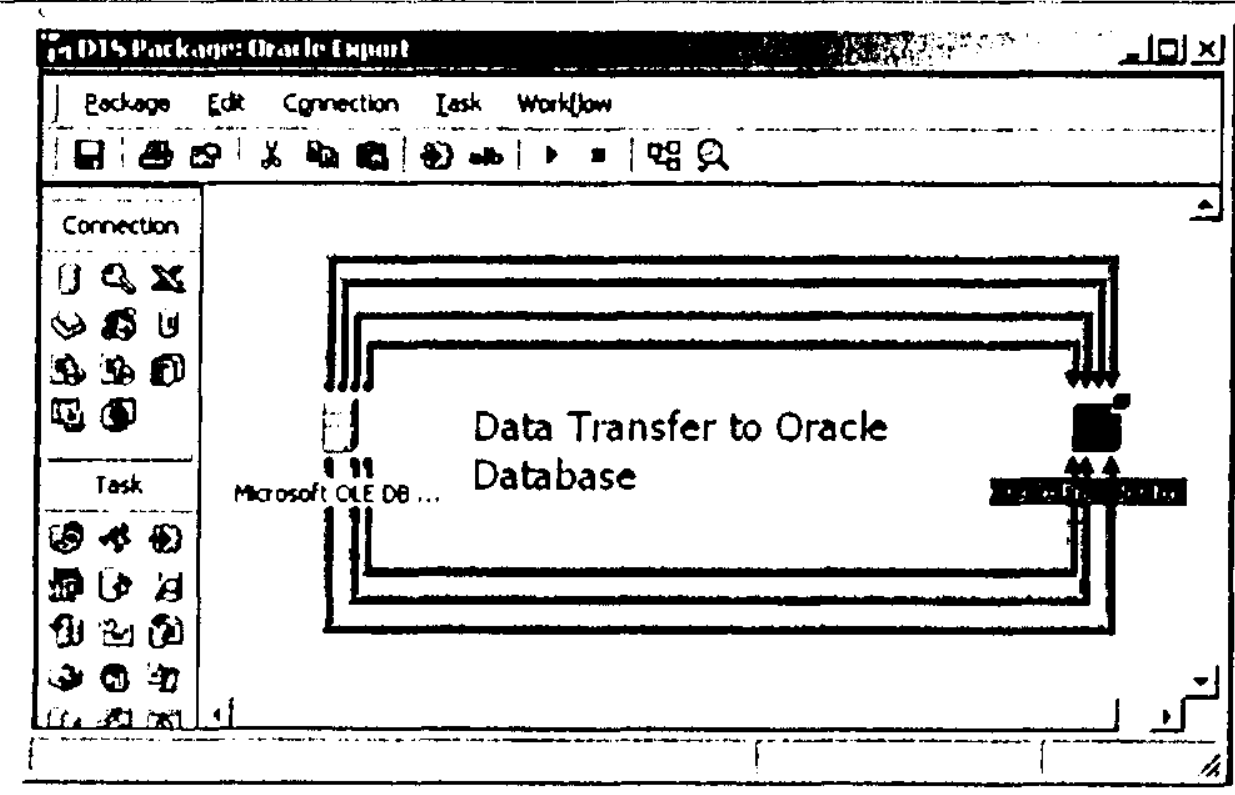

Figura 5-25 Esquema de transferência de dados do SQL Server para o Oracle.

Uma vez que os dados têm sido transferidos, o processo de mineração pode dar inicio. Para isso, chamamos o controlador de mineração adequado através de uma chamada de procedimento remoto (Remote Procedure Call - RPC), escalonado através do Scheduler Manager do SQL Server, como pode ser apreciado na Figura $5-26$.

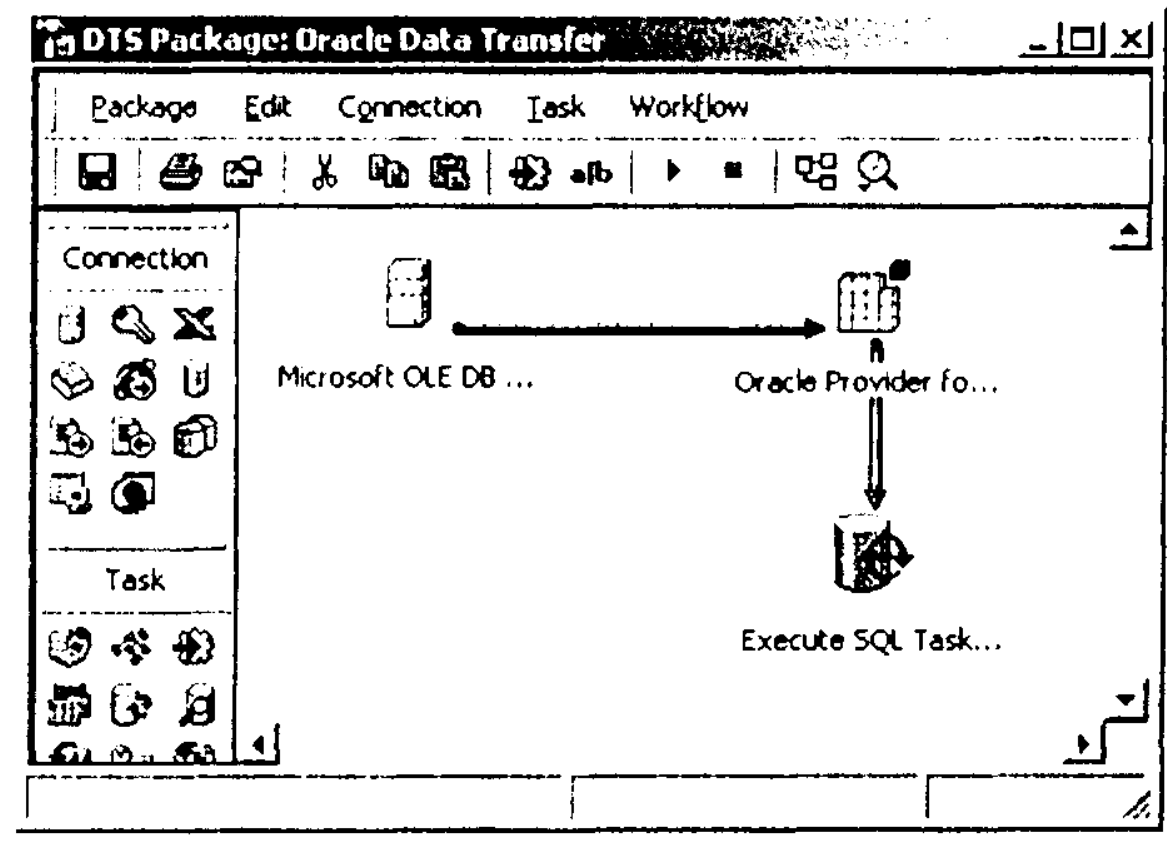

Figura 5-26 Execução de uma tarefa no Oracle através de uma RPC.

Quando os resultados do processo de mineração estão prontos, procedemos à recuperação dos resultados para sua utilizaçāo no sistema transacional (isto é. para serem utilizados na interface do protótipo). O processo é mostrado na Figura 5-27. 


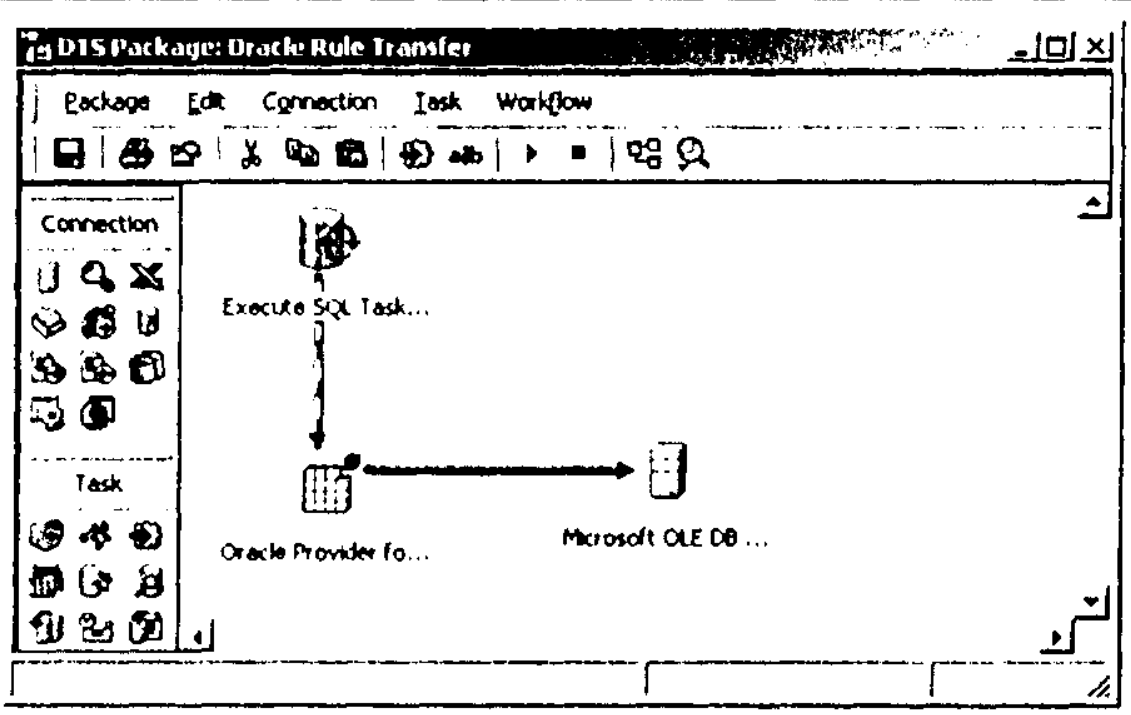

Figura 5-27 Recuperação dos resultados de mineração para o SQL Server.

Agora, com os resultados de mineração consolidados e dentro do sistema transacional, precisamos de algum mecanismo para sua manipulação. Conforme ao esquema mostrado no parágrafo 5.4, o pacote Mining Artifacts contem os controladores para manipulaçāo dos resultados do processo de mineração.

O pacote contêm a definição do controlador OntologyRulecontroller. Dito controlador é utilizado pela interface do portal para realizar uma previsāo dos nós interessantes para o usuário a partir da experiência extraida das interações anteriores. O método AddOntologyNode enfileira um novo acesso a um item da ontologia e o método GetConsequentNodes tenta realizar uma previsão a partir dos m_nQueuesize nós anteriormente visitados. O valor por defeito da fila é três, a qual impõe uma restrição ao número de predicados que uma regra pode ter ao momento da exploraçãolextração. O resultado final pode ser apreciado na Figura 5-10, no item Previsão.

Todo o processo descrito neste parágrafo é executado de forma periódica. Atualmente o sistema é re-alimentado a cada 24 horas, mas algumas otimizações foram necessárias para estabilizar o sistema, elas são detaihadas no parágrafo 5.6. 


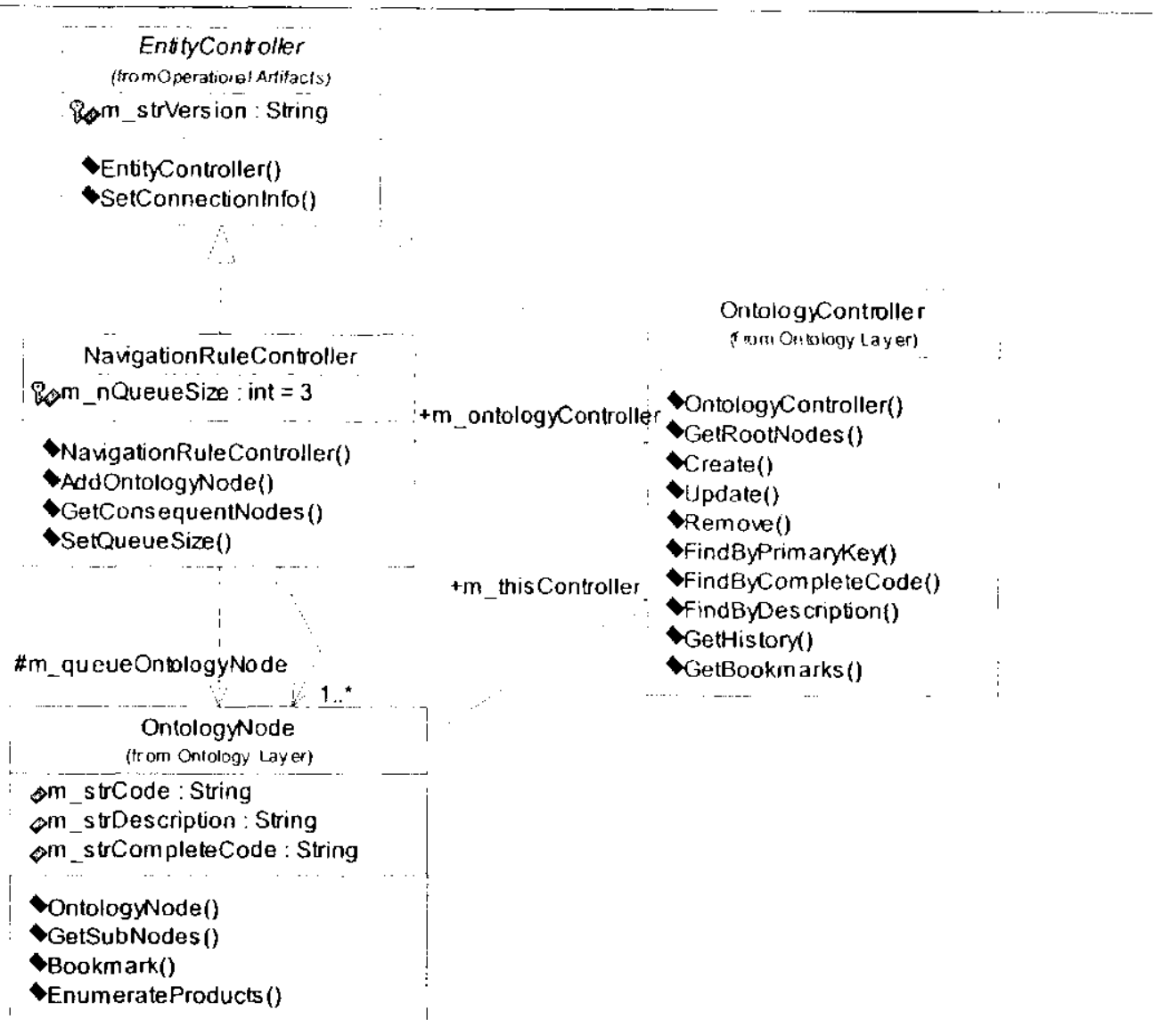

Figura 5-28 O pacote MiningArtifacts.

\subsection{Otimização}

Em vista do rápido crescimento do requerimento operacional do motor de data mining, devido ao incremento de atividade no banco de dados, foi necessário realizar urna otimizaçāo do processo de mineração fazendo uma divisão do trabatho de acordo com agrupações (clusters) obtidas a partir de uma análise dos dados.

Tal otimizaçāo foi realizada inserindo um pré-processamento de clustering no conjunto de dados globais, como mostrado na Figura 5-29.

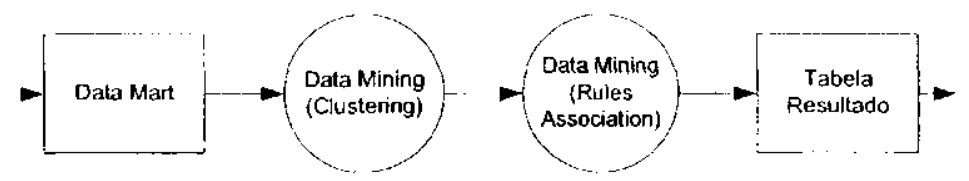

Figura 5-29 Inserindo outro processo de mineraçāo no esquema.

Com isto, foi possivel distribuir o processo de mineração identificando os principais grupos referenciados na ontologia. O exemplo mostrado na Figura 5-30 identifica dois grupos de dados obtidos em uma corrida do processo de aglomeraçāo. $O$ conjunto de regras obtido para cada grupo é agregado, obtendo-se de tal agregação 
- conjunto global de regras de associação a ser aplicadas na apresentação de previsões na interface de usuário.

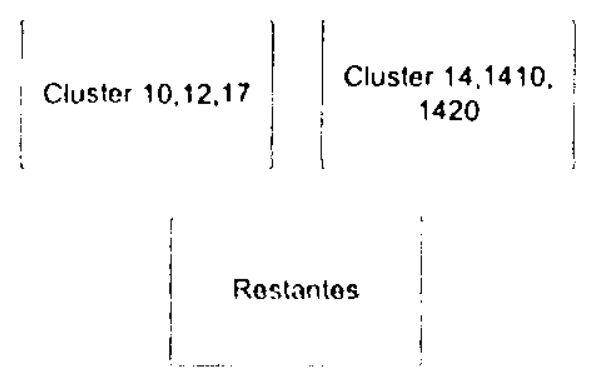

Figura 5-30 Exemplo de grupos obtidos no processo de aglomeraç㐅㐅. 


\section{Resultados e Conclusões}

\subsection{Resultados}

A Figura 6-1 mostra a interface do protótipo no seu estágio final, podemos observar vários dos elementos nela contidos. os quais são resultantes do trabalho de análise e implementação discutidos no Capitulo 5.

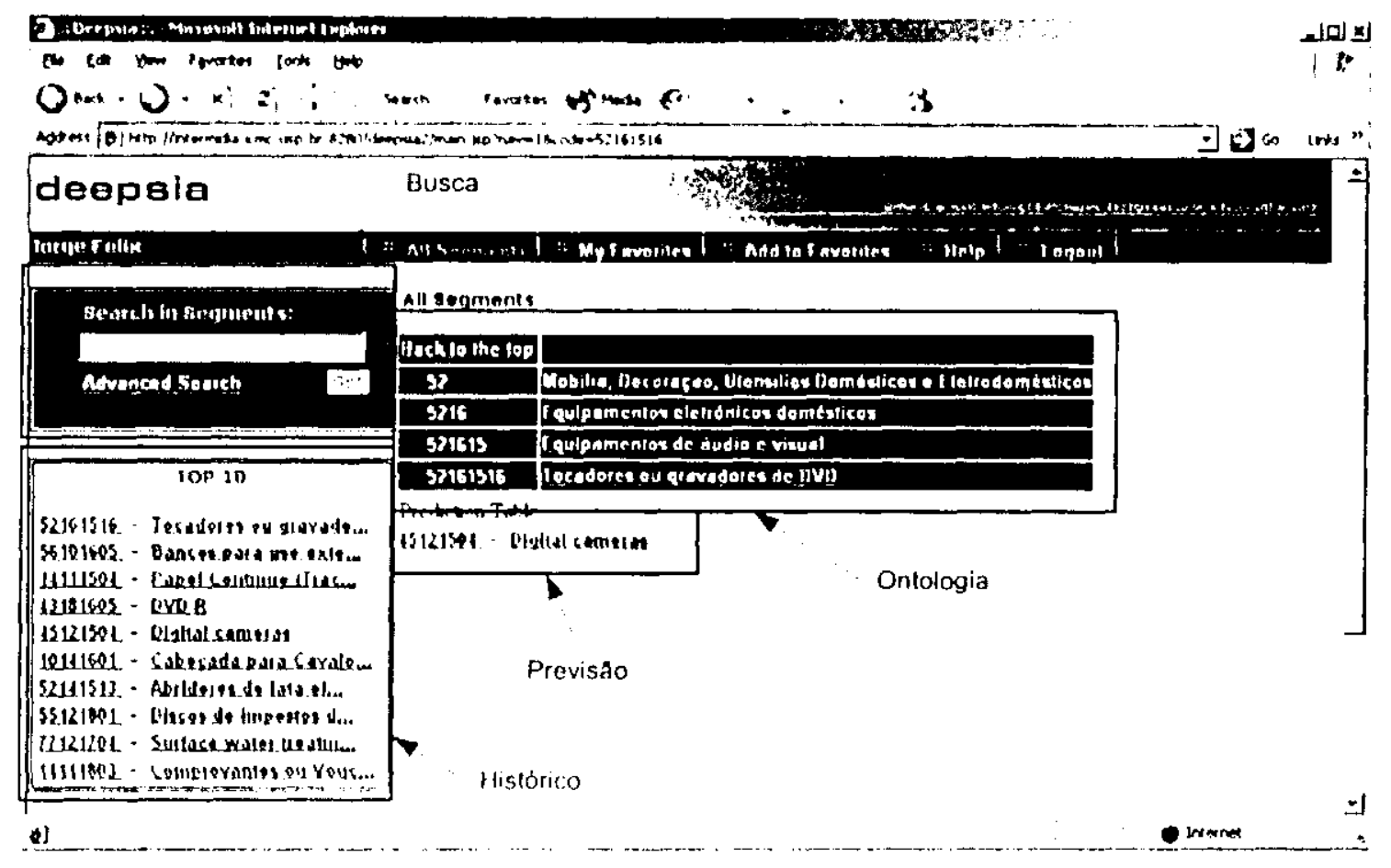

Figura 6-1 Prototipo no seu estágio final

A parte marcada como previsão na Figura 6-1 mostra como as regras de associação obtidas através dos processos de data mining foram integrados na interface. A medida que o usuário navega ou procura algum produto nela, o sistema deve registrar lal interação para tentar realizar uma previsão dos itens nos que ele poderia estar interessado. Na figura, para o usuário que examina o commodity 52161516 (Tocadores ou Gravadores de DVD) é apresentado também um link para o item 45121504 (Câmeras Digitais), sendo que o sistema encontrou uma correlação entre ambos, através de um algoritmo de Regras de Associação (ver parágrafo 4.5.3).

A Figura 6-2 resume os resultados obtidos na melhora da navegação na ontologia Fazemos uma comparação entre o sistema existente e o protótipo em dois estágios diferentes: sem ferramentas de histórico e previsão e no estágio final. 


\begin{tabular}{lccc} 
& $\begin{array}{c}\text { Prévio } \\
\text { Sistema } \\
\text { Baslco }\end{array}$ & Estágio I & Protótipo \\
\hline $\begin{array}{l}\text { Número de sessões } \\
\text { amostradas }\end{array}$ & 16 & 189 & 95 \\
$\begin{array}{l}\text { Total de referéncias } \\
\text { amostradas (clicks) }\end{array}$ & 235 & 1924 & 766 \\
$\begin{array}{l}\text { Total de referências } \\
\text { repetidas dentro de um } \\
\text { segmento }\end{array}$ & 193 & 1213 & 361 \\
$\begin{array}{l}\text { Média de referências por } \\
\text { sessão }\end{array}$ & 14,688 & 10,180 & 8,063 \\
$\begin{array}{l}\text { Média de referências por } \\
\text { sessão dentro de um } \\
\text { segmento } \\
\begin{array}{l}\text { Média de referências } \\
\text { repetidas por sessão }\end{array}\end{array}$ & 12,063 & 6,418 & 3,8 \\
\hline
\end{tabular}

Figura 6-2 Resultados do protótipo.

A explicação dos resultados da Figura 6-2 è a seguinte: o número de sessões é a quantidade de sessōes amostradas. O total de referências é o número total de registros de interação com a interface, isto é, a quantidade de "clicks" que o usuário fez em um nó da ontologia. O total de referências repetidas em um segmento é o número de "clicks" feitos dentro de uma classe, familia ou commodity de um mesmo segmento da ontologia. A média de referências por sessão é simplesmente a resultante da divisão do total de referências pelo nümero de sessões.

A média de referências por sessão dentro de um segmento, è a resultante da divisão do total de referências repetidas dentro de um segmento pelo número de sessōes. $E$ finalmente, a média de referências repetidas por sessão é o valor da média do número de referências repetidas absolutas, isto é, as vezes que o usuário voltou a um mesmo nó da ontologia dentro da mesma sessāo.

Um outro resultado interessante foi mencionado no parágrafo 5.5.4, onde foi inferida uma regra para o cálculo do número de nós representativos da ontologia que devem ser amostrados, utilizando como argumento a porcentagem de transações que queremos abarcar no processo de mineração. Isto evita ter que realizar cálculos de amostragem toda vez que o processo deve ser executado. 


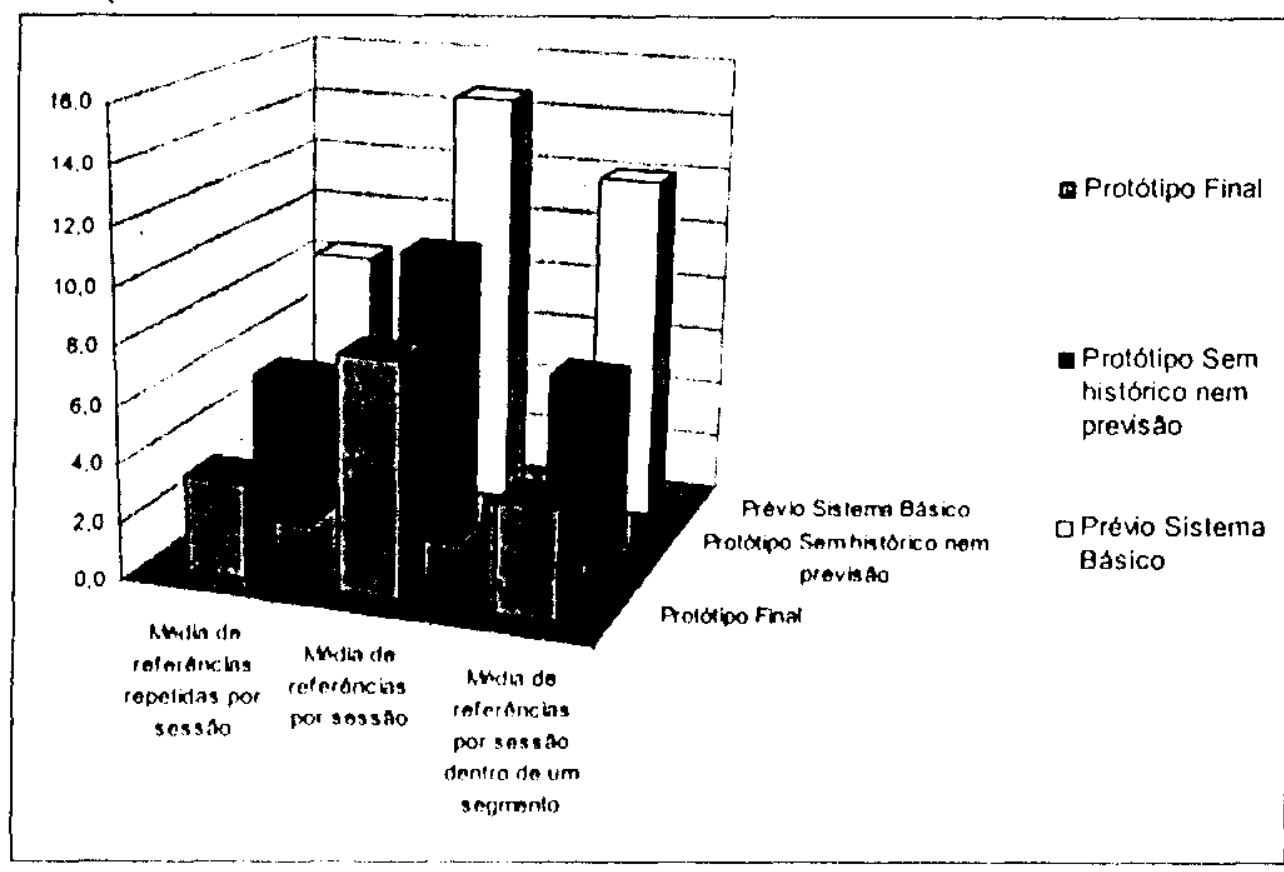

Figura 6-3 Médias comparativas dos resultados obtidos

Como podemos apreciar, a média de referèncias repetidas a um nó da ontologia foi reduzido razoavelmente. Isto pode indicar que o usuário requer menos esforço de navegação no protótipo para realizar as mesmas tarefas.

\subsection{Conclusōes}

A maioria dos ambientes de e-commerce, suportados por bancos de dados relacionais, nāo visam a integraçāo com processos de mineração, precisando de uma elaborada preparação dos dados antes de serem levados para o data warehouse.

O trabalho de obtenção de dados para análise é facilitado utilizando um esquema baseado em camadas de acesso aos mesmos, que possibilitam a inserção de códigos de rastreamento de eventos.

É possivel dizer também concluir que a heterogeneidade dos sistemas de ecommerce existentes faz com que seja necessária uma exploração previa dos requerimentos dos usuários que interagiram com os processos de análise. Precisase também de modelos e data marts de estrutura simples para facilitar o trabalho dos analistas.

Trabalhos futuros e stão e ncaminhados no s entido de fornecer $m$ arcos de trabalho padronizados para ajudar em parte ao processo analitico, por enquanto, sugere-se uma maior atenção na parie da modelagem e extração de dados. 


\section{Referências}

[ALE90] ALEKSANDER, I.: MORTON, H. An Introduction to Neural Computing, London: Chapman and Hall. Cambridge, MA: MIT Press. 1990

[ANA97] Data Warehousing in the Real World. ANAHORY, S.; MURRAY, D. Addison Wesley, 1997

[BRE84] Breiman, L.; Fricdman, J.; Olshen, R.; Stone, C., Classification and Regression Trees, Chapman \& Hall, New York.

[BRE94] Breiman, L. Bagging predictors. Technical Report 421, Department of Statistics, University of California at Berkeley, 1994

[CAL99] CALVANESE, D.: DE GIACOMO, G.; ROSATI, R. Data Integration and Reconciliation in Data Warehousing: Conceptual Modeling and Reasoning Support. Network and Information Systems 4. 1999.

[CHA97] CHAUDHURI, S.; DAYAL, U. An Overview of data warehousing and OLAP technology. ACM SIGMOD Record. v.26, pp. 85-7. 1997.

[CHE76] CHEN P.P.C. The Entity-Relationship Mode/-Toward a Unified View of Data. ACM TOOS vol. 1 no. 1, pp. $3-36$, March 1976.

[OASO1] DASSENI, E.; VERYKIOS, V.; ELMAGARMID, A.; BERTINO. E. Hiding Association Rules by Using Confidence and Support. Proc. of Jth Intl. Information Hiding Workshop (IHW), April 2001.

[FAY96] FAYYAD, U. M.; PIATESKY-SHAPIRO, G.; SMYTH, P.; UTHURUSAMY, R. Advances in Knowledge Discovery and Data Mining. AAAAIMIT Press, 1996.

[FAW96] FAWCETT, T. ; PROVOST, F. Combining Data Mining and Machine Learning for Effective User Profiling. Proceedings of KDD96, 1996.

[FRE96] Freund, Y.; SCHAPIRE, R. E. Experiments with a new boosting algorithm, in Proceedings of the Thirteenth International Conference on Machine Learning. pp 148-156, Morgan Kaufmann. 1996.

jFRE98] FREEMAN, M. The DBMS Guide to Data Mining Solutions, 1998. Disponivel em: hitp://www dbmsmag com/

:OL98] GOLFARELLI. M.; RIZZI. S. A Methodological Framework for Data Warehouse Design. Proceedings of Int'I Workshop on Data Warehousing and OLAP. Washington. D.C. pp 3-9. 1998 
[GRA97] GRAY, J.; BOSWORTH, A. LAYMAN, A.; PIRAHESH. H. Data Cube: A Relational Aggregation Operator Generalizing Group-By, Cross-Tab and Sub-Totals. Data Mining and Knowledge Discovery, 1(1):29-54, 1997

[GUP97] GUPTA, H.; HARINARAYAN, V.; RAJARAMAN, A.; ULLMAN, J. Index selection for OLAP. In International Conference on Data Engineering. Birmingham, UK, April 1997. Pg. 208-219. 1997.

[HAY99] HAYKIN. S. Noural Networks: a compreensive fundation - 2nd. Edition. Prentice Hall, New Jersey. 1999

! HUSO0] HUSEMANN, B.; LECHTENBORGER, J.; VOSSEN, G. Conceptual Data Warehouse Design. Proceedings of Int'l Workshop on Design and Management of Data Warchouses. Stockholm. Sweden. 2000.

[?NM96] INMON, W. H. Building the Data Warehouse. J. Wiley \& Sons, Inc., Second Edition. 1996

[KIM96] KIMBALL, R. The Data Warehouse Toolkit. Wiley Computer Publishing, 1996.

:KMF96] The Knowledge Management Forum. 1996. Disponivel em: http://www.kmforum.org/what_is.him

[KOH82] KOHONEN, T. Self-organizing of topologically correct feature maps. Biological Cybertnetics. 43, 59-69. 1982

KOC96] KOCK Jr., N.F.; MCQUEEN, R. J.;. BAKER, M. Learning and Process Improvement in Knowledge Organisations: A Critical Analysis of Four Contemporary Myths. The Learning Organization, pp. 31-40. 1996

[KOC97] KOCK, N.F., Jr.; MCQUEEN, R. J.; CORNER, J. L. The Nature of Data, Information and Knowledge Exchanges in Business Processes: Implications for Process Improvement and Organizational Learning. The Learning Organization, V.4, No.2, pp. $70-80.1997$.

[KRI97] KRIPPENDORF. M.; SONG, I. Y. Translation of Star Schema into Entity Relationship Diagrams. Proceedings of 8 th International Conference and Workshop on Database and Expert Systems Applications (DEXA97). Toulouse. France, pp. 390-395. Sept. 1997

AC00] LACH. J. "A Data Miner Goes for Gold on the Web". Business Week Online, September, 2000 
[LEH98] LEHNER, W.; ALBRECHT, J.; WEDEKIND, H. Normal Forms for Multidimensional Databases. Proceedings of SSDBM, pp. 63-72. 1998

[LUH62] MCLUHAN, M. The Gutenberg Galaxy: The Making of Typographic Man. Toronto: University of Toronto Press, 1962.

[MAG94] MAGDISON, J. The chaid approach to segmentation modeling: Chi-squared automatic interaction detection. In R. P. Bagozzi, editor, Advanced Methods of Marketing Research, pages 118--159. Cambridge, Massechusetts, 1994

[MAR03] MARTINS, J. J. Classifica̧̧āo de páginas na Internet. Dissertaçāo de Mestrado Instituto de Ciências Matemáticas e de Computação de São Carlos, Universidade de Sảo Paulo. 2003

[MAR89] Information Engineering, Book I: Introduction, MARTIN. J. Prentice Hall, Englewood Cliffs, 1989.

[MIC98] MICHALSKI, R. S.; BRATKO. I.; KUBAT, M. Machine Learning and Data Mining: Methods and Applications, John Wiley \& Sons, Ltd., 1998.

[MOD00] MOODY, D. L.; KORTINK, M. A. R. From enterprise models to dimensional models: A methodology for data warehouse and data mant design. In Proc. of 2nd Int. Workshop on Design and Management of Data Warehouses (DMDW). Stockholm (Sweden). 2000

[PED99] PEDERSEN, T. B.; JENSEN C. S. Multidimensional data modeling for complex data. In Proceedings of the 15th IEEE International Conference on Data Engineering, Sydney, Australia, 1999

[PIA91] Knowledge Discovery in Databases. PIATETSKY-SHAPIRO, G.; FRAWLEY, W. J. Menlo Park, CA: AAAI Press. 1991

[SAP98] SAPIA, C.; BLASCHKA, M.; HOFLING, G.; DINTER, B. Extending the E/R Model for the Multidimensional Paradigm. Advances in Database Technologies (ER '98 Workshop Proceedings), Springer-Verlag, pp. 105-116. 1998.

[SEN98] SEN, A.; JACOB, V.S. Industrial Strength Data Warehousing. Communications of the ACM. September, 1998.

[SCH01] SCHAFER, J. B.; KONSTAN, J. A.; RIEDL, J. E-commerce recommendation applications, Data Mining and Knowledge Discovery. 2001. 
[SUHOO] SUHAIL, A.; KOHAVI, R.; MASON, L.; ZHENG, Z. Integrating E-Commerce and Data Mining: Architecture and Challenges. Blue Martini Software. 2600 Campus Drive San Mateo, CA, 94403, USA, 2000.

[THE98] THEODORATOS. D.: SELLIS. T. Data Warehouse Schema and Instance Design. Proceedings of 17 th International Conference on Conceptual Modeling (ER98), Singapore, pp.363-376. Nov. 1998.

[TRY99] TRYFONA, N.; BUSBORG. F.; CHRISTIANSEN, J. G. B. starER: A Conceptual Model for Data Warohouse Design. Proceedings of Int'I Workshop on Data Warehousing and OLAP (DOLAP 99). Kansas City, MO. pp. 3-8. 1999.

[WOL92] WOLPERT, D. H. Stacked generalization. Neural Networks 5. 241-259. 1992. 


\section{Apêndice A - Conceitos úteis em Data Mining}

Os seguintes conceitos são essenciais para a compreensão das técnicas no processo de Data Mining:

- Bagging (Escolna, Média). O conceito de bagging (escolha por classificaçåo e uso de méclias para problemas de regressão com dependência de variáveis contínuas) é aplicado na área de data mining para previsāo (predictive data mining). Esta técnica, descrita por Breiman [BRE94], é utilizada para combinar classificações de previsão de múltiplos modelos, ou do mesmo tipo de modelo para dados de aprendizado diferentes. Serve também para direcionar a instabilidade inerente dos resultados quando modelos complexos estão sendo aplicados a conjuntos de dados relativamente pequenos. Uma forma de derivar uma previsão simples é utilizar todas as árvores achadas nas diferentes amostragens, e aplicar algum sistema de escolha simples. A classificação final será realizada com base na maior taxa de previsāo extraída das diferentes árvores. Pode-se notar que algumas combinaçōes destas previsões (weighted vote, weighted average) são possiveis e comumente utilizadas.

- Boosting. Este conceito é aplicado na área de data mining para previsão, e está baseado na geração de múltiplos modelos ou classificadores, derivando em pesos que combinam as previsões destes modelos em uma simples previsão ou classificaçāo [FRE96].

Um algoritmo simples para boosting trabalha da seguinte forma: Começa com a aplicação de algum método de classificação (por exemplo, uma árvore de classificaçāo como CART ou CHAID) nos dados de aprendizado, onde é assinado um peso igual para cada uma das observações. São então calculadas as classificaçōes de previsão, e são aplicados pesos às observaçōes nos dados de aprendizado os que são inversamente proporcionais ao nivel de certeza da classificaçāo. Em outras palavras, pesos maiores são estabelecidos para aquelas observaçōes que foram mais dificeis de classificar (onde a taxa de classificação errônea foi alta), e pesos pequenos para aqueles que foram facilmente classificados. 
O processo de Boosting gera uma seqüencia de classificadores', onde cada classificador consecutivo na seqüência é um "experto" em classificar observaçōes que nảo foram classificadas adequadamente pelo seu predecessor. Durante o processo de previsão e classificação dos novos casos (deployment), a previsão dos diferentes classificadores pode ser combinada (por exemplo, por meio de weight voting, ou algum outro processo baseado em pesos) para derivar em uma melhor previsão.

Pode-se observar também que boosting pode ser aplicada aos mélodos de aprendizagem que não s uportam explicitamente pesos ou custos de classificação. Neste caso, subconjuntos a leatórios de a mostras podem ser a plicados dentro dos dados cognitivos, em sucessivos estágios de um procedimento de boosting iterativo, onde a probabilidade para a escolha de uma observação dentro do subconjunto de amostras é inversamente proporcional ao nivel de certeza da previsão para uma observação na itcração precedente.

- Stacking (Stacked Generalization). Este conceito é aplicado para a combinação das previsōes de múltiplos modelos [WOL92]. É particularmente útil quando os tipos de modelos incluidos no projelo são muito diferenciados. Por exemplo, supondo que um projeto de data mining inclua métodos de árvores de classificação, tais como CART [BRE84] e CHAID [MAG94], analise linear discriminante (por exemplo GDA) e redes neurais, cada processo de cálculo geraria classificadores para um processo de classificação cruzada. A experiência mostra que a combinatória de previsões fornece um maior nivel de exatidão que previsões derivadas de um único método. No processo de stacking, as previsōes de diferentes classificadores são utilizadas como entradas para a meta-aprendizado (meta-leaming), a que tenta combinar as previsōes para criar uma melhor classificação de previsão. Isto significa que, por exemplo, as classificações de previsão das árvores de classificação, modelos lineares, e redes neurais podem ser utilizadas como entradas de um metaclassificador. Este meta-classificador tentará "apreender" a combinação das previsões dos diferentes modelos para alcançar um máximo nivel de exatidão na classificação.

- Deployment. Refere-se ao processo de aplicação de um modelo para previsão ou classificaçāo em dados novos. Após da identificação de alguns conjuntos de dados

\footnotetext{
Im classificador é um predicado para identificar classes de dados ou classes de objetos dentro de rinsitórios de dados [Sala7]
} 
para uma aplicação em particular, usualmente é desejável estender estes modelos para que novas p revisões s ejam rapidamente geradas (ou a dquiridas) p ara novos dados.

- Preparação dos dados (Data preparation). O estágio de consolidação e limpeza dos dados é conhecido com preparação dos dados, sendo ele importante e particularmente aplićável em projetos lipicos de data mining. onde grandes quantidades de dados são adquiridas por meio de processos automatizados (por exemplo, via Internet). Freqüentemente, o método de coleta de dados não e fortemente controlado, e alguns dados podem conter valores fora de intervalos permissiveis. combinações de dados impossiveis e demais. Analisar dados que não foram adequadamente filtrados podem produzir resultados equivocados ou confusos.

- Redução dos dados (Data reduction). O termo data reduction no contexto de data mining é geralmente aplicado em projetos onde o objetivo é agregar ou sumarizar a informação contida em grandes conjuntos de dados em pequenas unidades de informação. Os métodos de redução dos dados podem incluir tabulação, agregação (cálculo de estatisticas descritivas) ou técnicas mais sofisticadas como clustering ou análise dos componentes principais, etc.

- Aprendizado de Máquina (Machine Learning). Refere-se à capacidade de apreensão do experiências por parte de um sistema computacional. A diferencia da análise estatistica tradicional, a qual está geralmente enfocada na estimação de parâmetros populacionais via inferência estatistica, a ênfase em data mining (e machine lcarning) é usualmente a exatidão da previsão (predictive classification), sem importar se os modelo ou técnicas que estão sendo utilizadas para gerar a previsão são ou não interpretáveis ou abertas a explicações simples. Um bom exemplo deste tipo de técnica aplicada em predictive data mining sāo as redes neurais ou as técnicas de meta-aprendizagem tal como o processo de boosting. Existem trabalhos interessantes à respeito: análise de ambientes especificos, incluindo analise comportamental [FAW96], extração de conhecimento e outros [MIC98].

Estes modelos geralmente precisam de uma combinatória de vários modelos "genéricos", os quais năo estĩo associados a processos causais necessariamente. Pelo contrário. estas técnicas podem ser apresentadas para gerar previsões ou classificaçōes precisas com amostras por médio de uma validação cruzada.

- Método do vizinho mais perto (k-nearest neighbor). É uma técnica para classificar cada um dos registros em um conjunto de dados baseados em uma combinação das 
classes dos $k$ registros mais parecidos com ele dentro de um conjunto histórico de dados.

- Regras de indução. Extração de regras "if-then" explicitas dos dados com base na significância estatistica.

- Visualização dos dados. Interpretação visual de relações complexas dentro de dados multidimensionais. Ferramentas gráficas são utilizadas para representar as relações entre os dados. 


\section{Apêndice B - O projeto DEEPSIA}

$O$ projeto Dynamic on-linE IntErnet Purchasing System based on Intelligent Agents (DEEPSIA) está sendo desenvolvido no ámbito do programa europeu de pesquisa denominado Information Society Technologies (IST), O consórcio DEEPSIA é formado por ompresas e institutos de pesquisa de vários paises europeus, nomeadamente: empresa ComArch (Polônia), UNINOVA (Portugal), Universite Libre de Bruxeltes (Bélgica), University of Sunderland (Inglaterra), empresa Zeus (Grécia) e empresa Comunicación Interativa (Espanha). A USP representa a participaçāo brasileira em tal projeto.

A estratégia do DEEPSIA, baseada em uma solução centrada no comprador, visa facilitar a nntrada das Pequenas e Medianas Empresas (PMEs) no Comércio Eletronico fornecendo ofertas de produtos a venda adequadas às necessidades especificas de cada. A infraostrutura computacional a ser desenvolvida pelo DEEPSIA oferecerá uma interface adequada baseada em um catálogo de produtos personalizado, o qual será automaticamente alualizado com a informaçāo recolhida dos portais eletrônicos de comêrcio Mletrônico existentes na internet. O catálogo poderá conter também dados de produtos fornecidos por vendedores especificos cadastrados no comprador.

$\wedge$ seguir, é apresentado um resumo da arquitetura do projeto DEEPSIA

- Dynamic Catalogue (DC): Consistirá da interface do usuário, e será responsável pela manutenção e apresentação dos dados colelados pelos multi-agentes contactados, com base nas preferéncias do usuário fornecidas. Além de tais dados, o sistema possibilitará o acesso a informaçōes de sites visitados, e a configuração da ontologia (representando o perfil individual da expectativa de compra) pelo usuário. A empresa ComArch detém a responsabilidade de seu desenvolvimento;

- Portal Interface Agent (PIA): Será responsável por criar uma interface privilegiada entre os portais da Web e o Multi-Agent System (MAS). O agente atuará como um facilitador ao acesso a dados contidos nos sites e Bancos de Dados de fornecedores. Sua utilização pelos fornecedores (opcional), pode garantir que as informações sobre seus produtos serão acessadas pelo MAS, independente dos resultados das Luscas efetuadas pelo Web Crawler Agent;

- Multi-Agent System (MAS): Descrito como um sistema autônomo para coleta de dados e um processo semi-automático de atualização do catálogo, composto de um conjunto de agentes, com tarefas especificas. Ao comportamento individual de cada 
agente será atribuida uma base inicial de conhecimento, que reflete os objetivos estratégicos das PMEs. A responsabilidade de seu desenvolvimento é da UNINOVA. Os módulos deste subsistema incluem: Web Crawler Agent (WCA), Miner Agent (MA), Human Agent (HA), Facilitator Agent (FA), Collector Agent (CA).

\section{Participaçāo da USP no Projeto DEEPSIA}

A USP São Carlos, através do Grupo de Pesquisas em Segurança Computacional do Laboratório Intermidia do ICMC (Instituto de Ciências Matemáticas e de Computação) e do NUMAEESC (Núcleo de Manufatura Avançada), representa a participação brasileira no projeto, sendo a ele integrada a partir (lo segundo semestre de 2001 com apoio financeiro do $\mathrm{CNPq}$.

O compromisso do NUMA para o projeto refere-se à execução de uma "Pesquisa Sócioeconómica" e o levantamento dos "Requisitos dos Usuários", que descreverăo a forma do nrocesso de compra e os tipos de produtos procurados pelas PMEs brasileiras. Com base no estudo, o grupo definirá e especificará a ontologia dos produtos.

O grupo de pesquisas do ICMC terá como objetivo a especificação e a implementação do Miner Agent previsto pela arquitetura do MAS. 